Florida International University FIU Digital Commons

$3-22-2013$

\title{
Trends in Water Quality within the Broward County Portion of the Biscayne Aquifer
}

Leigh Auwers Ammon

Florida International University, lammo001@fiu.edu

DOI: $10.25148 /$ etd.FI13042335

Follow this and additional works at: https://digitalcommons.fiu.edu/etd

Part of the Environmental Sciences Commons

\section{Recommended Citation}

Ammon, Leigh Auwers, "Trends in Water Quality within the Broward County Portion of the Biscayne Aquifer" (2013). FIU Electronic Theses and Dissertations. 868.

https://digitalcommons.fiu.edu/etd/868

This work is brought to you for free and open access by the University Graduate School at FIU Digital Commons. It has been accepted for inclusion in FIU Electronic Theses and Dissertations by an authorized administrator of FIU Digital Commons. For more information, please contact dcc@fiu.edu. 


\section{FLORIDA INTERNATIONAL UNIVERSITY}

Miami, Florida

TRENDS IN WATER QUALITY WITHIN THE BROWARD COUNTY

PORTION OF THE BISCAYNE AQUIFER

A thesis submitted in partial fulfillment of the

requirements for the degree of

MASTER OF SCIENCE

in

ENVIRONMENTAL STUDIES

by

Leigh Auwers Ammon 


\section{To: Dean Kenneth Furton}

College of Arts and Sciences

This thesis, written by Leigh Auwers Ammon, and entitled Trends in Water Quality within the Broward County Portion of the Biscayne Aquifer, having been approved in respect to style and intellectual content, is referred to you for judgment.

We have read this thesis and recommend that it be approved.

$\begin{array}{r}\hline \text { René Price } \\ \hline \text { Krishnaswam Jayachandran } \\ \hline \text { Assefa M. Melesse, Major Professor }\end{array}$

Date of Defense: March 22, 2013

The thesis of Leigh Auwers Ammon is approved.

$\begin{array}{r}\text { Dean Kenneth Furton } \\ \text { College of Arts and Sciences } \\ \hline \begin{array}{r}\text { Dean Lakshmi N. Reddi } \\ \text { University Graduate School }\end{array}\end{array}$

Florida International University, 2013 


\section{ACKNOWLEDGMENTS}

I would like to express my gratitude to the members of my thesis committee - Dr. Assefa Melesse, Dr. Krishnaswamy Jayachandran, and Dr. René Price - for their confidence in my capabilities to undertake this study and their guidance throughout the entire process. Special thanks to my major professor, Dr. Assefa Melesse for accepting me as an advisee and for the support and encouragement that has seen me through my program of study and research.

I would also like to express my appreciation to the Department of Earth and Environment and the Graduate School of Florida International University for giving me the opportunity to pursue a Master of Science degree in Environmental Studies and for the generous support that has facilitated my study here. 


\section{ABSTRACT OF THE THESIS \\ TRENDS IN WATER QUALITY WITHIN THE BROWARD COUNTY \\ PORTION OF THE BISCAYNE AQUIFER}

by

Leigh Auwers Ammon

Florida International University, 2013

Miami, Florida

Professor Assefa M. Melesse, Major Professor

Continuous and reliable monitoring of contaminants in drinking water, which adversely affect human health, is the main goal of the Broward County Well Field Protection Program. In this study the individual monitoring station locations were used in a yearly and quarterly spatiotemporal Ordinary Kriging interpolation to create a raster network of contaminant detections. In the final analysis, the raster spatiotemporal nitrate concentration trends were overlaid with a pollution vulnerability index to determine if the concentrations are influenced by a set of independent variables. The pollution vulnerability factors are depth to water, recharge, aquifer media, soil, impact to vadose zone, and conductivity. The creation of the nitrate raster dataset had an average RMS Standardized error close to 1 at 0.98 . The greatest frequency of detections and the highest concentrations are found in the months of April, May, June, July, August, and September. An average of $76.4 \%$ of the nitrate intersected with cells of the pollution vulnerability index over 100 .

Key words: Biscayne Aquifer, GIS, kriging, spatiotemporal contaminant trends, nitrates, Broward, pollution index 


\section{TABLE OF CONTENTS}

CHAPTER

PAGE

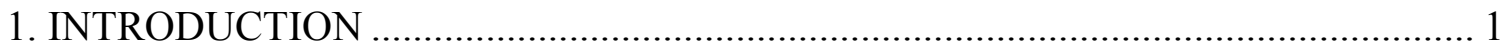

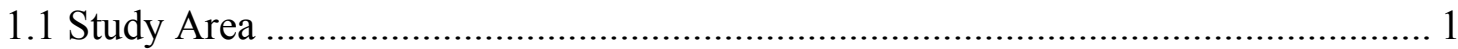

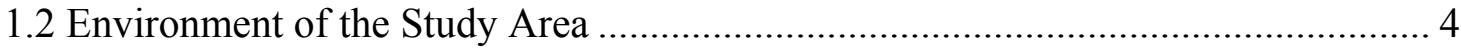

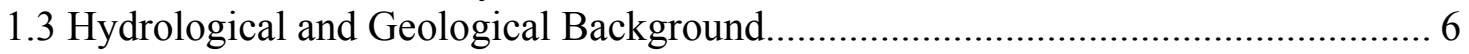

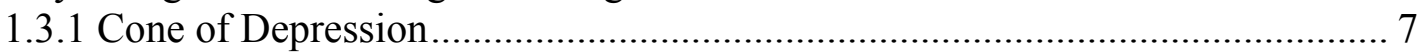

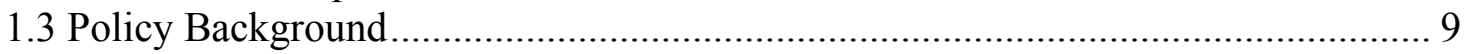

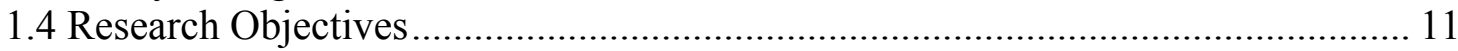

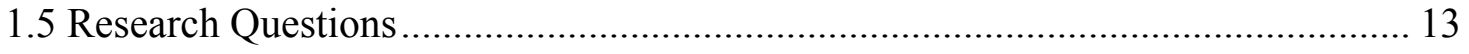

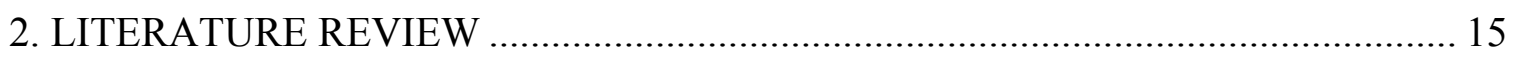

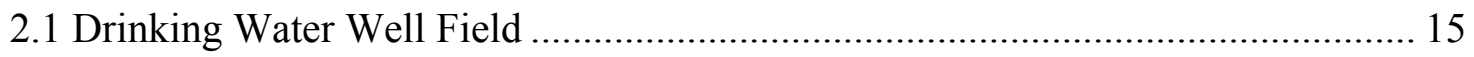

2.2 Groundwater Pollution Vulnerability Index ……............................................... 16

2.2.1 Pollution Index Vulnerability Factors......................................................... 18

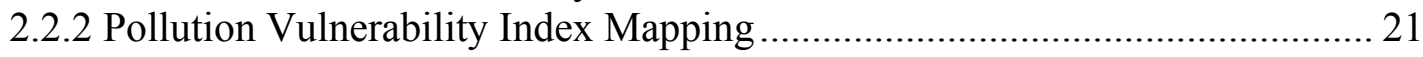

2.2.3 Pollution Vulnerability Method Issues ............................................................... 23

2.2.4 Pollution Vulnerability Index Trends ............................................................ 24

2.3 Indicator Chemicals in Drinking Water .............................................................. 25

2.3.1 Nitrate, Lead, and Toluene....................................................................... 26

2.4 Using GIS in Contaminant Water Interpolation .................................................. 28

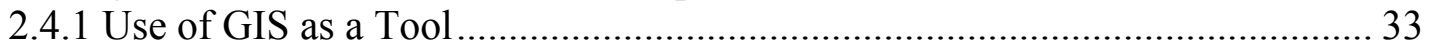

2.5 Dissolved Chemical Constituent Transport in the Biscayne Aquifer ..................... 36

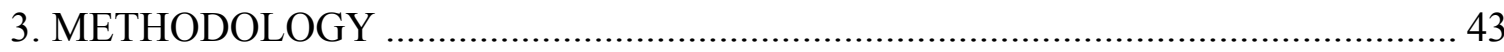

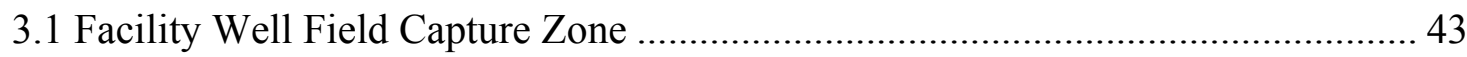

3.1.1 Contamination Source Index and Well Index................................................. 46

3.2 GIS and Contaminant Modeling ....................................................................... 49

3.2.1 Contaminant Model Inputs and Raw Data Preprocessing .............................. 50

3.2.2 GIS Parameters …………………............................................................ 52

3.2.3 Data Exploration and Structural Analysis of Contaminant Coverage in an AOI

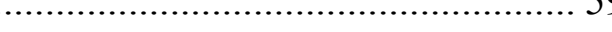

3.3 GIS and Pollution Vulnerability Index Modeling........................................................... 62

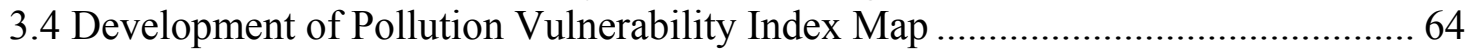

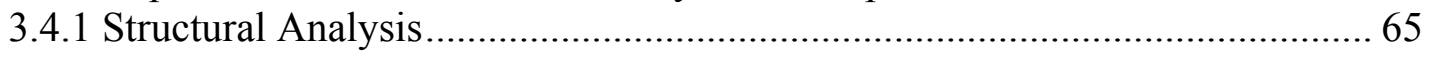

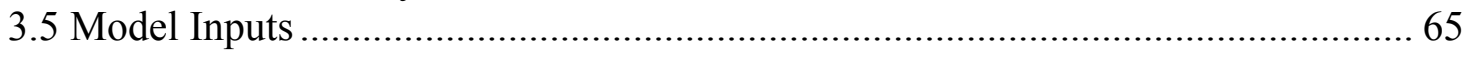

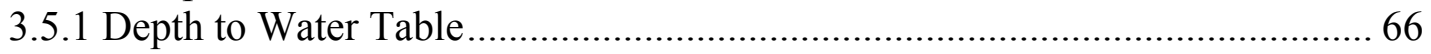

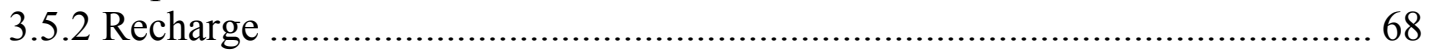

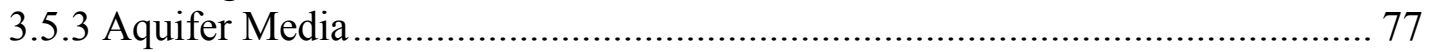

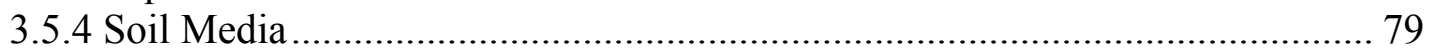

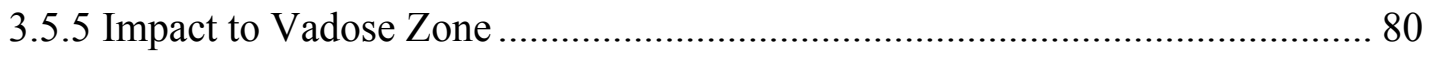

3.5.6 Hydraulic Conductivity .............................................................................. 82

3.5 Sensitivity and Validation of the Contamination Map ……................................... 83 


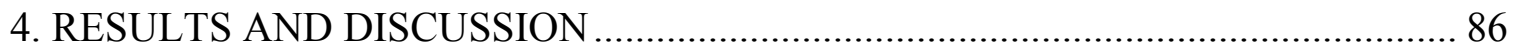

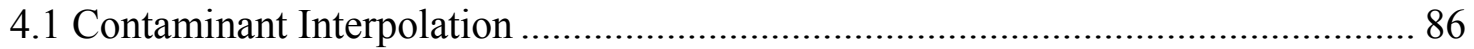

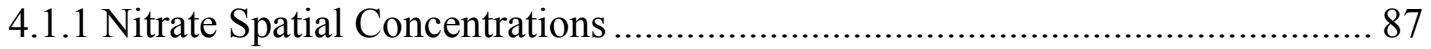

4.1.2 Toluene Spatial Concentrations .................................................................. 92

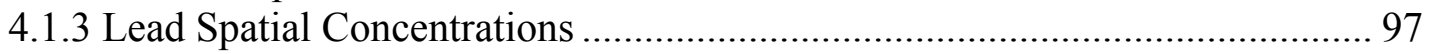

4.2 Area of Interest Temporal Concentrations.................................................... 102

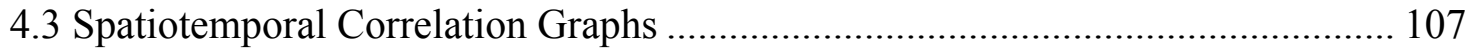

4.4 Pollution Vulnerability Index Map ................................................................. 109

4.4.1 Parameter Impact on Pollution Vulnerability Index ................................... 109

4.4.2 Validation of Output Pollution Vulnerability Index Model......................... 115

5. CONCLUSION AND RECOMMENDATIONS ................................................. 121

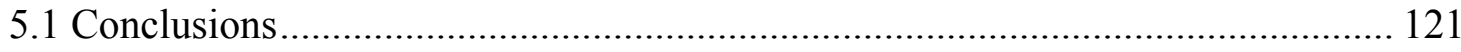

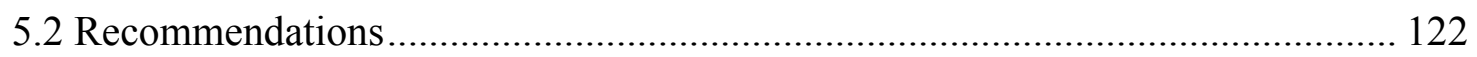

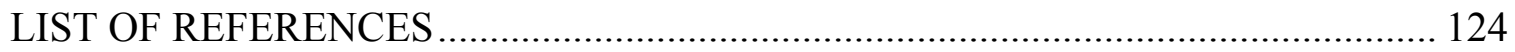

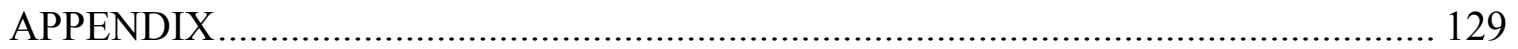




\section{LIST OF TABLES}

TABLE

PAGE

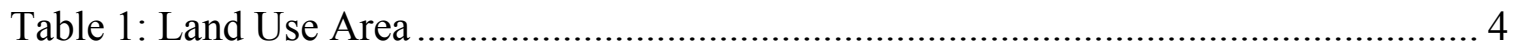

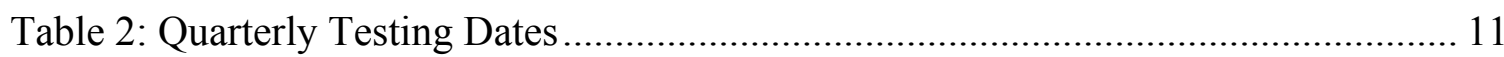

Table 3: Preliminary Statistical Analysis of Nitrate Data for Interpolation Method........ 54

Table 4: Preliminary Statistical Analysis of Lead Data for Interpolation Method ........... 56

Table 5: Preliminary Statistical Analysis of Toluene Data for Interpolation Method...... 57

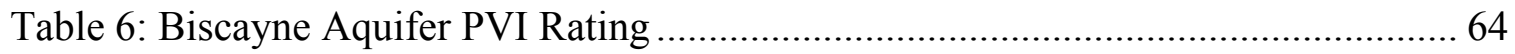

Table 7: Depth to Water Rating Breakdown for Depth to Water Figure........................... 66

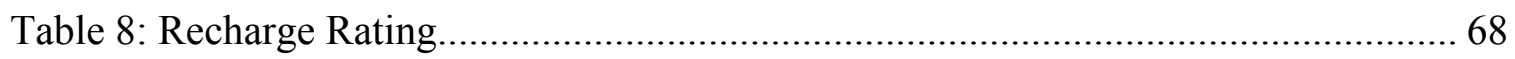

Table 9: Average Yearly Evaporation from the Fort Lauderdale Experiment Station..... 69

Table 10: Hydrological Soil Group........................................................................... 70

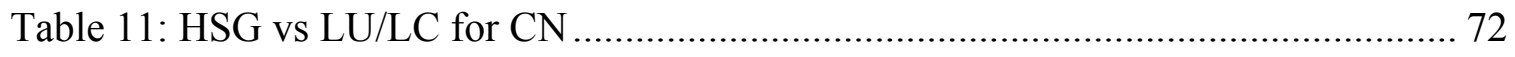

Table 12: Aquifer Media Pollution Vulnerability Rating ............................................. 78

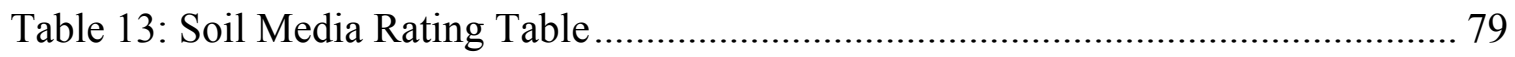

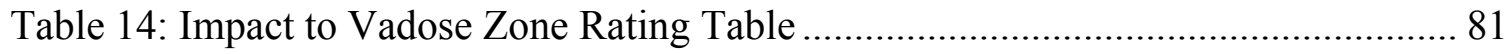

Table 15: Hydraulic Conductivity Rating Table........................................................ 82

Table 16: Nitrate Interpolation Results..................................................................... 88

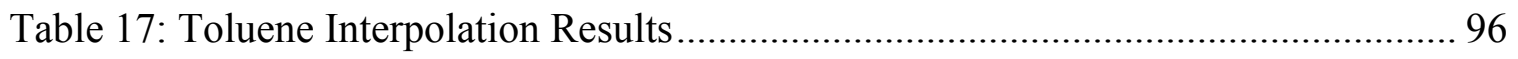

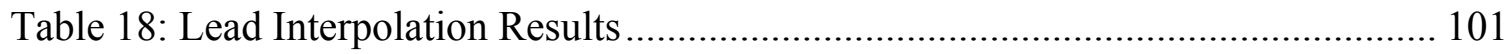

Table 19: Nitrate AOI Interpolation Results.............................................................. 106

Table 20: Pollution Vulnerability Level by Area ........................................................ 113 


\section{LIST OF FIGURES}

FIGURE

PAGE

Figure 1: Map of Broward County Study Area ........................................................ 2

Figure 2: Major Cities and Roads in Broward County ................................................ 2

Figure 3: Map of Broward County Canals and Land Use, Reference Table 1 for LU/LC

Code...... 3

Figure 4: Map of Broward County Well Field Capture Zones ..................................... 45

Figure 5: Potential Facility Contamination Source Index......................................... 48

Figure 6: Northern Directional Trend Analysis for Toluene Y2011 and Nitrate Q2Y2011 52

Figure 7: Map of Spatiotemporal Nitrate Concentrations........................................... 55

Figure 8: Map of Spatiotemporal Lead Concentrations ............................................ 57

Figure 9: Map of Spatiotemporal Toluene Concentrations......................................... 58

Figure 10: Map of Broward County AOI for Well Field Facilities ................................ 61

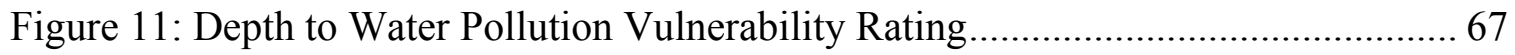

Figure 12: Map of Broward County Land Use / Land Cover for 2009 .......................... 70

Figure 13: Map of Broward County Hydrologic Soil Groups .................................... 71

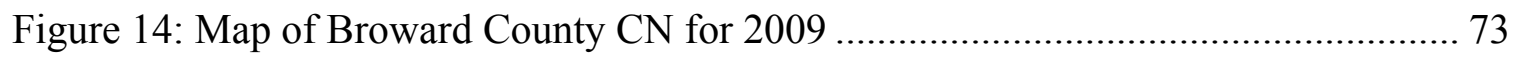

Figure 15: Historical monthly rainfall data for individual field sites, SFWMD,

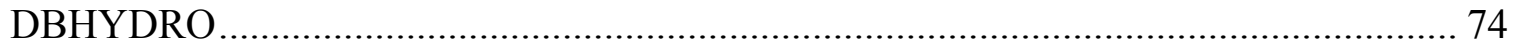

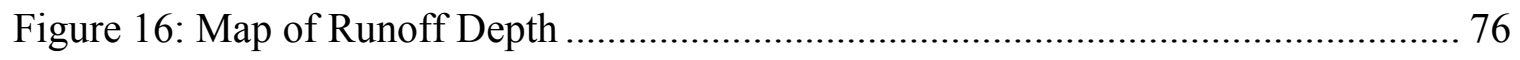

Figure 17: Map of Broward County Recharge Pollution Vulnerability Rating............... 77

Figure 18: Map of Broward County Aquifer Media Pollution Vulnerability Rating ....... 78

Figure 19: Map of Soil Type Pollution Vulnerability Rating .................................... 80 
Figure 20: Map of Broward County Impact to Vadose Zone Pollution Vulnerability

Rating...... 82

Figure 21: Map of Broward County Hydraulic Conductivity Pollution Vulnerability

Rating. 83

Figure 22: Map of Nitrate Interpolation Results...................................................... 88

Figure 23: Quarterly Nitrate Averages .............................................................. 90

Figure 24: Averaged Quarterly Concentrations for 6-Year Timeframe ........................ 90

Figure 25: Quarterly Detections Averaged .......................................................... 91

Figure 26: Total Quarterly Detections .................................................................. 91

Figure 27: Map of Toluene Interpolation Results ................................................. 95

Figure 28: Map of Lead Interpolation Results ..................................................... 101

Figure 29: Map of Surface Nitrate AOI Interpolation Results ................................... 103

Figure 30: Map of Shallow Nitrate AOI Interpolation Results.................................. 104

Figure 31: Map of Deep Nitrate AOI Interpolation Results ...................................... 105

Figure 32: Nitrate well location, depth and concentration relationship....................... 108

Figure 33: Pie Chart of Pollution Vulnerability by Area, Refer to Figure 34 for Legend

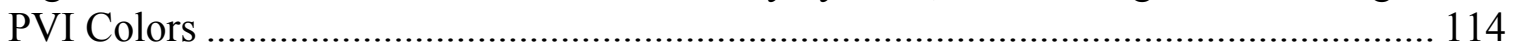

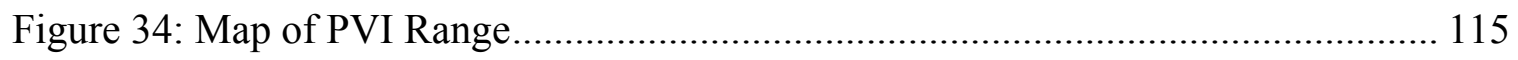

Figure 35: Facility Source and PVI Correlation ................................................... 116

Figure 36: PVI and Nitrate Detection Correlation ............................................. 118

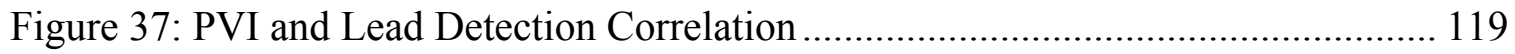

Figure 38: PVI and Toluene Detection Correlation.............................................. 120

Figure 39: 2006 Quarterly Nitrate Interpolation Map........................................... 129

Figure 40: 2007 Quarterly Nitrate Interpolation Map............................................. 130 
Figure 41: 2008 Quarterly Nitrate Interpolation Map.............................................. 131

Figure 42: 2009 Quarterly Nitrate Interpolation Map............................................ 132

Figure 43: 2010 Quarterly Nitrate Interpolation Map............................................ 133

Figure 44: 2011 Quarterly Nitrate Interpolation Map............................................. 134 


\section{LIST OF ACRONYMS}

\begin{tabular}{|c|c|}
\hline A & Aquifer Media (DRASTIC) \\
\hline AOI & Area of Interest \\
\hline AST & Aboveground Storage Tank \\
\hline BPBCW & Broward-Palm Beach Coast Watershed \\
\hline $\mathrm{C}$ & Conductivity (DRASTIC $)$ \\
\hline $\mathrm{CN}$ & Curve Number \\
\hline $\mathrm{D}$ & Depth to Water Table (ㅁASTIC) \\
\hline EAR & Environmental Assessment and Remediation \\
\hline EPA & Environmental Protection Agency \\
\hline ERDAS & Earth Resources Data Analysis System \\
\hline FDEP & Florida Department of Environmental Protection \\
\hline FGDL & Florida Geographic Data Library \\
\hline GIS & Geographic Information Systems \\
\hline HSG & Hydrologic Soil Group \\
\hline $\mathrm{I}$ & Impact to Water Table (DRASTIC) \\
\hline IDW & Inverse Distance Weighted \\
\hline LANDSAT & Land Remote-Sensing Satellite \\
\hline LULC & Land Use / Land Cover \\
\hline MCL & Maximum Contaminant Level \\
\hline MDL & Method Detection Limit \\
\hline NPDES & National Pollutant Discharge Elimination System \\
\hline $\mathrm{OK}$ & Ordinary Kriging \\
\hline
\end{tabular}




$\begin{array}{ll}\text { PVI } & \text { Pollution Vulnerability Index } \\ \text { POSSE } & \text { Public One Stop Service } \\ \text { Q } & \text { Runoff Depth } \\ \text { R } & \text { Recharge (DㅁASTIC) } \\ \text { RMS } & \text { Root-Mean-Square } \\ \text { S } & \text { Soil Type (DRA } \underline{\text { STIC) }} \\ \text { SARA } & \text { Superfund Amendments and Reauthorization Act } \\ \text { SI } & \text { Source Index } \\ \text { T } & \text { Topography (DRASTIC) } \\ \text { TMDL } & \text { Total Maximum Daily Load } \\ \text { UST } & \text { Underground Storage Tank } \\ \text { WI } & \text { Well Index }\end{array}$




\section{INTRODUCTION}

This section introduces the Broward County environmental code, which incorporates localized aquifer factors as they pertain to the development and implementation of science based well field protection policies. The contaminant characteristics of lead, nitrate, and toluene, as the focus contaminants in this study, are discussed in this section as well. The study area, research questions, and objectives of this thesis will also be examined.

\subsection{Study Area}

This research covers the southeast coastal area of Broward County Florida, which has a current population of 1,780,172 (U.S. Census Bureau, 2011) and applied to the portion of Broward County underlain by the Biscayne aquifer. The political boundary of Broward County Florida is located within the Broward-Palm Beach Coast Watershed (BPBCW) and has a developable area of $1101.74 \mathrm{~km}^{2}$, approximately $7.82 \%$ of the total BPBCW.

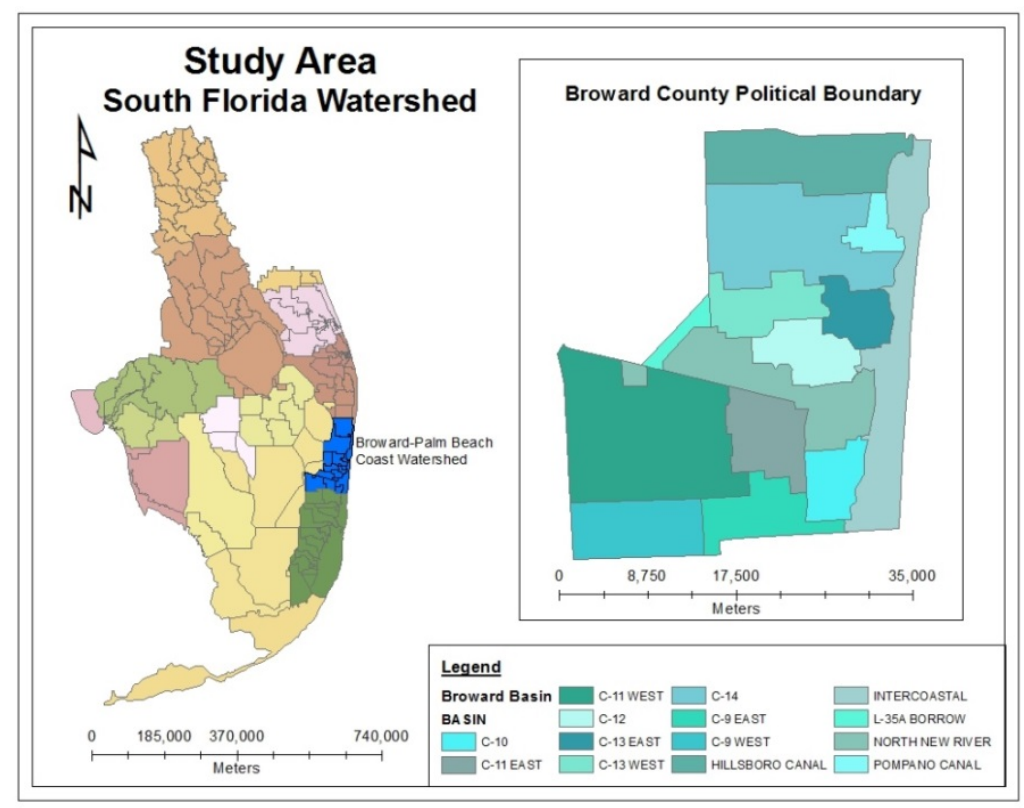


Figure 1: Map of Broward County Study Area

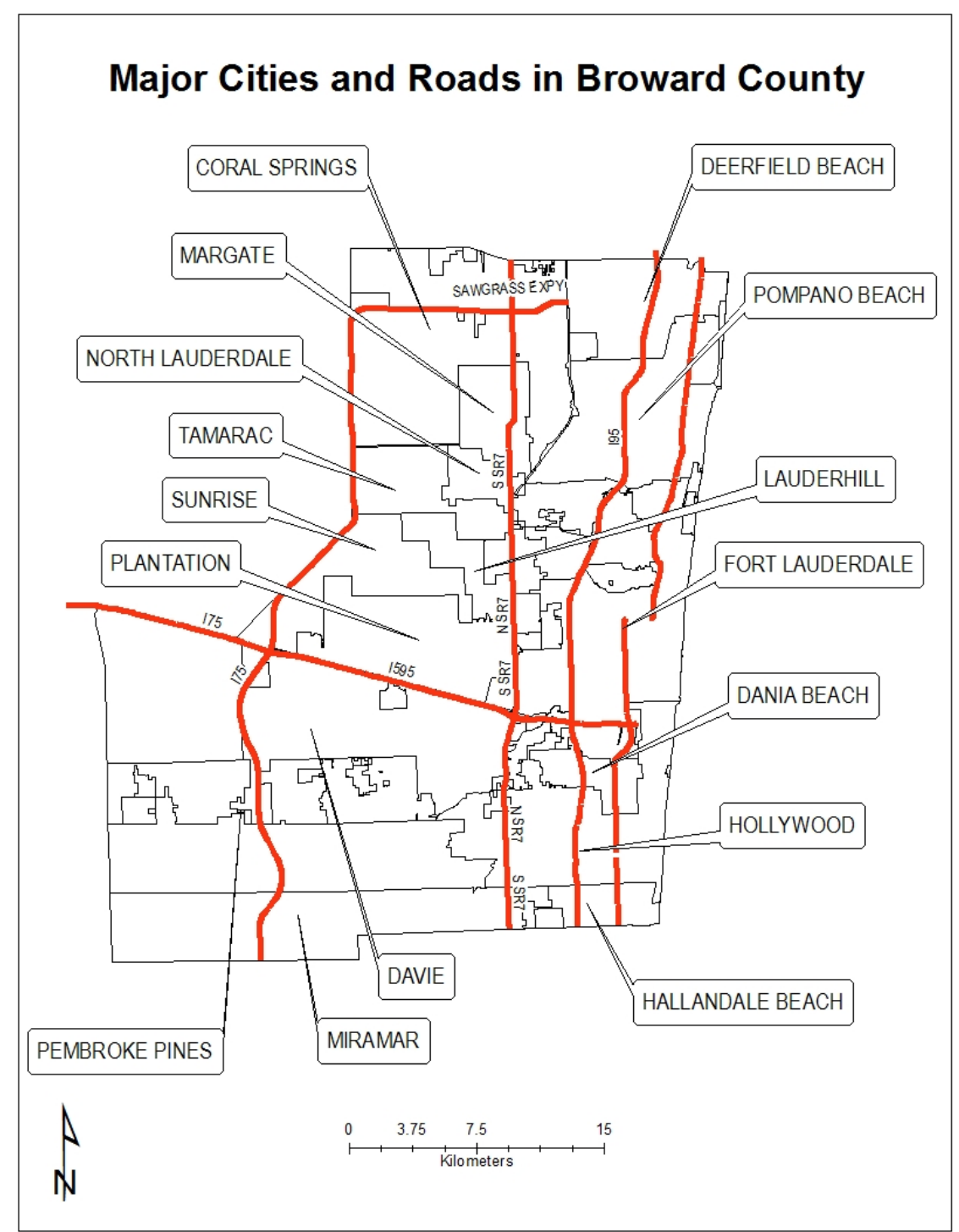

Figure 2: Major Cities and Roads in Broward County

Historically groundwater has been a globally important natural resource for water supply due to its low contamination capabilities, when compared to surface water, as well as its large storage capacity (Hiratsuka, 2011). However, in recent years, due to an increase in urban development, high population growth, and excessive use of fertilizer and pesticides, this resource has come under threat of degradation through overuse, 
inappropriate use, as well as increased potential contamination sources and releases. This study will demonstrate a method to track the travel time and direction of contaminants through an aquifer using geographic information systems (GIS). This study does not incorporate data beyond the political boundaries of Broward County even though the Biscayne Aquifer spans most of south Florida.

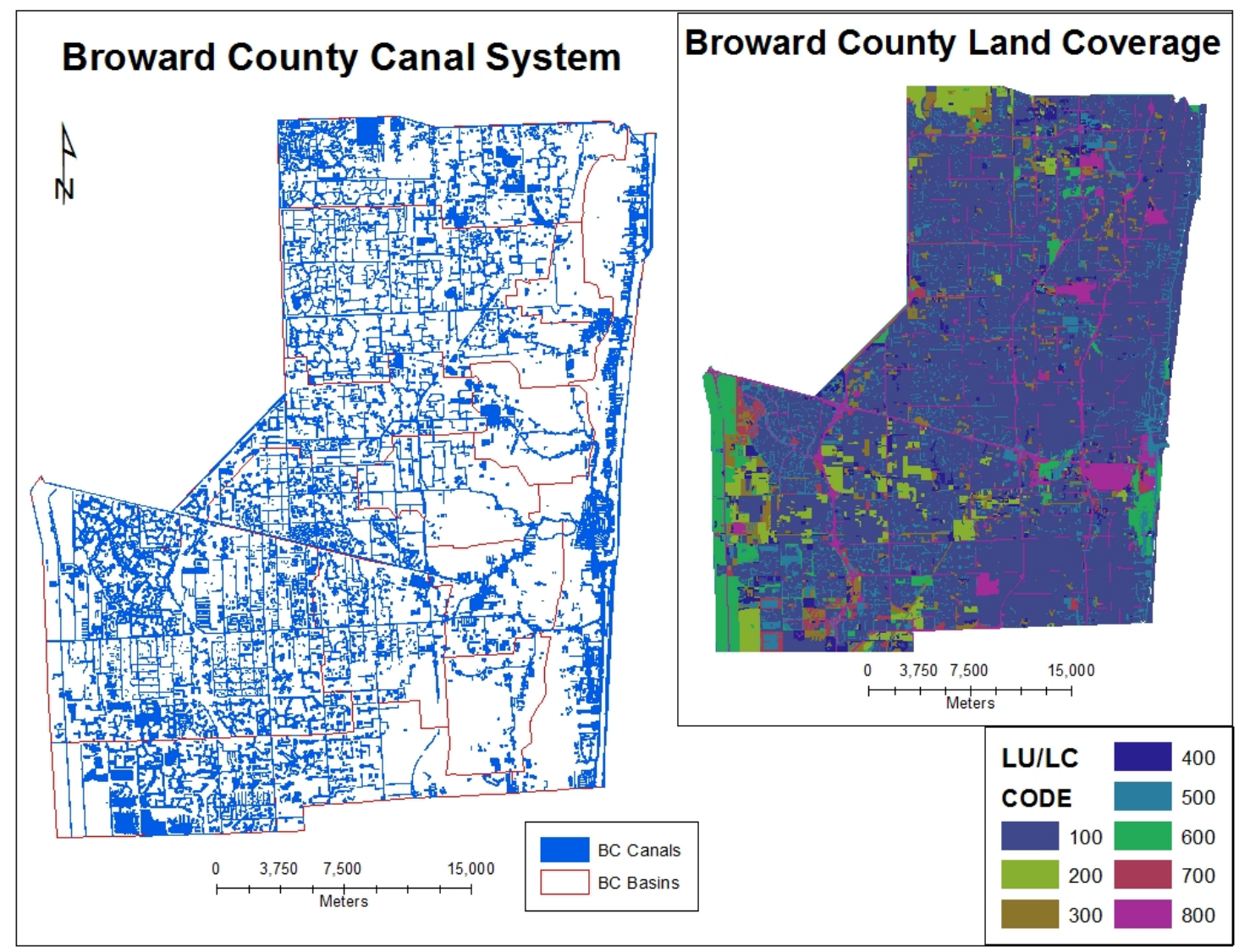

Figure 3: Map of Broward County Canals and Land Use, Reference Table 1 for LU/LC Code 
Table 1: Land Use Area

\begin{tabular}{|c|c|c|r|}
\hline \multicolumn{4}{|c|}{ Land Use Area } \\
\hline LU/LC & Code & Area $\left(\mathrm{m}^{2}\right)$ & Percentage \\
\hline Urban & 100 & 723647269.89 & $60.00 \%$ \\
\hline Agriculture & 200 & 51899488.06 & $4.30 \%$ \\
\hline Range Land & 300 & 49983319.16 & $4.14 \%$ \\
\hline Forest & 400 & 31130599.33 & $2.58 \%$ \\
\hline Water & 500 & 176960810.31 & $14.67 \%$ \\
\hline Wetlands & 600 & 52118036.62 & $4.32 \%$ \\
\hline Barren Land & 700 & 23182642.22 & $1.92 \%$ \\
\hline Roads & 800 & 97118621.63 & $8.05 \%$ \\
\hline
\end{tabular}

The Broward County surface is largely composed of urban, industrial, and agricultural land use areas (Broward County Maps). The chemical and physical processes of carbonate aquifers, located in highly urbanized areas, which have undergone karstification, such as the Biscayne Aquifer, must be researched as those processes have the potential to greatly affect the groundwater quality of the region (Renken, 2008). This research will use GIS modeling to analyze the spatiotemporal trends of significant environmental indicator chemicals detected during well field monitoring of the Biscayne Aquifer. Water samples from different wells throughout the county were analyzed for the following chemicals: nitrates, lead, and toluene.

\subsection{Environment of the Study Area}

The studies compiled for this research agree that the Biscayne Aquifer is vulnerable to many different sources of pollution. The type of media that composes this karst aquifer is what makes it so susceptible to pollution. According to Assaf (2009) the Biscayne Aquifer is composed of karstified limestone, which is a highly porous media that offers 
little opposition to contamination movement between surface water and groundwater. The potable wells in Broward County generally extend down to depths of $-18 \mathrm{~m}$ to $-62 \mathrm{~m}$ and are located at the depth of the well field's primary production zone (Harvey, 2008). The touching-vug flow zones, located from $-10 \mathrm{~m}$ to $-18 \mathrm{~m}$, are located at the depth that is most likely to influence the amount of water withdrawn from drinking water production wells (Renken, 2008).

The Biscayne Aquifer also contains many conduits, which form as a result of localized input from surface streams coming into contact with an unconfined portion of the aquifer (Bailly-Comte, 2010). The surface and subsurface waters mix which leads to the dissolution of aquifer media due to the under saturated nature of surface water relative to the carbonate minerals found in the aquifer. The Biscayne Aquifer is however unlike other karst environments, such as the Edwards aquifer, the Madison limestone, or the Paleozoic carbonate rocks of the Appalachians, all of which can be distinguished by large conduits (Renken, 2008). The Biscayne aquifer contains small-scale horizontal, lithostratigraphically concentrated, conduit development and features leading to high matrix conductivity. If contaminants from the surface are found solely within conduits the contaminant plume will be obvious fairly quickly; the outflow of this contaminated groundwater to surface water will be great in size but short-lived (Screaton, 2004). Water flow is often faster through conduits because they are composed of younger rocks that are not recrystalized carbonates. Within the conduits, during low flow conditions such as found during the dry season, the conduits will drain water from the surrounding matrix (Bailly-Comte, 2010). During high flow conditions such as those found during the rainy 
season, may cause the larger conduits to reverse water flow from the conduits back into the adjacent aquifer matrix (Screaton, 2004). The groundwater recharge for the Biscayne Aquifer is mainly fed by precipitation received during the wet season (Pathak, 2010).

However, most of the recharge is discharged as a base-flow, which occurs after the wet season and between major rainfall episodes (Armour, 2010).

\subsection{Hydrological and Geological Background}

The Biscayne aquifer, located in south Florida, has been identified as the sole source of potable drinking water for 2.4 million citizens (Renken, 2008). Broward County is divided up into 14 different political basins: C-9 East, C-9 West, C-10, C-11 East, C-11 West, C-12, C-13 East, C-13 West, C-14, Hillsboro Canal, Intercostal, L-35A Borrow, North New River, and Pompano Canal. The aquifer media is composed of a highly transmissive, porous karst limestone and the aquifer itself is unconfined. These features can significantly increase contaminant infiltration into the drinking water and subsequent contaminant transportation and pollution within the drinking water aquifer (Collin 1998).

Once the contaminants have entered an aquifer, travel time within the aquifer is dependent on the influence of aquifer features such as porosity, hydraulic conductivity, soil type, and geologic formation. Drinking water protection is difficult to implement in karst aquifers because of the high potential for rapid movement of contaminants and limited attenuation of pollutants in any one place within the aquifer (Renken, 2008). The swift movement of contaminants is intensified by eogenetic karst characteristics of the Biscayne aquifer, where limestone is close to the land surface augmenting conduit and porosity development (Florea, 2007). Water flow within the Biscayne is 
lithostratigraphically controlled, moving water through flow zones that occur within highly transmissive, touching-vug pore space, which establish the stratiform flow zones (Pore Classes, 2013). The transmissivity values for this aquifer range from 0.4 to $3.1 \mathrm{~m}^{2} / \mathrm{s}$ and are at the high end of values recorded for geologic materials (Renken, 2008). These flow zones are capable of transporting contaminants hundreds of meters to kilometers within the aquifer (Renken, 2008).

\subsubsection{Cone of Depression}

Other features found within the drinking water aquifer affecting contaminant travel time are the multiple cones of depression created by drinking water supply wells. Broward County public drinking water wells pump water solely from the karst Biscayne Aquifer. A cone of depression is created when the water table, in the area surrounding a wellhead, drops as a result of pumping at the drinking water well (Pinder, 2009). These cones of depression are formed as water is drawn radially to the well causing the water table level to decline. However, the water table of the Biscayne aquifer occurs near the land surface even with the extensive pumping rates of potable wells within the well fields (Renken, 2008). The size of the cone within the different levels of the aquifer is based on the pumping rate and hydraulic characteristics of the aquifer itself. The high permeability of the karst aquifer allows a significant quantity of water flow through the unconfined aquifer media of the carbonate limestone that constitutes the Biscayne Aquifer (Ginn, 2004). In the shallow subsurface of the aquifer the cones of depression, created by in-use potable wells, respond rapidly to precipitation events (Renken, 2008). Wider, and 
shallow, cones of depression, and therefore, wider cones of influence, typically occur around wells in aquifers of high transmissivity. Well field protection regions include surface and subsurface areas marked to protect public drinking water systems. Due to increased aquifer sensitivity, well field protection zones are designated in these areas in order to mitigate and control contamination and pollution risks. Typically, the well field protection region coincides with the width of the cone of depression around a well field projected at the land. Multiple pumping wells located in close proximity to each other, as occurs in well fields, results in individual pumping cones, overlapping, producing well field protection zones of various shapes and sizes when projected on the ground surface. The well field protection zone boundaries are representative of contaminant travel times within the Biscayne aquifer. The closer the zone is to the wellhead the greater the level of protection is applied in regards to the contaminants that are allowed to be used, stored and/or handled on the land surface of the well field (Fasbender et al., 2009).

Contaminant travel times within groundwater for much of the United States are usually delineated as 1-, 5-, and 10- year land areas (Miller, 2005). Due to the porous nature of the karst aquifer the time-of-travel for contaminants is displayed in days not years. The porosity of the Biscayne aquifer was estimated in several preceding investigations with porosity values spanning from $10 \%$ to over $50 \%$ (Renken, 2008). However, these estimates may not account for the potentially high flow through void space and the connectivity of the void space within the heterogeneous media of the aquifer (Renken, 2008). The Broward County well field policies state that there are three different time travel zones surrounding each potable wellhead; zone 1, the area situated between the 
potable wells and the 10-day travel time contour, zone 2, the area situated between the 10-day and the 30-day contours, and zone 3, the area situated between the 30-day and the 210-day contours. Currently, these three different travel times for contaminants do not accurately capture local environmental factors for estimating contamination point sources, flow rate, and flow direction (Renken, 2008). When these cones of influence are created by the pumping drinking water wells, there is a likelihood that contaminants will interact with the different layers of the aquifer. It is assumed that contaminants which are introduced into the aquifer within the cone of influence are transported to an in-use potable well. Within the area closest to the wellhead, zones 1 and 2, the use of contaminants that have an adverse health effect on humans and the environment is prohibited (Miller, 2005).

\subsection{Policy Background}

The Federal Government and the State of Florida both have programs that are designed to protect public drinking water sources. Florida Administrative Code, Chapters 62 through 521, governs the State Wellhead Protection Program. The Well Field Protection Program (Well Field Program) is governed through Chapter 27 of Appendix 11 in Article XIII of the Broward County Natural Resource Protection Code. The Broward County groundwater protection program was developed through a well field protection program managed by the County government. The aquifer is monitored for federal drinking water regulation compliance by local governmental administrations and the water supply municipalities. Both of these programs monitor water in an effort to protect the public 
drinking water supply from contamination pollution. These programs require the quarterly monitoring of contaminants like lead, nitrates, and toluene that are used in businesses such as automotive shops, fueling stations, and horticultural product suppliers. These chemicals are detrimental to human health and are indicators of an anthropogenic impact to the drinking water supply. Those contaminants are listed as such in the Emergency Planning and Community Right-to-Know Act (EPCRA) under the Code of Federal Regulations (CFR), 40 CFR Parts 68, 302, 355, and 372. Those facilities and municipalities within protected well field zones have designated contaminant-sampling plans incorporated into their Hazardous Material Facility License. These sampling plans reflect the contaminants to be stored, handled, used and/or produced within the facility, and are hazardous to human health and drinking water quality (BC Code of Ordinances, Article XIII). The sampling plans are based on chemical inventories performed by county inspectors working for the Pollution Prevention, Remediation, and Air Quality Division. This study will not attempt to incorporate toxicology information, environmental carrying capacity or the impacts these contaminants have on human health into the analysis.

The well field and surface pollutant discharge detection data are reviewed by separate governmental entities. Presently there is no long-term spatial coverage plan designed to track and share contamination detections between governmental agencies and municipalities. The local Well Field Program considers each well field separately when testing quarterly for contaminants, a process that does not reflect the travel time of contaminants from one well field to another within this aquifer. 
Table 2: Quarterly Testing Dates

\begin{tabular}{|c|c|}
\hline \multicolumn{2}{|c|}{ Yearly Monitoring Quarters } \\
\hline Quarter 1 & January, February, March \\
\hline Quarter 2 & April, May, June \\
\hline Quarter 3 & July, August, September \\
\hline Quarter 4 & October, November, December \\
\hline
\end{tabular}

While in transit, the contaminants considered enter the different zones of influence created by pumping production wells. As stated in Broward County governmental policy, these zones represent approximately how long it would take a regulated substance to reach the drinking water supply well if there was a release to the land and/or surface water. The zones of influence refer to those zones delineated by contaminant iso-travel time contours around existing or proposed well fields (BC Code of Ordinances, Sec. 27376). There are three set zones of influence, each dictating progressively stronger levels of environmental protection in regards to contaminant usage, storage and handling. The Environmental Assessment and Remediation (EAR) Section of Broward County Government generates contaminant travel time contours through hydrological model calibrations.

\subsection{Research Objectives}

This research is aimed at showing how GIS integration of contaminant tracking, along with thoughtful modeling methods based on existing data, can be useful tools for government to formulate policy decisions, and identify specific areas that are particularly sensitive to pollutant releases (Wang, 2012). In the long run, using GIS for contaminant tracking in the aquifer will lead to a greater understanding of contaminant flow and the 
subsequent protection of drinking water. This study aims to contribute to the Broward County governmental process of installing new potable wells in areas expected to be the least impacted by pollution vulnerability factors. The overall objective of this research is to assess and understand the spatiotemporal movements of contaminants within the Broward County segment of the Biscayne Aquifer.

The study addresses the interactions between contaminants leaching into the ground water through runoff, lateral movements of contaminants through water retention ponds and canals, and periods of aquifer contaminant influx (Armour et al., 2010). Water quality indicators indicative of agricultural sources (i.e. nitrate), industrial sources (i.e. lead), and petroleum sources (i.e. toluene) were used to track the health of an aquifer near a well field (Almasri et al., 2007). GIS modeling of these contaminants allow for the tracking of potential point and non-point surface pollution sources (Cosenza et al., 2007). The specific objectives of this study are to:

1. generate lateral, vertical, and seasonal maps of continuous raster coverage layers from the stationary contaminant detection points in Broward County,

2. develop temporal (inter and intra-annual) mapping trends of the contaminants (nitrate, lead, and toluene) from the quarterly (2006 - 2011) monitoring data,

3. construct lateral and vertical maps of the detected contaminants in an area of interest (AOI) containing solid waste facilities, significant levels of impervious surfaces, automotive repair shops, and fuel stations, and 
4. conduct statistical analyses in order to understand the spatiotemporally correlated trends of the contaminants to pollution vulnerability index (PVI) factors.

These four objectives provided the basis to determine if there is a statistical correlation over time and space between the specified independent pollution vulnerability factors and the minimum contaminant detection levels.

\subsection{Research Questions}

Monitoring contaminant movement and concentration over time within the Biscayne Aquifer will contribute to the production of spatially relevant data necessary to generate spatially relevant raster maps demonstrating the vulnerability of certain sections of the Biscayne aquifer to pollution. Following such formulation and compilation of various data and model sources, the relevant questions are:

1. Is there a spatiotemporal trend in the potable well detection data (nitrate, lead, and toluene)?

2. Are the well contaminant detection points unconnected? Or is there smoothness to the contaminant detection data (i.e. Tobler's First Law of Geography)?

3. Are the PVI factors and spatiotemporal contaminant trends significantly correlated?

4. Which potable wells are the most vulnerable to contamination based on realtime contaminant detection data and the site-specific PVI? 
Vertical, horizontal, and temporal movements of the three contaminants were obtained from quarterly monitoring and potable well water quality samples. The GIS contaminant model of different contaminant raster coverages will demonstrate the different types of annual and seasonal temporal movement specific to the three different contaminants. Horizontal movement of the contaminants is expected to trend in a Southeast direction, towards the ocean and Miami-Dade County. Vertical movement of the contaminants is expected to show a greater contaminant concentration within the shallower areas of the aquifer. 


\section{LITERATURE REVIEW}

This section surveys previous research related to the current study. Summaries are presented regarding: the use of GIS for contaminant tracking; the environment of a karst aquifer; and movement of contaminants within the Biscayne Aquifer in Miami-Dade county. The use GIS as a tool, representative of scientific information in an easily understandable visual format, to make raw data increasingly accessible to the public and policy makers is also discussed.

\subsection{Drinking Water Well Field}

According to the United States Geological Survey and Screaton (2004) the Biscayne Aquifer is the principal water supply for all of Dade and Broward Counties and the southeastern part of Palm Beach County in southern Florida. As the primary source of freshwater in the region the Biscayne Aquifer is used for domestic, public-supply wells, and agricultural activities. A study by Nolan and Stoner (2000) indicates that the most polluted drinking water wells within the United States are found in agricultural and urban settings. Miami, Broward, and Palm Beach are all coastal counties. The county locations and high withdrawal rates of water from the aquifer are resulting in an increase of salts in the ambient groundwater from intruding ocean water, which has a higher water pressure than fresh water (Secunda, 1998).

The well field protection areas in Broward County are defined as those surface and subsurface areas surrounding a well field which supply a community drinking water 
system with water (Miller, 2005). Potential contaminants have a more direct pathway to the source of drinking water through these protected surface and subsurface areas. The goal of the Broward County Well Field program is to reduce both direct contaminant pathways and nonpoint sources of pollution in the watershed. This reduction in sources can be accomplished through the execution of management measures such as best management practices and land use policies (Randhir, 2011).

\subsection{Groundwater Pollution Vulnerability Index}

The United States Environmental Protection Agency (USEPA) developed a PVI method using depth to water table, recharge, aquifer media, soil media, topography, impact to vadose zone and hydraulic conductivity (Kerr, 1987; Nobre, 2007). These are seven media parameters, collectively called DRASTIC, that are used traditionally in a groundwater PVI method approved by the EPA (Kerr, 1987). The DRASTIC method uses a linear model to calculate the pollution vulnerability of the aquifer environment (Pathak, 2010).

Studies by Thapinta (2002), Pathak (2010), Nobre (2007), and Secunda (1998) used vulnerability factors to create a groundwater pollution vulnerability map. These vulnerability factors are pollution indicators for the aquifer groundwater. The factors are aspects of the surrounding environment that would adversely affect the health of the aquifer; a PVI map is created based on factors representing the groundwater environment (Kerr, 1987). Each of these seven factors was weighted based on its relative importance 
and impact to groundwater vulnerability due to pollution contamination (Thapinta, 2002). The ranking of these environmental factors is also determined by the magnitude of each class of contaminant to groundwater impact (Nobre, 2007). Each pollution factor is further divided into either significant media types or numerical ranges, which have an influence on pollution potential (Secunda, 1998). Each pollution vulnerability factor is divided into ranges, and each range has a numerical multiplier assigned (Pathak, 2010). The pollution vulnerability factors become map attributes that are assigned numerical indices so that pollution vulnerability can be gauged statistically.

The DRASTIC method was developed by USEPA as a way to qualitatively evaluate the relative vulnerability of a public drinking water aquifer to anthropogenic contamination through different types of land use (Secunda, 1998). The evaluation is accomplished by creating pollution vulnerability scores at different locations through the numerical joining of environmental factors affecting movement of surface contaminants to groundwater (Thapinta, 2002). The higher the vulnerability scores the greater the potential for pollution contamination (Huan, 2012). According to Pathak (2010), this layer overlay method is one of the most widely used to compute groundwater vulnerability indices over large geographical areas; these areas often involve a variety of hydrogeological settings. With the DRASTIC method providing the ability to track vulnerable areas of the surface aquifer, techniques were developed to predict which subsurface areas are more likely than others to become polluted as a result of actions taking place at or near the land surface (Pathak, 2010 and Huan, 2012). According to Secunda (1998), the DRASTIC model has proven to be useful when estimating vadose zone susceptibility to pollutants 
permeating from the ground surface through synthesis of the seven mappable hydrogeological impact factors. However, certain ratings assigned by the EPA's committee of experts were found to be more applicable than others within different regions of the world; so where required localized ratings have been modified to accommodate for local environmental differences (Secunda, 1998). According to Morio (2010), this ability to tune the DRASTIC method to different environments allows for a more accurate spatial distribution of estimated contaminants in groundwater.

Modifications to the DRASTIC method also depend on the type, amount and quality of data that is available in the region being studied. The PVI method is also determined by the objective of the overall study (Morio, 2010). In the DRASTIC method, the disposition of the vulnerability is integrated into the model by separating the numerical values or media type of each factor into ranges and then assigning a rating value to each range (Pathak, 2010; Huan, 2012). However, the DRASTIC method will ignore the difference of factor values within an assigned range and is therefore unable to reflect small variations of hydrogeological factors on groundwater pollution vulnerability (Pathak, 2010). According to Nobre (2007), in the final DRASTIC map the greater the intrinsic vulnerability index values the greater contamination potential.

\subsubsection{Pollution Index Vulnerability Factors}

The first of the pollution factors captured in the DRASTIC metric is depth (D) to water table. According to Nobre (2007) and Pathak (2010), this vulnerability factor is usually generated by a knowledge database of municipal and private borehole logs. This database 
contains direct measurements of existing groundwater wells, which recount unique well features every time they are used (Pathak, 2010). In south Florida, the depth to water table during the dry season is roughly -0.6 to $-1.2 \mathrm{~m}$ below the surface and during the wet season the water table usually reaches the standing water covering the Holocene deposits, which are layered over the Biscayne aquifer (Renken, 2008). The second pollution factor is recharge $(\mathrm{R})$ : the recharge map is usually constructed by a combination of natural precipitation layer, a land use/land cover (LULC) map, and a soil curve number (CN) (Nobre, 2007). According to Nobre, the precipitation information used in generating the recharge coverage is usually based on the collection of raw data from government agency rain gauges. For instance, in many cases high runoff areas are associated with agriculture and urban land uses (Randhir, 2011). Furthermore, the information regarding groundwater flow is intended to improve the DRASTIC interpolation accuracy especially if contaminant concentration data is scarce (Pacheco, 2012). The third pollution factor is aquifer (A) media type. The influence this factor has on pollution vulnerability varies widely depending on the aquifer environment. According to Secunda (1998) the karstic limestone that composes the Biscayne Aquifer is assigned a higher rating, which means higher pollution potential. This particular geologic formation serves as one of the easier transport pathways for pollution contaminants to reach the aquifer (Nobre, 2007; Pacheco, 2012). The fourth pollution factor is the aquifer soil (S) media type. The Biscayne Aquifer is mostly composed of sand and sandy loam, which is assigned one of the higher pollution vulnerability ratings. Those soils characteristics that lead to high porosity also have a high potential for contamination percolation to the water-table below (Secunda, 1998). In a case such as this, in order to 
obtain a more accurate reading of the effect that soil media will have on pollution potential the hydrologic soil group (HSG) - infiltration potential of soil - was combined with the land use categories creating twelve combination ranges for four soil groups and three LULC categories (Nobre, 2007). For instance, assigning land uses different ratings and weights allows for the characterization of extensive land uses, like effluent irrigation of crops, as potential sources of groundwater pollution (Secunda, 1998). The different land use classifications are determined by training the Land Remote-Sensing Satellite System (LANDSAT) 5-TM imagery data to recognize different wavelengths as being representative of different LULC coverage (Nobre, 2007). The additional parameters incorporated into DRASTIC land cover and CNs are helpful in increasing the accuracy of vadose zone vulnerability (Secunda, 1998). The goal of this approach is to obtain greater accuracy in soil media estimates because temporal and spatial changes in LULC can have significant detrimental effects on the health of an aquifer ecosystem (Randhir, 2011; Veni, 1998). Those areas where urban land covers are the major land use can demonstrate the highest impervious cover in the watershed (Randhir, 2011). High runoff potential and topsoil loss are associated with agriculture and early urban land uses (Randhir, 2011; Veni, 1998). The fifth pollution factor is topography ( $\mathrm{T}$ ) of the aquifer environment. According to Secunda (1998) the topography of the flat plain of south Florida leads to higher percolation time from surface water to the water table. This environment causes higher pollution vulnerability ratings (Navas, 2011). The sixth pollution factor is the impact (I) to vadose zone of the aquifer environment. According to Secunda, limestone lithology is dominant in the Biscayne Aquifer environment of south Florida (Secunda, 1998). This environment indicates that the pollution vulnerability ratings for this region 
will be higher than those regions with granite lithology (Han, 2006). The seventh pollution factor is hydraulic conductivity (C). Most of the data readings used to compute the conductivity raster coverage for a region comes from aquifer pump tests of monitoring and potable municipal wells (Rahman, 2007; Nobre, 2007).

\subsubsection{Pollution Vulnerability Index Mapping}

As the seven pollution factors are assigned weights and ratings, a trend in pollution vulnerability mapping begins to develop. Secunda, (1998), suggests that the higher indices in the final DRASTIC map are the result of the cumulative rating and weight contributions of the following three environmental factors: high recharge coefficient, low depth to water-table, and sandy soils (Secunda, 1998). According to Thapinta (2002), over the past two decades there have generally been three approaches used to assess groundwater pollution susceptibility: direct observations, simulation methods, and index methods. The first two methods measure groundwater vulnerability using monitoring data and this data is typically paired with contaminant characteristics to increase accuracy (Nobre, 2007). Direct observation and simulation methods render the most conclusive results; however, there is rarely sufficient data available to develop accurate regional vulnerability assessments (Rahman, 2007). Index methods, like the DRASTIC model, combine factors that affect the movement of contaminants from the surface to subsurface environment. The final numerical output yields vulnerability scores at different spatial locations throughout the aquifer surface (Thapinta, 2002). The pollution index factors for DRASTIC are chosen based on specific regionalized data (Secunda, 1998). This allows 
for local environmental experts to make study area modifications to the vulnerability factor weights and ratings during the evaluation period (Secunda, 1998). For instance, in a 2002 study by Thapinta to assess groundwater pollution potential by pesticides in Central Thailand the numerical ratings for each environmental factor were rank correlated with known monitoring detections for pesticide to determine the relative significance of each factor (Thapinta, 2002). According to a study by Pathak (2010), overlaying local knowledge and regional pollution vulnerability factors will modify and improve the DRASTIC method to reflect a reliable tool for ground water protection. The methodology presented in a 2006 study by Nobre (2007), regarding groundwater vulnerability and risk mapping, determined that it is possible to define the highest risk areas within well fields and from the contaminant sources within the well capture zone delineate the expected impact to the affected drinking water well.

The purpose of the PVI method is to bridge the gap between data intensive methods and non-reproducible subjective methods that are used if known data is scarce (Morio, 2010). According to Thapinta and Pathak this method can produce a generalized knowledge base and be used over a large region of space while not having to gather extensive amounts of field data (Thapinta, 2002; Pathak, 2010). Contaminant data limitations are usually characteristic of early project stages regarding drinking water withdrawal from an aquifer. In many of these cases the information regarding subsurface pollution only comes from primary site investigations and local historical information (Morio, 2010). However, the DRASTIC model can be changed to accurately reflect local hydrological settings and environmental issues (Pathak, 2010). 
Developing pollution vulnerability factor coverages that are representative of the large aquifer environment provide the methodological basis for identifying wide reaching spatial problems (Thapinta, 2002). This vulnerability index model also acts as a predictive tool for the management of water resource use in aquifers (Pathak, 2010). Those areas that have high pollution vulnerability necessitate detailed inspections of the current contaminant vulnerability and groundwater pollution (Thapinta, 2002). Therefore, groundwater vulnerability maps are useful tools that can be used to effectively allocate limited monitoring resources to these areas where monitoring is most needed (Thapinta, 2002). Consequently DRASTIC, as a PVI method, creates method that is a fiscally responsible way to prioritize specific areas for ground water protection and instill accurate monitoring efforts (Assaf, 2009). For instance, correct knowledge of locations vulnerable to pollution can be used to place monitoring wells, if the hydrology of the aquifer indicates that well field zones will be deleteriously affected outside of the currently designated well field zones (Thapinta, 2002). In large geographical areas with limited environmental data, the aquifer ground water index maps provide the first information which local municipalities, administrators and governmental agencies use in the creation of regional and local groundwater resource protection and management plans (Dixon, 2005; Pathak, 2010).

\subsubsection{Pollution Vulnerability Method Issues}

Although the DRASTIC model is good for demonstrating a generalized knowledge dataset there are still some problems with accurate implementation of the model. When 
this model is applied to the same hydrogeological system across large spatial areas dramatically dissimilar results can be generated due to the lack of proper validation (Pathak, 2010). Furthermore, when verifying the accuracy of the DRASTIC model by conducting a correlation between the gathered real-time field data and the final DRASTIC model coverage a large number of non-detects from the field data can contribute to a low number of significant correlations between the two layers (Thapinta, 2002; Huan, 2012). Another limit to the DRASTIC index method is the implication that pollution is entering the aquifer from non-point and pollutant loading sources (Assaf, 2009). As such point-source pollution vulnerability is not accounted for in the index because point source contamination is usually released directly to the environment, circumventing many factors that could retard contamination (Assaf, 2009). Therefore, this limits the accuracy of the DRASTIC model in those watershed areas which have anthropogenic activities such as those requiring Total Maximum Daily Load (TMDL) permits, solid waste sites, change of top layer characteristics, and other activities that form point pollution pathways to the environment due to direct discharge (Assaf, 2009).

\subsubsection{Pollution Vulnerability Index Trends}

Groundwater vulnerability assessment can be identified as a pattern recognition problem viewed in the form of a map in a GIS environment (Wang, 2012). In order to verify the significance of the pollution index method, the resulting potential vulnerability range coverage and groundwater data sample layers are overlaid on the map to determine if the groundwater vulnerability level generated from the DRASTIC method and the observed 
data correspond spatially with each other (Pathak, 2010). In some studies the validity of the DRASTIC model was estimated through the comparison of the final index values with known ground water monitoring data (Secunda, 1998). According to a case study by Pathak (2010), the output of the vulnerability index models could be tested and validated by using the known nitrate data taken from the shallow aquifer in Kathmandu. This correlation can be determined by cross sectioning the vulnerability index compared to actual contaminant presence and location within the aquifer (Nobre, 2007).

\subsection{Indicator Chemicals in Drinking Water}

The protection of groundwater, and thus the requisite study of indicator chemicals, is globally important (Pathak, 2010). Groundwater, as a renewable natural resource, is valuable due to its large storage capacity and low susceptibility to pollution in comparison to surface (Pathak, 2010; Navas, 2012). However, groundwater is continuously under threat of degradation both by anthropogenic contamination and by inappropriate use (Pathak, 2010). Studies show that some of the most contaminated wells are located underneath agricultural land, followed by urban land due to rapid development (Mattern, 2009; Pathak, 2010). The solutes of major environmental concern, nitrate and phosphate, are exported via groundwater discharge in agricultural regions; the solutes usually originate from fertilizers applied to intensive cropping systems (Rasiah, 2010). In many regions of the world rapid urbanization and development is unplanned and haphazard. Therefore, the migration and conversion of pollutants in water pollution 
accidents typically are the result of a dynamic, complex, and nonlinear system of anthropogenic activities (Zhang, 2011).

\subsubsection{Nitrate, Lead, and Toluene}

Three contaminants, nitrate, lead, and toluene, are being used in the Groundwater Quality Index of this study. The Maximum Contaminant Level (MCL) for these contaminants is referred to in the 1974 Safe Drinking Water Act. This law regulates enforceable ground water regulation levels and establishes the prescribed level of contaminant concentrations at which no adverse health effects are likely to occur. These contaminants were chosen because they each represent common sources of drinking water contamination and they are the most prevalent in terms of total detection concentration amounts (Water: Safe Drinking Water Act (SDWA), 2012).

These three contaminants are introduced to the aquifer by widespread improper business practices found within Broward County. The presence of nitrate in groundwater can indicate runoff from fertilizer use, nitrification of ammonia from leaking septic tanks or natural erosion of deposits (Lake, 2003). The MCL for nitrate is 10 miligrams per liter (mg/L); continued exposure to nitrate in drinking water above the MCL may lead to cases of methemoglobinemia or blue-baby syndrome (Gurdak, 2012). High levels of nitrate reduce the ability of red blood cells to carry oxygen, leading to a bluish skin tone and the risk of death (Gurdak, 2012). The continued exposure to this contaminant, at concentrations as low as 2.5 to $4 \mathrm{mg} / \mathrm{L}$, may lead to the same health concerns discussed 
previously. The method detection limit for nitrate is $0.01 \mathrm{mg} / \mathrm{L}$ (US EPA's Methods and Minimum Detection Limits, 2007).

Lead in groundwater may be due to improper disposal of consumer products, e.g., bullets around outdoor gun ranges if not properly disposed of, lead-acid battery corrosion, or degradation of older household plumbing systems (Cao, 2002). The MCL for lead is $0.015 \mathrm{mg} / \mathrm{L}$. The continued exposure of lead above the MCL in children may cause delayed physical and mental development (Davis, 2009). In adults continued exposure to this chemical may cause high blood pressure and kidney malfunctions (Lead in Paint, Dust, and Soil, 2011). The method detection limit for lead is $0.005 \mathrm{mg} / \mathrm{L}$ ((US EPA's Methods and Minimum Detection Limits, 2007).

Toluene in ground water may indicate the presence of landfills, discharge from petroleum or chemical factories or leachate from gasoline or diesel storage tanks (Wang, 2012). Almost all toluene is derived from petroleum processing; most is never recovered. The most common use of toluene is in the production of benzene. Toluene is also used as an octane booster or enhancer in gasoline. The MCL for toluene is $1 \mathrm{mg} / \mathrm{L}$ (Safe Drinking Water Act, 1998). Toluene can cause nervous system damage as well as liver or kidney damage (USEPA Toluene Chemical Survey, 1994). The method detection limit for toluene is $0.0005 \mathrm{mg} / \mathrm{L}$ (US EPA's Methods and Minimum Detection Limits, 2007). 


\subsection{Using GIS in Contaminant Water Interpolation}

Accurate contaminant water interpolation in GIS is based on spatial continuity. Creating continuous raster coverage over large areas from point datasets is performed through interpolation. Interpolation utilizes concentration measurements mostly from monitoring point observation data distribution networks (Morio, 2010). The continuous raster coverage relationship is an important characteristic of spatial data that provides awareness into into the physical, or spatial, environment of the phenomena being studied (Assaf, 2009). For instance, GIS technology has been used to produce maps of groundwater vulnerability relative to pesticide contamination in central Thailand (Thapinta, 2002). Interpolation is applied to point datasets in order to estimate the values of a chosen raster cell, or physical point, in which no real-time field sampling was ever performed (Vyciene, 2009). All input data layers used in the interpolation are generated from their original source either as a point, line, or polygon layer (Pathak, 2010).

There are two main types of interpolation that are used in spatially tracking water contamination movement. The first is the deterministic spline method of interpolation. This is where the interpolated surface cells are created closer in value to the point value of the original primary point data (Vyciene, 2009). However, this practice is not suitable for dataset phenomena representing a wide range of numerical records within a small distance from each other (Vyciene, 2009; Navas, 2011). If the point dataset is spatially uneven or classified the spline method is not suitable; instead the spline method works better if the points are located in a grid setup (Vyciene, 2009). Spline interpolation is also sensitive if the quality of the preliminary datasets is in question (Vyciene, 2009; 
Whitman, 2010). The second is the statistical kriging method of interpolation. The predictive values are produced on a weighted linear combination of the available sample points (Vyciene, 2009; Whitman, 2010). Kriging algorithms use various mathematical functions to model the varying $z$ values between known points to create a continuous spatial coverage (Vyciene, 2009).

The extent of contamination for the calculation of a groundwater quality index can be assessed using the ArcGIS package of programs (Assaf, 2009), which includes Spatial Analyst and Geostatistical Analyst (Vyciene, 2009). The interpolated layers are converted into raster layers so that the real time contaminant data can be used in conjunction with the PVI, DRASTIC, within Spatial Analyst, Geostatistical Analyst, and Geostatistical Calculator (Pathak, 2010). In this process the cell size to be used for the raster is chosen based on the spatial resolution of available data as well as computational considerations (Thapinta, 2002). In particular, the end result of any assessment or conversion cannot be shown in greater detail than that of the least detailed input factor (Secunda, 1998). Conversely, the smaller the cell sizes the better the reflection of the hydro-environment realities within the study area (Secunda, 1998). In most studies the available data for the DRASTIC pollution factors only allowed for a $30 \mathrm{~m} \times 30 \mathrm{~m}$ grid resolution for the generation of a continuous output layer (Pathak, 2010). Typically, there is a compromise between resolution (and required model accuracy), and resulting map utility - a highly detailed map implies hydrogeologic features that are merely artifacts of the interpolation model, whereas a less detailed map may not contain enough detail to $b$ of any real use. 
The final raster coverage results map can be formatted to show the spatial location and the probability of contaminant concentrations greater than the MCL (Assaf, 2009).

In the creation of the DRASTIC layers, IS also uses interpolation for the generation of the original factor layers and a raster calculator for the generation of the final PVI layer. In a study by Pathak (2010), both an inverse distance moving average (IDW) interpolation technique and ordinary kriging $(\mathrm{OK})$ were utilized in transforming the measured depthto-groundwater point data to a raster surface. In a study by Nobre (2007), the DRASTIC factor depth-to-water table was created via the OK method; it was assumed that the variables were normally distributed. In Nobre's analysis (2007), the precipitation coverage was generated by the Thiessen polygon method; the product of which was then converted to a raster layer. In a study by Thapinta (2002) both rainfall, in point format, and well depth, in vector format, were converted to raster grids through spline interpolation. The DRASTIC vulnerability index factors have two different raster layers for each parameter: one for rating (within the parameter) and one for individual weights (Secunda, 1998). There are nine different types of interpolation techniques that can potentially be used to create a uniform raster layer, which in turn can be used in conjunction with the chosen pollution vulnerability factors (Whitman, 2010). This puts the groundwater quality index and DRASTIC layers in the same data format for statistical interpretation.

In a GIS environment the creation of groundwater vulnerability maps and groundwater quality index allows for a statistical comparison between the two. The statistical 
comparison is accomplished through map algebra operational procedures (DeMers, 2002). This can create a basis for a long-term sustainable resource management and groundwater protection program based on those areas of high aquifer vulnerability (Nobre, 2007; Navas, 2011). The generation of a PVI covering the entirety an aquifer system in watershed scale is so powerful because of the visual and spatial capabilities of GIS (Pathak, 2010). Utilizing GIS for predicting the two components of temporal and spatial change is accomplished through the interface between adjacent raster cells (Randhir, 2011). Nobre (2007) indicated that the integration approach in a GIS environment used for producing a vulnerability index provides a mechanism for identifying what areas within the aquifer watershed should be protected by land use restrictions and prioritized for ground water monitoring.

The same study also indicated that using GIS to map spatial data, through the application of specific GIS tools, is subject to significant uncertainties (Nobre, 2007). For instance, the interpolation of regional data using geostatistics, the transformation of data from vector to raster format, and the classification of environmental factors by pollution vulnerability weights and ratings can result in outcomes that may not be demonstrative of the environmental condition within the timeframe being researched (Nobre, 2007). However, cross validation techniques can be used to validate the accuracy of datasets produced by the model in all situations (Vyciene, 2009). The technique has five parameters that can be used in assessing the error between between the known and predicted datasets. These parameters consist of the mean error, root mean squared 
prediction error, average standard error, mean standardized error and root mean squared standardized error.

OK is the interpolation method most often used in the generation of regionalized cell values from scattered data points (Rivest, 2011). This interpolation method is a popular method of spatial interpolation for contouring and surface mapping (Bonham-Carter, 1994). In order to properly assess the variability in an OK model it is important that the average standard errors are close to the root-mean-squared predication errors (Vyciene, 2009). The rules for the placement of these errors in confirming the accuracy of the prediction model are as follows. If the average standard errors are greater than the root mean square prediction error there has been an overestimation of the prediction variability (Vyciene, 2009). However, if the average standard error is less than the root mean square prediction errors then there is an underestimation of the prediction variability given by the model (Vyciene, 2009). If the root-mean-squared standardized value is less than 1 the model has overestimated the prediction values. However, if the root-mean-squared standardized value is greater than 1 , this indicates that the predictions have been underestimated (Vyciene, 2009). In the OK interpolation method the most important geostatistical indicator is the standard root mean square error. This parameter demonstrates how representative the chosen interpolation method is for the chosen hydrologic characteristic (Morio, 2010). The closer the standard-root-mean-square error is to 1 , the better the continuous output prediction coverage for that dataset (Vyciene, 2009). 
Over the past few decades the GIS geostatistical methods have been widely applied in situations where time series monitoring data needs to be sequentially incorporated into mathematical models (Morio, 2010). Both spline and kriging interpolation modeling methods can be used to develop either temporal or spatial variation coverages (Zhang, 2011). However, even though kriging has a tendency to smooth the original data distributions, this interpolation method maintains a closer semblance to the true shape of the original dataset (Vyciene, 2009; Rivest, 2011). A further constraint to the interpolation methods is that any cell can only represent one fixed output at a time (Randhir, 2011).

\subsubsection{Use of GIS as a Tool}

The goal of this study is to use GIS modeling technology to develop an intrinsic PVI map to groundwater. This goal is based on the many unique variables that must be considered in order to create a sustainable long-term protection of drinking water within an unconfined karst aquifer environment. The use of GIS in this type of study is essential. GIS has been typically used to create maps of watershed vulnerability, contaminant risk ranking, and has focused on contaminant plumes within different types of aquifer environments. Yet a review of the literature indicates that although GIS has been used in many modeling studies, GIS has not been used in conjunction with hydrologic modeling to create a contaminant flow model within this type of aquifer. Additionally, past hydrological contaminant vulnerability research studies utilizing GIS have not investigated a karst aquifer environment. Different types of aquifer environments directly 
affect how contaminants will move over time and space making any conclusions drawn from these past studies inapplicable with this case study.

As demonstrated in the work of Finkel et al., (2010) GIS can be used to generate water quality modeling to determine contaminant concentration changes over time and through the aquifer space. GIS can also be used to generate an overlay index method of those variables, which make an aquifer vulnerable to pollution influx. This is done in order to predict which areas of the aquifer are more likely than others to become polluted.

Generally there are three ways that contaminants in groundwater can be classified and tracked: (1) direct observation of contaminants within the aquifer which is the most accurate but there is typically not high enough observation density for regional vulnerability assessments; (2) simulation methods; and (3) index methods (Thapinta, 2002). The number of direct observations of contaminants through monitoring techniques in Broward County is skewed towards the eastern portion of the county making any conclusions of pollution vulnerability incompatible with application throughout the rest of the county. Both simulation and index methods use environmental variables and chemical properties for vulnerability assessments but due to deficient data and computational burden the simulation method is better utilized at the local rather than regional level of study. In this case the ground water index vulnerability map will be based on seven variables that influence the hydrogeological environment that make up the aquifer and surrounding environment. These environmental parameters influence how susceptible different parts of the aquifer are to different types of contamination. The 
variables, ranked according to attributes affecting pollution vulnerability in the aquifer environment, are depth to water table, recharge, aquifer media, soil type, topography, impact on vadose zone, and hydraulic conductivity (Nobre, 2007). The model is called DRASTIC. This model is used to assign large spatial areas different vulnerability scores while not requiring that extensive amounts of field data be gathered. GIS is ideal for this type of model because it has capability for easily displaying, recognizing, compiling and comparing the different hydrological areas within certain regions of the study area (Miller 2005). Because of the Well Field Program and National Pollutant Discharge Elimination System (NPDES) Program there is a basis of field data to verify the output of the DRASTIC model to be generated for each year of the 2006-2011 study. Therefore, this study will also examine the validity of the DRASTIC index by comparing those areas in Broward County deemed vulnerable to pollution to the groundwater field data generated from the two programs.

In addition to the lack of spatiotemporal contaminant studies within this aquifer system other issues stress the imperativeness of performing this type of work. Population increase throughout south Florida has also negatively affected long term aquifer sustainability due to increased utilization of groundwater resources beyond potential recharge capacity; leading to coastal saltwater intrusion and inland pollution leachate infiltration (Assaf, 2008). This increasing demand for water affects the natural flow of nutrients, as well as contaminants introduced by anthropogenic sources at the aquifer surface. As the state of Florida incorporates increasingly lenient business legislature and development ventures, the integration of less stringent environmental protection laws are 
being integrated into the state and local regulatory code of ordinances. As a result of this the hydrologic environment of the Biscayne Aquifer is made even more unique due to the complex spatially varying land cover patterns throughout Broward County as well as the varying rainfall patterns over the six years. The environmental necessity for monitoring contaminants found within the drinking water aquifer, in Florida's increasingly business oriented governmental society is imperative. As the influx of businesses within Broward County continues to grow, increasing chances of pollution vulnerability, the importance of a strong GIS based model monitoring system becomes more evident when studying problems that are spatial in nature.

\subsection{Dissolved Chemical Constituent Transport in the Biscayne Aquifer}

In April 2003 a tracer test was conducted using Rhodamine WT (RWT), a fluorescent dye, in order to obtain greater information regarding impact that the chemical and physical processes have on the migration of contaminants, chemicals, within the Biscayne aquifer (Shapiro, 2008). In February 2004 there was a companion tracer test used to analyze the different Biscayne aquifer factors affecting the transport of chemicals and pathogens. This test utilized different sized microspheres to imitate the movement of oocyst through different types of aquifer media (Harvey, 2008). These two tests were conducted in the northern portion of the Miami-Dade well fields and were used to expand the knowledge base of the potential ability for the karst limestone to transport suspended chemical components as well as waterborne pathogens (Renken, 2008). 
The velocities obtained during transport of previous dye tracer tests conducted by the Miami-Dade Department of Environmental Resources Management ranged from 1 to 30 $\mathrm{m} / \mathrm{d}$ (Renken, 2008). Many of the tracer tests conducted before 2003 had focused solely on generating a travel time association from point to point within the aquifer (Renken, 2008). The 2003 tracer test demonstrated a lack of dye dispersivity from the path of the groundwater flow within the aquifer formation. This test indicated that the lack of dye dilution, from the injection well to the production well, was representative of chemical interaction with the groundwater drawn to the production well from the surrounding aquifer formation (Renken, 2008).

One of the aquifer formations responsible for this interaction between the injection well, high levels of tracer concentration, and detection of the tracer at the production well are the touching-vug flow zones directly below the surface casing in the injection well (Shapiro, 2008). The groundwater movement through touching-vug flow zones are characterized by a merger of vugs into pathways marked by repeated twists, turns and bends through which groundwater moves from vug to vug. The high porosity of these stratiform touching-vug flow zones are efficient pathways for tracer, and contaminant, movement in the drinking water well fields. The 2004 tracer tests tracked the $97 \mathrm{~m}$ transport route of the different sized microspheres, 1.6, 2.9, and $4.9 \mathrm{um}$, to the pumping well (S-3164) through the karst limestone of the Biscayne aquifer (Harvey, 2008). The removal of these microspheres at well S-3164 was inversely size dependent (Harvey, 2008 ) with $2.9 \%$ of the largest microspheres ( $4.9 \mathrm{um}$ ) removed and $5.8 \%$ of the smallest microspheres (1.6 um) removed (Harvey, 2008). The highest concentration peak for the 
microspheres was observed traveling at a faster rate through the karst aquifer limestone than was originally calculated from an in situ transport test which utilized a nonreactive tracer (Harvey, 2008). According to Shapiro the multiple pathways of limestone conduit openings are representative of varying average velocities, which range over multiple orders of magnitude, which affect the dispersion and clustering of the dye and microspheres (Harvey, 2008). For instance, microspheres not found within one day of their introduction to the aquifer indicates that particulate tracers only travel substantial through those karst conduits with the highest velocity (Harvey, 2008; Bailly-Comte, 2010). The field demonstrations of the April 2003 and February 2004 field tests demonstrate the insufficiency of incorporating only total porosity to calculate the well field protection zone travel time boundaries around production wells. The tests also reinforce the need to use colloidal particles that are similar in oocyst size and Rhodamine dye, indicative of contaminant transport, to demonstrate the affect these two factors could have on production well vulnerability in aquifers that have complex matrix porosity and velocity flow paths (Harvey, 2008).

Chemical contamination events ranging from days to months to years within the Biscayne aquifer could result in the dilapidation of water quality (Shapiro, 2008). During the April 2003 test Rhodamine dye was used to reflect the movement of contaminants within the production well drawdown area. One aquifer feature, touching-vug flow zones, seems to control much of the groundwater and chemical transport, inflow or outflow (Manda, 2005). Borehole image logs estimate this aquifer feature to be approximately $0.9 \mathrm{~m}$ in thickness (Renken, 2008). Moreover, the shallow uncapped karst limestone aquifer is 
hydrologically connected to surface water and therefore has a greater chance of oocyst introduction as well as contamination from surface spills (Harvey, 2008).

The two different tracer aquifer tests performed in the Miami-Dade portion of the Biscayne aquifer in 2003 and 2004 indicates that the aquifer is conducted as a dualporosity matrix medium and shows that the high transport of tracers is comparable to other types of karst (Renken, 2008). The dual-porosity feature of the aquifer exists because of the presence of touching-vug flow zones. This aquifer media factor is further characterized by the formation of stratiform zones of high permeability as well as burrows, and interburrows, increased by karst media dissolution (Renken, 2008). These aquifer features create an environment where an in-use production well does not greatly change the water table level because the water contained within the porous aquifer matrix is released and supplements the water being withdrawn from the touching-vug porosity (Renken, 2008).

The 2004 tracer test also demonstrated that the ambient hydraulic stresses have an inconsequential impact on the groundwater flow conditions during the tracer injection itself as well as during the monitoring and tracer recovery period at the production well (Shapiro, 2008). However, the limestone void space of the Biscayne aquifer is seriously different from other distinguishing karst features (Renken, 2008). In this aquifer setting the groundwater can flow through a network composed of separate vugs, where flow occurs though matrix porosity, or through interconnected vugs, where flow happens through touching conduits (Renken, 2008). 
Due to the touching-vug porosity in the Biscayne aquifer there is likely to be a high level of surface area for dispersal of groundwater because of the interconnected conduits in the touching-vug void space (Shapiro, 2008) of the karst limestone. However, the limestone is heterogeneous in nature and as a result has large variability in matrix porosity (Shapiro 2008; Bailly-Comte, 2010). The transport of contaminants within the touching-vug flow zones are influenced by multiple pathways containing fluid velocities that range over numerous orders of magnitude (Shapiro, 2008).

The touching-vug flow zones are the primary way, which solutes, particulates, and fluids are transported within the Biscayne aquifer (Harvey, 2008). There are certain pathways within the aquifer, which, over time, have become preferred groundwater flow zone paths due to the high touching-vug porosity (Harvey, 2008). There are several research studies, which have shown that the transport flow regime of chemicals through fractures rock can be accounted for by a one-dimensional, linear flow system (Bailly-Comte, 2010). This is due to the consistent channeling of groundwater flow within the highly permeable carbonate fractures (Shapiro, 2008). The extensive surface porosity of the touching-vug flow zone accounts for most of the groundwater transmission in the limestone (Shapiro, 2008). The faster flow zones of higher macroporosity indicate the likelihood that the contaminants will travel longer distances with lower removal of contaminants from the water flow (Harvey 2008). The slower flow zones indicate that contaminants would be quickly dissipated because of filtration and settling (Harvey 2008). However, because of the heterogeneous porosity of the limestone the flow system is likely to reflect characteristics of both linear and radial aquifer conditions (Shapiro, 2008). 
The touching-vug flow zones of the aquifer matrix porosity are associated with high storativity and high transmissivity of water (Shapiro, 2008). For example, increases in the water table brought on by heavy rainfall can dissipate after roughly 1 day (Shapiro, 2008). The region of the touching-vug flow zone located at $-10.0 \mathrm{~m}$ was responsible for most of the tracer movement because the transmissivity of the touching-vugs at this depth of the aquifer is greater than those touching-vugs at greater depth (Shapiro, 2008).

The carbonate and fractured rocks within the Biscayne aquifer are full of even smaller fractures and conduits. The majority of the tracer movement, or chemical mass movement, is affected by the hydraulic conductivity of these fractures and conduits because their flow velocity can range over many orders of magnitude (Bailly-Comte, 2010). According to Becker and Shapiro (2000), the hydraulic conductivity of fractures range over more than 6 orders of magnitude (Shapiro, 2008) within the geologic setting of the Biscayne aquifer. Due to this, the tracers used in the 2003 and 2004 tests exhibited changeability in the velocity over multiple orders of magnitude (Shapiro, 2008). Those individual conduit flow paths exhibiting the fastest velocities within the fractured rocks of the Biscayne aquifer controlled the first detection arrivals and the peak concentration arrivals of the chemical constituents (Shapiro, 2008).

The flow paths and corresponding velocity indicates that in the heterogeneous setting of the karst aquifer is not representative of the Fickian interpretation of hydrodynamic dispersion (Shapiro, 2008) where the mass transport of chemicals is proportional to the concentration gradient of the aquifer matrix and in the direction of the concentration 
gradient. Determining the preferred pathways and end fate of contaminants introduced to the subsurface groundwater within the karst limestone is important in gauging contaminant longevity within the aquifer. The implementation of water resource protection and management shouldn't be determined by a groundwater flow model based, which relies solely on estimates of bulk hydraulic properties (Renken, 2008). 


\section{METHODOLOGY}

This chapter introduces the Broward County well field capture zones. The PVI model was integrated into a GIS-based interface to facilitate the delineation of known and unknown contaminant areas of interest within the county. GIS was also used to extract the necessary model input layers, such as $\mathrm{CN}$ and runoff rates, for the pollution vulnerability model. The interpolated contaminant raster layers were also created from known stationary contaminant points through this interface.

\subsection{Facility Well Field Capture Zone}

The primary contaminant data sources used in this research are taken from the surfacemonitoring stations of the NPDES program, monitoring well and potable well points of the Well Field Program and located within the surface well field boundaries ratified by the Broward County government. The contaminant detection point layers will reflect data from 26 different well fields and 47 different well depths, ranging from - 15 feet to -202 feet, within the potable well cones of influence. Contaminant detection data outside of the surface well field boundaries is not used in this research. Surface monitoring stations are located throughout the county but only the stations located within the boundary were used in this research. There are also no wells approved by county government for monitoring or potable water withdrawal which the county maintains continuous quarterly detection data. This research therefore only focuses on those detection points that are approved and maintained by governmental entities. Therefore, this research only reflects 
aquifer movement of contaminants from within the cones of influence generated by the potable wells.

The well field capture zones used in this research have been approved by the Broward County Board of County Commissioners. Facilities utilizing hazardous materials and located within well field boundaries 2 and 1 must obtain licenses and install monitoring wells for tracking of contaminants. All hazardous material facilities that have a Hazardous Material and/or Storage Tank license are stored in the county Public One Stop Service (POSSE) management database. 


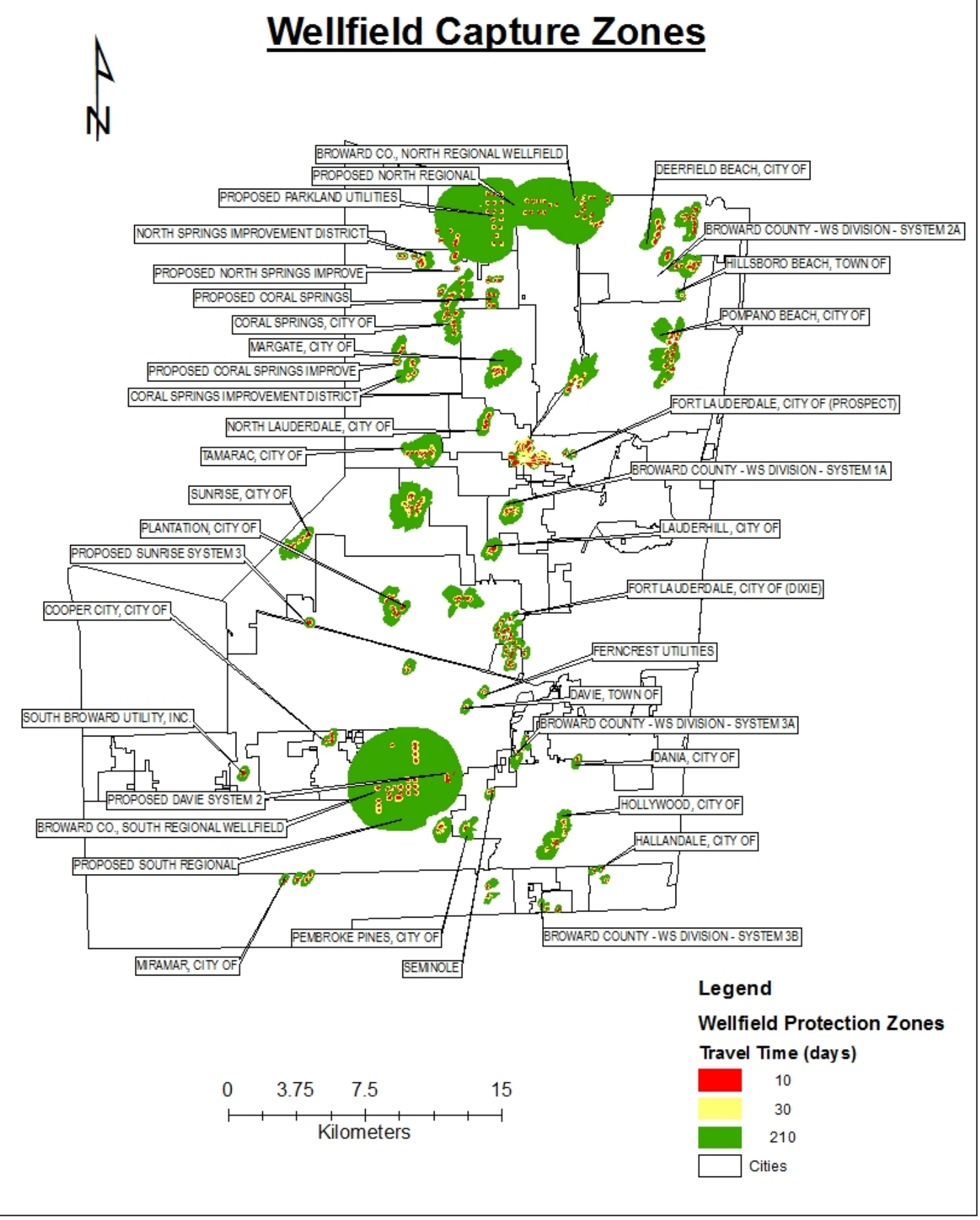

Figure 4: Map of Broward County Well Field Capture Zones 
In this research project the facilities with wells on their properties were captured in a separate spatial GIS layer. When the facilities are created a stationary point is generated in the POSSE_FACILITIES point shapefile. To capture those facilities located within the 37 Broward County well fields the Select by Location Tool was utilized so that POSSE_FACILITIES completely contained within well field zone 3, the largest of the well field boundaries, were selected and exported to a new layer Wellfield_Facilities.

\subsubsection{Contamination Source Index and Well Index}

Determining if a facility within the well field boundary required a monitoring well for the tracking of chemicals that are used on site depends on the 10 factors: secondary containment, discharge, evidence of release, solvents $>25$ gallons, most protected wellfield zone, chemicals detected, AST $>550$ gallons, UST $>110$ gallons, Superfund Amendments and Reauthorization Act (SARA) Title III Vessel, SARA Title III Facility. The Source Index (SI) of contaminants at each facility for this research was determined by these 10 factors, where the contaminants are on the facility property in relation to the nearest supply well, and where the facility falls within the oblong well field protection boundary.

For each of the 3 contaminants being tracked a separate monitoring and potable well GIS layer was created. Within the layers the Broward County potable wells were assigned a well index based on the individual contaminant locations (those facilities contained within the individual potable well protection boundary) and location to the nearest 
potable well by zone. The original Broward County supply well GIS layer was imported into the Geodatabase and specific wells were extracted after determining which potable wells had contaminant detections during the timeframe of the 5-year study. The Broward County GIS potable well layer was Merged with the monitoring well layer created for this research and then the excel spreadsheet containing contaminant detections by facility and well field was Joined with this PW_MW.shp layer. This was accomplished through each separate well field and contaminants tracked in this research because monitoring and potable wells often have the same names in different well field locations. 


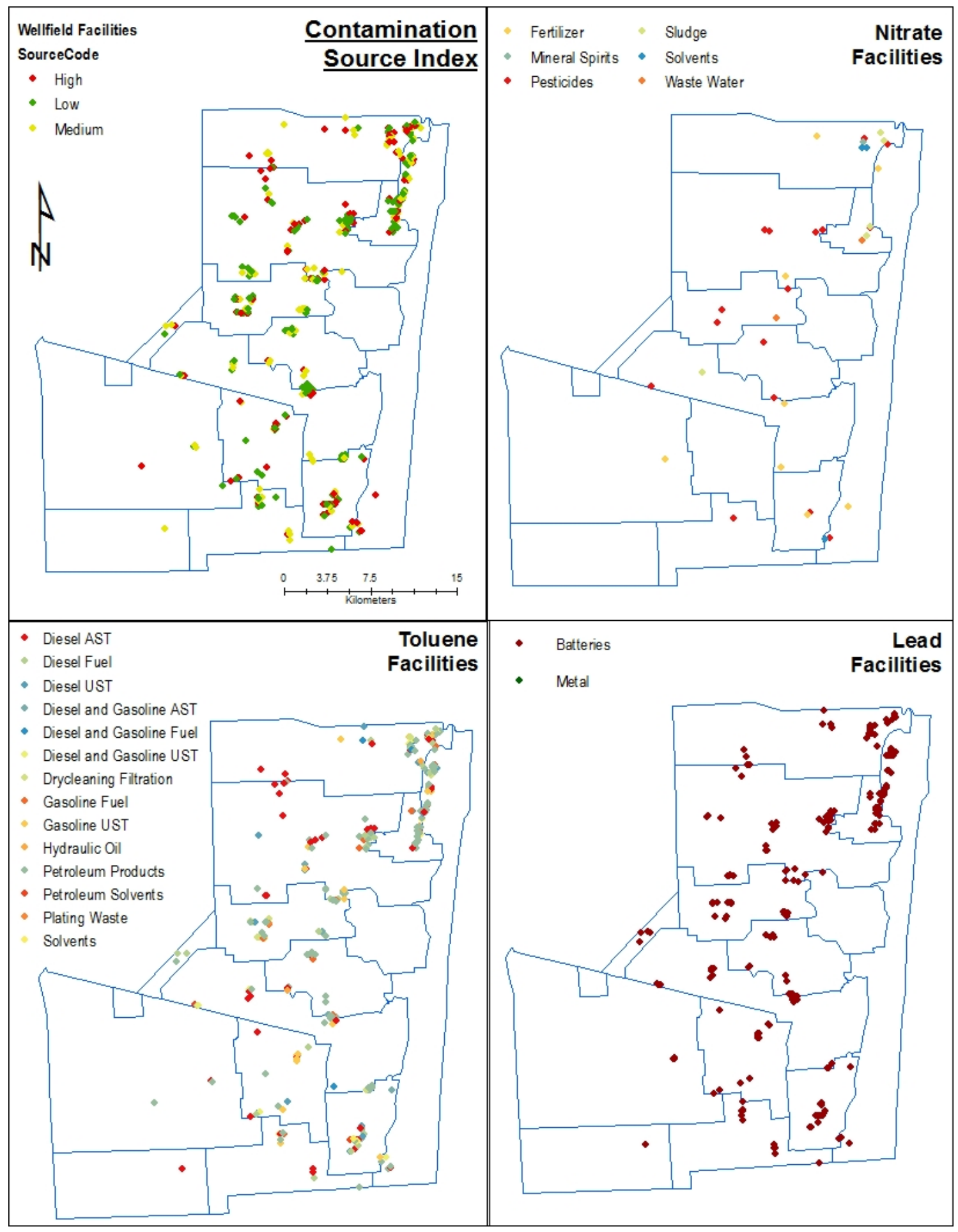

Figure 5: Potential Facility Contamination SI 


\subsection{GIS and Contaminant Modeling}

ArcGIS Geostatistical Analyst was used to interpolate continuous raster layer maps from the spatially discrete points associated with the quarterly and yearly average contaminant concentration data. The Broward County well field protection program started collecting quarterly subsurface monitoring well and subsurface potable well contaminant detection data in 2006; this study observes the time range from the beginning of 2006 through the end of 2011. Contaminant data was chosen based on availability within the well field program across county extents. Using GIS, three different vertical layers for nitrates, were quantitatively compared to observe the variation in contaminant concentration between different depths of the Biscayne Aquifer. The depths used were -5 feet, -15 feet, and the range of -60 feet to -202 feet. The presence of any statistically significant influences between the three layers was determined through a cross correlation graph of well depth versus nitrate concentration. In the second analysis, the three vertical monitoring levels for each contaminant were merged to generate a single continuous raster layer for each year the contaminants were tracked. This raster layer will reveal a lateral, seasonal contaminant map across Broward County. In the third analysis, these maps will allow for an association study between the spatial distribution of contaminants and the location of potential areas of vulnerability that may be more susceptible to and impacted by anthropogenic actions. 


\subsubsection{Contaminant Model Inputs and Raw Data Preprocessing}

The datasets used in the individual objectives within this study are the same sets used throughout the study. The locations of the potable wells were taken from the official Broward County government issued GIS layer. The location of the monitoring wells was verified through the licenses issued by the well field program and by visual field identification of the wellhead locations. The NPDES pollutant discharge monitoring station locations were verified through maps located on the U.S. Environmental Protection Agency (EPA) website and through field visits to the different surface monitoring stations. The attribute tables created in this study contain the spatial coordinates of potable and monitoring well locations, the surface water discharge monitoring station locations, temporal data of the dates the water samples were taken, and the contaminant concentrations in milligrams per liter (mg/L) (Lake, 2003).

The well field contaminant detections were collected at irregular spatial intervals as dictated by the location of the well fields across the county. The density of available data may fluctuate from well field to well field depending on the distribution of given sample points. Therefore, the interpolation technique used had to account for the randomly spaced detection points. The local polynomial interpolation, $\mathrm{OK}$, creates a surface that is optimal for calculating a surface that has low differences between interpolated and true surface values. The kriging interpolation is smoothing and is optimal to use in those conditions where a trend needs to be developed from multiple points from wide numerical and spatial ranges. 
The raster coverage layer for contaminant concentration change across the county over time was generated by OK interpolation technique at a $75-25 \%$ split of training and validation groups from the stationary monitoring point data. In the generation of regression models with the ordinary kirging tool, the validation dataset will allow for accuracy testing of the interpolated contaminant concentration layers for the seasonal and averaged yearly monitoring points. Contaminant trends were assessed from the first quarter 2006 to the fourth quarter 2011 to show overall yearly and quarterly spatiotemporal changes.

The quarterly detection point data from January 2006 to December 2011 were used to explore the temporal contaminant trends of nitrates, lead, and toluene in the Broward County segment of the Biscayne Aquifer. However, due to certain management of the program toluene had no detections before 2007; there were only 4 years of detections for this contaminant unlike the other two chemicals being tracked. The three sources of point data (i.e. monitoring wells, potable wells, and surface water monitoring stations) were merged for nitrates only in order to track contaminant concentrations over time. The temporal layer will combine all three layers of the point detection locations to attain a continuous raster coverage layer of contaminants across the Biscayne Aquifer. The spatial locations of the monitoring point features is the common attribute that is used to link the attribute table created in Excel to the monitoring point locations created inside of a GIS environment. In this case the non-detects were input as the minimum detection limit (MDL) of the 3 different contaminants tracked. The contaminant data was input into Microsoft Excel format from detection reports generated quarterly in POSSE and then 
converted to a CSV format to Join to the spatial layer of monitoring, potable, and surface station location shapefiles.

\subsubsection{GIS Parameters}

The stationary well data does not exhibit a normal distribution in the histogram or a Normal QQ Plot. The data were skewed left in the histogram. Therefore, the data was transformed and conformed to a normal distribution before interpolation in OK. The log transformation was used because even after the outliers were removed from the dataset there were still some localized large values and skewed distributions of data. Logarithmic transformation was applied to the dataset to produce a bell shaped histogram. The trend analysis tool demonstrated a U-shaped trend for the contaminant datasets. This indicated that a second order polynomial for global trend model should be implemented for the skewed dataset interpolation.
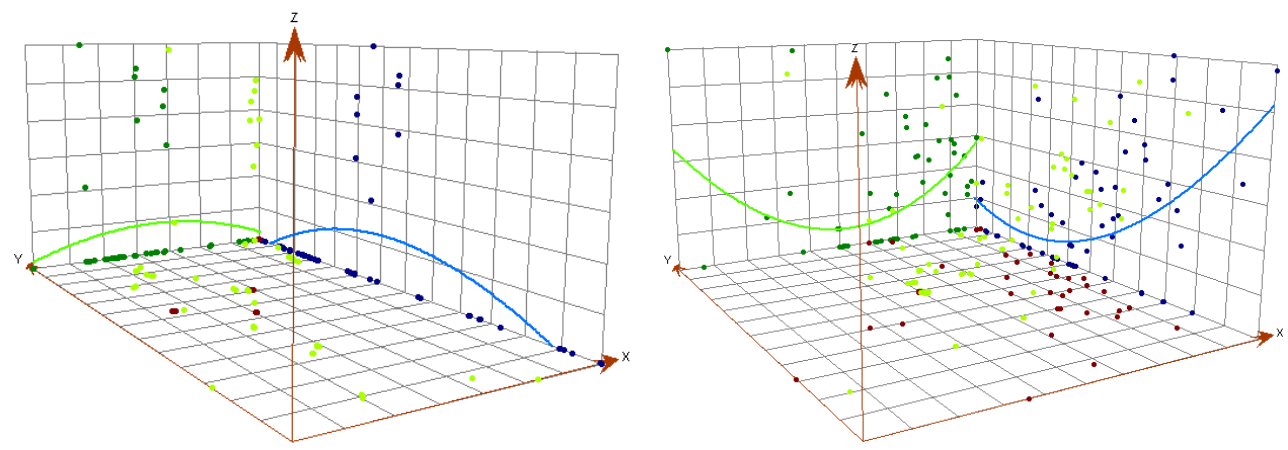

Figure 6: Northern Directional Trend Analysis for Toluene Y2011 and Nitrate Q2Y2011

To develop the nitrate raster surface for objective 1 the monitoring, potable and surface water datasets were merged. Contaminant concentrations found during surface water 
monitoring are from the NPDES program. Contaminant concentrations found in subsurface monitoring and potable wells are from the Well Field Program. Those three GIS layers were merged for the nitrate concentration layer only to create a nitrate layer containing 3 different aquifer depths. The well stations included in this study are comprised of 46 monitoring wells, 31 potable wells, and 44 surface locations. The potable well depths used in this study range from $-80 \mathrm{ft}$ to $-202 \mathrm{ft}$, the monitoring wells reach depths of $-15 \mathrm{ft}$, and the surface locations are at $-5 \mathrm{ft}$ in open bodies of water.

When analyzing the merged potable and monitoring well toluene dataset for the correct interpolation technique it was determined that there were not enough quarterly detections to complete the $\mathrm{OK}$ interpolation. However, the merged yearly average detections had enough known points to complete the OK interpolation. Although in each of the 5 yearly averages the outliers could not be removed if the $\mathrm{OK}$ interpolation was to be completed. For nitrates, a second order trend removal or no trend removal at all was implemented for the interpolation depending on what the Trend Analysis reflected during the data exploration process. 
Table 3: Preliminary Statistical Analysis of Nitrate Data for Interpolation Method

\begin{tabular}{|l|r|r|r|l|}
\hline & \multicolumn{5}{|c|}{ Nitrates } \\
\hline Date & $\begin{array}{l}\text { Wells } \\
\text { Tested }\end{array}$ & $\begin{array}{l}\text { Total } \\
\text { Detections }\end{array}$ & Outliers & Trend Removal \\
\hline Q1Y06 & 93 & 49 & 6 & 2nd Order Polynomial \\
\hline Q2Y06 & 93 & 53 & 11 & 2nd Order Polynomial \\
\hline Q3Y06 & 93 & 62 & 10 & 2nd Order Polynomial \\
\hline Q4Y06 & 93 & 65 & 2 & 2nd Order Polynomial \\
\hline Y2006 & 93 & 80 & 8 & 2nd Order Polynomial \\
\hline Q1Y07 & 93 & 65 & 5 & 2nd Order Polynomial \\
\hline Q2Y07 & 93 & 65 & 9 & 2nd Order Polynomial \\
\hline Q3Y07 & 93 & 56 & 9 & 2nd Order Polynomial \\
\hline Q4Y07 & 93 & 65 & 4 & 2nd Order Polynomial \\
\hline Y2007 & 93 & 79 & 8 & 2nd Order Polynomial \\
\hline Q1Y08 & 93 & 59 & 8 & 2nd Order Polynomial \\
\hline Q2Y08 & 93 & 50 & 14 & 2nd Order Polynomial \\
\hline Q3Y08 & 93 & 57 & 8 & 2nd Order Polynomial \\
\hline & & & & Autocorrelation breached, \\
\hline Q4Y08 & 93 & 9 & 0 & No trend \\
\hline Y2008 & 93 & 64 & 11 & No trend removal used \\
\hline Q1Y09 & 93 & 53 & 14 & No trend removal used \\
\hline Q2Y09 & 93 & 60 & 7 & 2nd Order Polynomial \\
\hline Q3Y09 & 93 & 55 & 5 & No trend removal used \\
\hline Q4Y09 & 93 & 54 & 5 & No trend removal used \\
\hline Y2009 & 93 & 60 & 8 & Third Order used \\
\hline Q1Y10 & 93 & 57 & 3 & 2nd Order Polynomial \\
\hline Q2Y10 & 93 & 46 & 3 & Third Order used \\
\hline Q3Y10 & 93 & 45 & 4 & No trend removal used \\
\hline Q4Y10 & 93 & 46 & 4 & 2nd Order Polynomial \\
\hline Y2010 & 93 & 61 & 0 & No trend removal used \\
\hline Q1Y11 & 93 & 50 & 4 & No trend removal used \\
\hline Q2Y11 & 93 & 47 & 6 & 2nd Order Polynomial \\
\hline Q3Y11 & 93 & 47 & 13 & 2nd Order Polynomial \\
\hline Q4Y11 & 93 & 10 & 0 & 2nd Order Polynomial \\
\hline Y2011 & 93 & 55 & 5 & No trend removal used \\
\hline
\end{tabular}




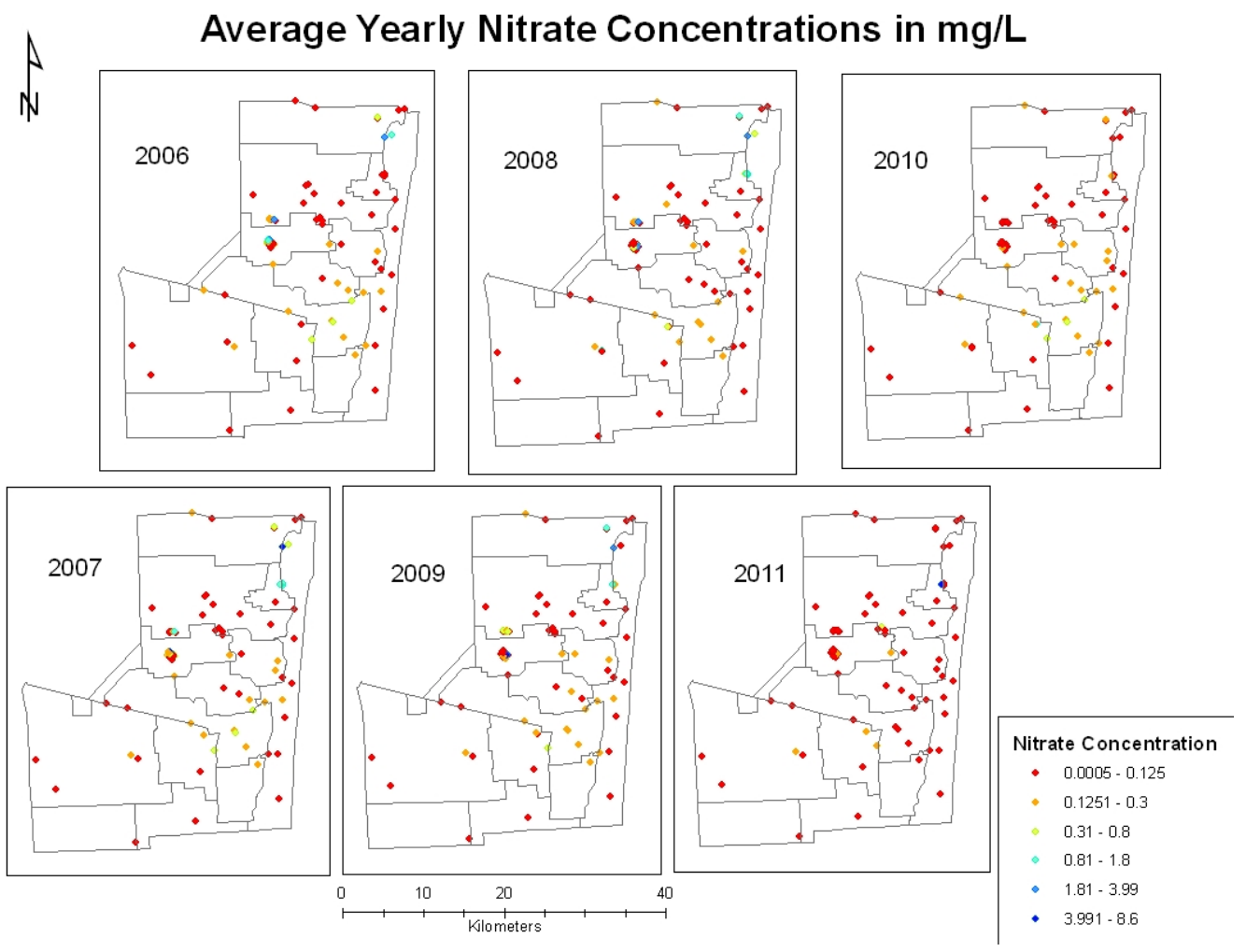

Figure 7: Map of Spatiotemporal Nitrate Concentrations

When analyzing the merged potable and monitoring well lead and toluene dataset for the correct interpolation technique it was determined that the location of lead and toluene detections was concentrated in one area of the county and the total number of detections did not allow for an interpolation technique to be implemented on the quarterly datasets. However, the yearly average contained enough known detection points to complete the OK interpolation; but with no $75-25 \%$ split of training and validation groups. Instead the nugget was as close to 0 as possible, the Root Mean Square (RMS) Standardized was as close to 1 as possible, and the RMS was as close to 0 as possible for validation of the coverage. 
Table 4: Preliminary Statistical Analysis of Lead Data for Interpolation Method

\begin{tabular}{|c|c|c|c|}
\hline \multicolumn{4}{|r|}{ Lead } \\
\hline Date & $\begin{array}{l}\text { Wells } \\
\text { Tested }\end{array}$ & $\begin{array}{l}\text { Total } \\
\text { Detections }\end{array}$ & Outliers \\
\hline Q1Y06 & 84 & 6 & \\
\hline Q2Y06 & 84 & 13 & \\
\hline Q3Y06 & 84 & 5 & \\
\hline Q4Y06 & 84 & 5 & \\
\hline Y2006 & 84 & 18 & $\begin{array}{l}\text { All detections above MDL are outliers, } \\
\text { All detections kept for interpolation }\end{array}$ \\
\hline Q1Y07 & 84 & 5 & \\
\hline Q2Y07 & 84 & 9 & \\
\hline Q3Y07 & 84 & 8 & \\
\hline Q4Y07 & 84 & 16 & \\
\hline Y2007 & 84 & 30 & $\begin{array}{l}\text { All detections above MDL are outliers, } \\
\text { All detections kept for interpolation }\end{array}$ \\
\hline Q1Y08 & 84 & 22 & \\
\hline Q2Y08 & 84 & 20 & \\
\hline Q3Y08 & 84 & 7 & \\
\hline Q4Y08 & 84 & 8 & \\
\hline Y2008 & 84 & 36 & $\begin{array}{l}16 \text { values eliminated because } \\
\text { considered outliers, } \\
\text { Not enough data, so kept in dataset for } \\
\text { interpolation }\end{array}$ \\
\hline Q1Y09 & 84 & 12 & \\
\hline Q2Y09 & 84 & 13 & \\
\hline Q3Y09 & 84 & 7 & \\
\hline Q4Y09 & 84 & 8 & \\
\hline Y2009 & 84 & 25 & 4, Not removed \\
\hline Q1Y10 & 84 & 8 & \\
\hline Q2Y10 & 84 & 11 & \\
\hline Q3Y10 & 84 & 9 & \\
\hline Q4Y10 & 84 & 7 & \\
\hline Y2010 & 84 & 25 & 9, Not removed \\
\hline Q1Y11 & 84 & 9 & \\
\hline Q2Y11 & 84 & 5 & \\
\hline Q3Y11 & 84 & 8 & \\
\hline Q4Y11 & 84 & 6 & \\
\hline Y2011 & 84 & 17 & No detections considered outliers \\
\hline
\end{tabular}



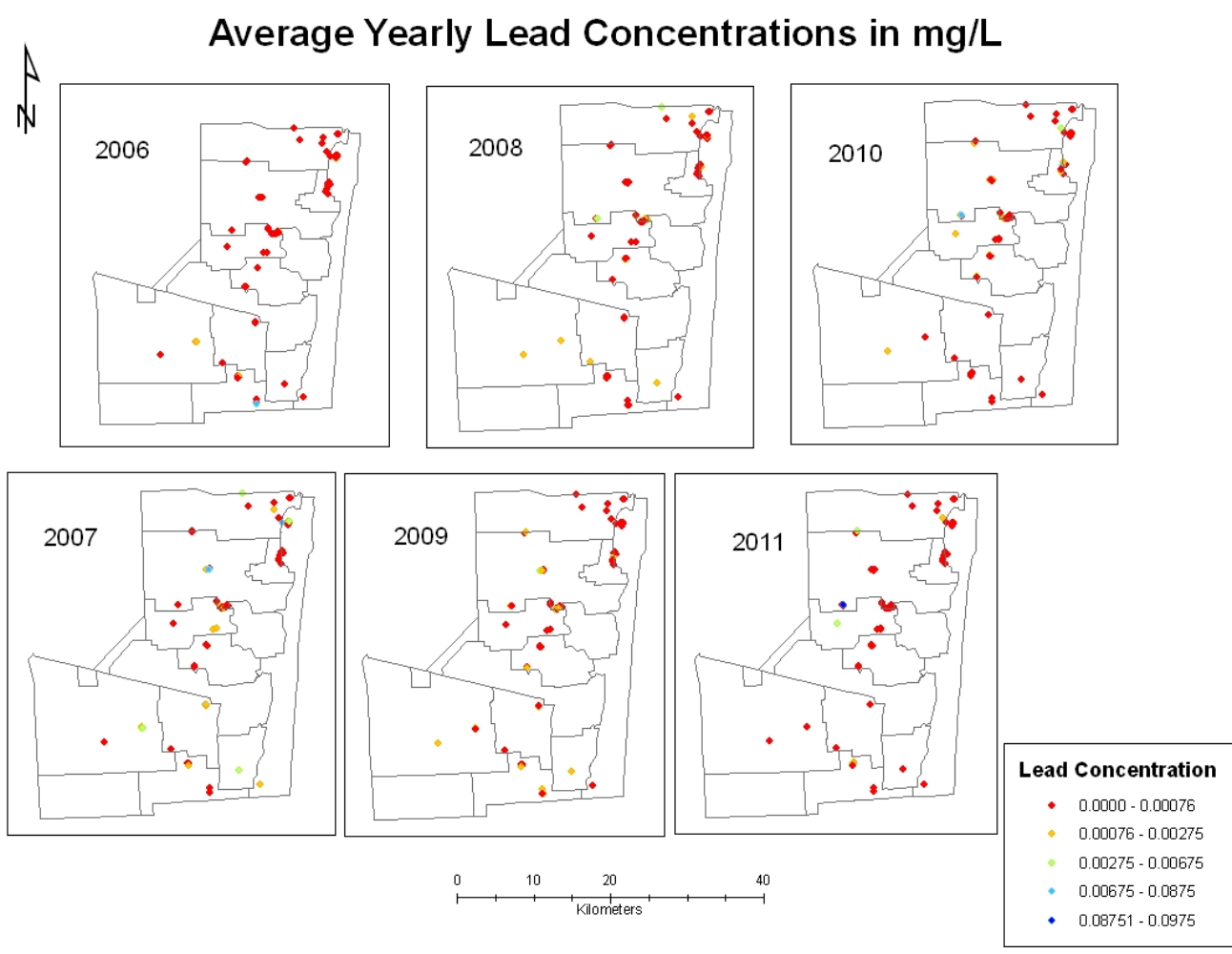

Figure 8: Map of Spatiotemporal Lead Concentrations

Table 5: Preliminary Statistical Analysis of Toluene Data for Interpolation Method

\begin{tabular}{|l|r|l|l|}
\hline \multicolumn{5}{|c|}{ Toluene } \\
\hline & $\begin{array}{l}\text { Wells } \\
\text { Dested }\end{array}$ & $\begin{array}{l}\text { Total } \\
\text { Detections }\end{array}$ & Outliers \\
\hline Q1Y07 & 56 & 15 & \\
\hline Q2Y07 & 56 & 3 & \\
\hline Q3Y07 & 56 & 7 & \\
\hline Q4Y07 & 56 & 9 & \\
\hline Y2007 & 56 & 21 & 6, Not removed \\
\hline Q1Y08 & 56 & 3 & \\
\hline Q2Y08 & 56 & 4 & \\
\hline Q3Y08 & 56 & 9 & \\
\hline Q4Y08 & 56 & 2 & \\
\hline Y2008 & 56 & 18 & 7, Not removed \\
\hline Q1Y09 & 56 & 1 & \\
\hline Q2Y09 & 56 & 4 & \\
\hline
\end{tabular}




\begin{tabular}{|l|r|r|l|}
\hline \multicolumn{3}{|c|}{ Toluene } \\
\hline Q3Y09 & 56 & 5 & \\
\hline Q4Y09 & 56 & 1 & \\
\hline & & $\begin{array}{l}\text { All detections above MDL are } \\
\text { outliers, } \\
\text { Yll detections kept for } \\
\text { interpolation }\end{array}$ \\
\hline Q1Y10 & 56 & 0 & \\
\hline Q2Y10 & 56 & 12 & \\
\hline Q3Y10 & 56 & 4 & \\
\hline Q4Y10 & 56 & 3 & \\
\hline Y2010 & 56 & 19 & 6, Not removed \\
\hline Q1Y11 & 56 & 9 & \\
\hline Q2Y11 & 56 & 1 & \\
\hline Q3Y11 & 56 & 6 & \\
\hline Q4Y11 & 56 & 3 & \\
\hline Y2011 & 56 & 17 & 8, Not removed \\
\hline
\end{tabular}

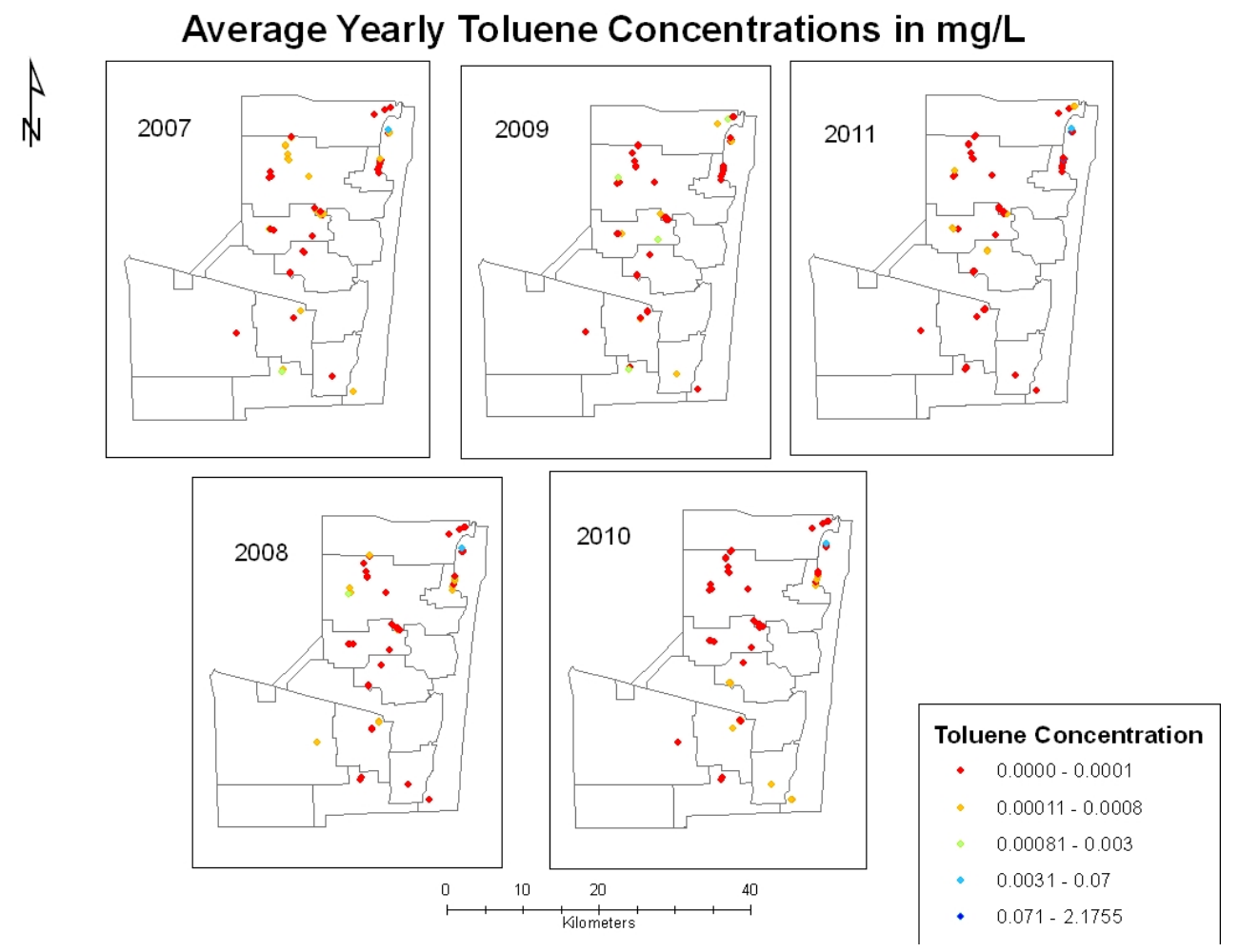

Figure 9: Map of Spatiotemporal Toluene Concentrations 
The interpolated yearly and seasonal raster layers for each of the five years are shown in a graph of contaminant concentration versus time in order to assess any contaminant concentration trends expressed within the three different contaminants. The raster layers were represented in map layouts with contour lines delineating the changes in concentration. The same average yearly layers were overlaid against the PVI in GIS so comparisons could be made across different concentration levels.

\subsubsection{Data Exploration and Structural Analysis of Contaminant Coverage in an AOI}

Changes in contaminant concentrations within the lateral and vertical spatial dimensions of the study area were monitored and observed. The vertical detection layers are made up of NPDES surface monitoring points, well field monitoring well points, and the potable well point data. The surface readings were taken from the NPDES pollutant monitoring stations. The NPDES surface monitoring stations are located in areas where businesses are permitted to discharge specified chemicals to surface water. The shallow well field monitoring wells are -15 feet below ground level while potable wells are located -80 to -202 feet below ground level. The shallow monitoring wells are located at the licensed businesses, within the well field, located in those areas close to the potable wellhead. Different municipal water treatment plants throughout the county operate the potable wells; these well locations were chosen based on proximity to water treatment plants. In Broward County water treatment plants are commonly surrounded by, or are near, land areas classified as industrial or urban. These three different data gathering systems 
encompass a large coverage area, both laterally and vertically, allowing for the complete tracking of contaminant plumes within Broward County.

The raster coverage of individual contaminant concentrations were generated through the OK interpolation method using the three different sets of stationary data points. These detection layers will reflect contaminants within various levels of the Biscayne Aquifer. The contaminants are represented through the stationary drinking water wells, monitoring wells, and pollutant discharge points within the county. Raster coverage was generated for each quarter, as well as yearly averages, of the five-year period. However, the whole county raster coverage will not be analyzed. The three layers of the aquifer were overlaid to analyze the differences in contaminant concentrations; this section is an expansion of the analysis study begun in objective 1 . The vertical detection layers will track the independent contaminant concentrations across four specific AOIs and present data as seasonal and yearly phenomenon. The AOIs were chosen based on proximity to land usage areas that demonstrate contaminant origins and potential pathways to the aquifer, i.e., industrial parks, agricultural plots, bodies of water, and landfills (Wang, 2012). These land usages are dispersed throughout the county complicating the originating source of contaminants located in the aquifer. The map of the AOI contains: Highway 595, solid waste facility, golf course, and gasoline stations. 


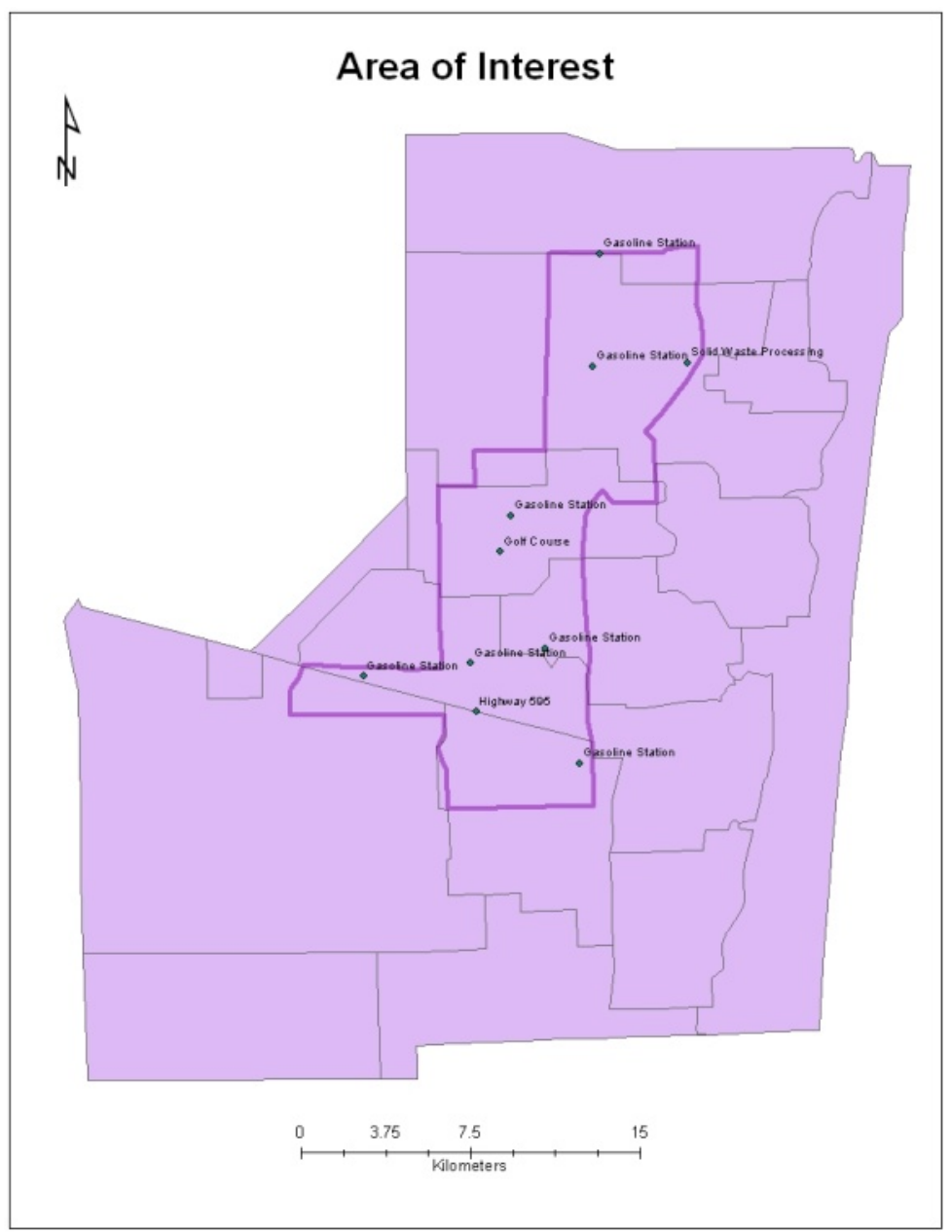

Figure 10: Map of Broward County AOI for Well Field Facilities

The lateral layers were created with greater emphasis on time frames due to the greater spatial coverage possible in the lateral movement of contaminants across the Biscayne Aquifer. The AOI of the lateral analysis is the entirety of Broward County. The point layers for surface, monitoring well, and potable well contamination concentration data were combined into one aquifer dataset that was used to create raster layers of the entire study area using the OK interpolation method. The lateral layers created were monitoring for broad trends of contaminant concentration and movement. The seasonal contaminant 
concentration detection layers were developed from data supplied by businesses and municipalities that have hazardous material licenses that require quarterly sampling for contaminants. The average yearly contaminant concentration data was generated from the averaged quarterly data located in the attribute tables for each of the individual contaminants. This data from the required quarterly sampling plans are from those businesses and municipalities located in zone 2 . OK was used to create the raster layers using contaminant concentrations measured at different depths of the aquifer, where data is available.

\subsection{GIS and Pollution Vulnerability Index Modeling}

The concentrations of the chemicals tracked in this study have changed over the course of the six-year time frame. This analysis of objective 4 is designed to determine what influence independent variables have on the spatial and temporal aquifer contaminant concentrations. Do to uneven well density throughout the county there was not sufficient density of contaminant observation for a regional vulnerability assessment. A PVI was generated to determine what areas of the county were most vulnerable to pollution. The method in this study was based on the DRASTIC method using the environmental parameters depth to aquifer, recharge, aquifer media, soil media, topography, impact to vadose zone, and conductivity as indicatory of pollution vulnerability in the aquifer. Six parameters of data were compiled for the aquifer PVI of this study: depth to water table, recharge, aquifer media, soil media, impact to vadose zone, and hydraulic conductivity. 
The original DRASTIC model included the topography parameter. However, the inclusion of this parameter did not change the final model output and so was not included in the model calculations. The original DRASTIC model did not include $\mathrm{CN}$ in the recharge and soil media parameter calculations. The modification of these parameters transforms the DRASTIC method into a representative ground water map by improving computational technique and local input parameters. This additional input utilized in the model improves sensitivity analysis in order to evaluate the relative importance of the model parameters, which are then reflected in their individual weights and ratings.

In the previous objectives the temporal and spatial raster chemical coverages were analyzed for trends in their own sections with no analysis considering what external variables may have influenced the changes in contaminant concentration. This section will focus on contaminant data explanation through the use of temporal, lateral, and vertical contaminant raster layers generated in objectives 1 and 2 . To validate the accuracy of the DRASTIC PVI coverage, the spatiotemporal trends of nitrates concentrations were tracked and used to create a raster network of continuous contaminant detections over time. The GIS Analyst Tool was used to model subsurface features, like contaminant concentrations, and overlay them with the independent environmental parameters of the PVI (Huan, 2012). 


\subsection{Development of Pollution Vulnerability Index Map}

The rating of each numerical range or category within the 6 different pollution

vulnerability factors was assigned a weight to create a numerical output to be used in the

final analysis of the PVI map. The following table is a representation of how all of the

different parameters are being broken down into distinct Ratings and Weights. In the final

pollution vulnerability map the higher the pollution vulnerability score the higher

probability that a certain section of the aquifer is contaminated.

Table 6: Biscayne Aquifer PVI Rating

\begin{tabular}{|c|c|c|c|c|c|c|c|c|c|c|c|}
\hline \multirow{2}{*}{ Parameters } & \multirow{2}{*}{$W_{i}$} & \multicolumn{10}{|c|}{ PVI Rating $\left(R_{i}\right)$} \\
\hline & & 1 & 2 & 3 & 4 & 5 & 6 & 7 & 8 & 9 & 10 \\
\hline $\begin{array}{l}\text { Depth to water table } \\
\text { (m), } d\end{array}$ & 5 & & & & & & & & $4.7-7.1$ & $1.5-4.6$ & $0-1.4$ \\
\hline Recharge (mm), $r$ & 4 & $0-50$ & & $\begin{array}{l}51- \\
102\end{array}$ & & & $\begin{array}{c}103- \\
138.7\end{array}$ & & & & \\
\hline Aquifer media, $a$ & 3 & & & & $\begin{array}{l}\text { Sand } \\
\text { Shell } \\
\text { and } \\
\text { Marl }\end{array}$ & & & & Peat & & $\begin{array}{c}\text { Karst } \\
\text { Limestone }\end{array}$ \\
\hline $\begin{array}{l}\text { Soil/LULC } \\
\text { combination map - } \\
\text { HSG \& CN, s }\end{array}$ & 3 & $\begin{array}{l}\mathrm{C} / \mathrm{D} \\
94 / 99\end{array}$ & $\begin{array}{c}\mathrm{B} / \mathrm{C} \\
92 / 91\end{array}$ & $\begin{array}{c}\text { A } \\
89\end{array}$ & $\begin{array}{l}\mathrm{C} / \mathrm{D} \\
85 / 80\end{array}$ & $\begin{array}{l}\mathrm{A} / \mathrm{B} / \mathrm{C} \\
76 / 79\end{array}$ & $\begin{array}{l}\mathrm{C} \\
72\end{array}$ & $\begin{array}{c}\mathrm{A} \\
65 / 67\end{array}$ & $\begin{array}{l}\text { A } \\
49\end{array}$ & $\begin{array}{l}\text { A } \\
43\end{array}$ & \\
\hline $\begin{array}{l}\text { Impact of Vadose } \\
\text { Zone, } i\end{array}$ & 5 & & & & & & & & $\begin{array}{c}\text { Karst } \\
\text { Limestone }\end{array}$ & $\begin{array}{c}\text { Bedded } \\
\text { Limestone }\end{array}$ & $\begin{array}{l}\text { Sand and } \\
\text { Gravel }\end{array}$ \\
\hline $\begin{array}{l}\text { Hydraulic } \\
\text { Conductivity }(\mathrm{m} / \mathrm{d}) \text {, } \\
c\end{array}$ & 3 & $0-4.1$ & $\begin{array}{l}4.2- \\
12.2\end{array}$ & & $\begin{array}{l}12.2- \\
28.5\end{array}$ & & $\begin{array}{l}28.5- \\
40.7\end{array}$ & & $40.7-51.1$ & & \\
\hline
\end{tabular}




\subsubsection{Structural Analysis}

The final output raster grids for each of the 6 pollution vulnerability parameters were created within the 8-bit Attribute Table column labeled Output. In this column each discrete cell, representing the distinct Ratings within the individual parameters, was multiplied by the assigned weight of the parameter using Field Calculator. Once the Ratings and Weights were combined to create a raster Output the Join function in GIS was used to $A d d$ each of the individual PVI layers together. The breakdown of equation used is as follows:

$\mathrm{PVI}=R_{d} W_{d}+R_{r} W_{r}+R_{a} W_{a}+R_{s} W_{s}+R_{i} W_{i}+R_{c} W_{c}$

$$
R=\text { rating; } W=\text { weight }
$$

Equation 1: PVI Model (Saidi, 2009 and Kerr, 1987)

\subsection{Model Inputs}

The integration of local knowledge and regional pollution vulnerability parameters will improve the DRASTIC method and create reliable tool for ground water pollution vulnerability identification. Each of the 6 factors, shown in Table 13, was weighted based on order of importance and impact to groundwater vulnerability when compared against the relative weight another factor would have on groundwater vulnerability to pollution contamination. Then within the individual categories the numerical ranges or specific classes within the categories were further classified by ratings to demonstrate the relative impact they would have on pollution vulnerability to the aquifer. The bigger the rating 
value within the individual factors denotes the greater impact the category input facet will have on the PVI score of the aquifer.

The 6 input data layers gathered for the PVI method was created from original sources as either a point or polygon layer. These layers were then converted from a vector (point and polygon) to a raster (grid) layer using GIS. All 6 of the pollution vulnerability layers converted were created with a predetermined resolution of discrete $30 \times 30$ meter cells.

\subsubsection{Depth to Water Table}

The depth to water from the soil surface was calculated from the Broward County potable well database maintained by the Well Field Program and from the SFWMD original GIS shapefile of water table depth. The downloaded SFWMD shapefile verified depths for the entirety of Broward County against the point depths for the potable wells monitored by the county. This shapefile was clipped using the Broward County approved polyline layer. The depth to water table rating for the pollution vulnerability map was prepared by assigning sensitivity rating values as:

Table 7: Depth to Water Rating Breakdown for Depth to Water Figure

\begin{tabular}{|c|c|}
\hline $\begin{array}{c}\text { Depth to Water } \\
\text { Table (Meters) }\end{array}$ & $\boldsymbol{R}_{\boldsymbol{d}}$ \\
\hline $0.30-0.61$ & 10 \\
\hline $0.91-1.22$ & 9 \\
\hline $1.52-2.13$ & 7 \\
\hline $2.44-3.05$ & 5 \\
\hline $3.35-4.57$ & 3 \\
\hline $4.88-7.92$ & 2 \\
\hline $8.53-13.41$ & 1 \\
\hline
\end{tabular}


In the clipped county version of the depth to water final rating there were no areas going past -23 feet to the water table.

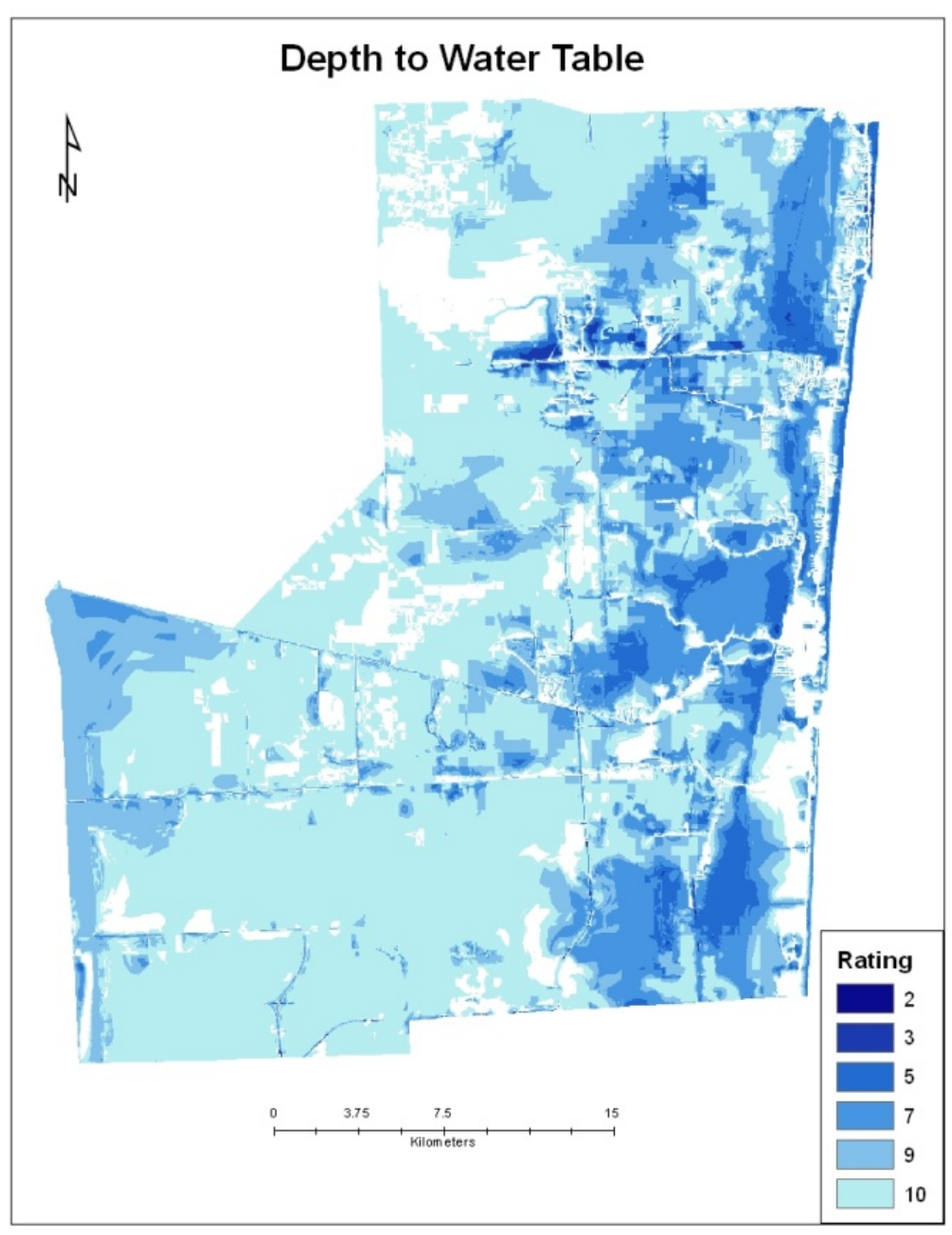

Figure 11: Depth to Water Pollution Vulnerability Rating 


\subsubsection{Recharge}

The shallow karst Biscayne Aquifer of Broward County recharges mainly from infiltration by precipitation and direct recharge from the Everglades. Therefore, the net recharge was calculated by using the following formula:

Recharge rate $(V)=e-q$

Equation 2: Recharge Rate

The runoff depth $(q)$ is taken from the CN Equation which is shown in Equation 4. The yearly evaporation data $(e)$ was taken from a single station located in Fort Lauderdale (NOAA Technical Report 2003) and is shown in Table 9.

The final recharge rating pollution vulnerability map was prepared by assigning sensitivity rating values as:

Table 8: Recharge Rating

\begin{tabular}{|c|c|}
\hline $\begin{array}{c}\boldsymbol{V} \\
(\mathbf{m m} / \text { year) }\end{array}$ & $\boldsymbol{R} \boldsymbol{r}$ \\
\hline $0-50$ & 1 \\
\hline $51-102$ & 3 \\
\hline $103-138.7$ & 6 \\
\hline
\end{tabular}


Table 9: Average Yearly Evaporation from the Fort Lauderdale Experiment Station

\begin{tabular}{|c|c|c|}
\hline Pan Evaporation & $70.39 / 12$ & $5.87 \mathrm{in}$ \\
\hline Evaporation polygon & $5.87 \times 0.75$ & $4.39 \mathrm{in}$ \\
\hline Raster & $4.39 \times 25.5$ & $111.74 \mathrm{~mm}$ \\
\hline
\end{tabular}

The runoff equation used in this research is based on the infiltration capacity of the surface. Therefore, surface runoff is dependent on the different combinations of soil, land use, and land cover (LULC) types. The Broward County Basin GIS layer contains all of the sub-basins within the county. Land cover aerial photographs were used to model landscape patterns for the five years of the study. Aerial satellite images from 2006, 2008 , and 2011 were used to model a rough landscape pattern of the study area through the use of the Earth Resources Data Analysis System (ERDAS) unsupervised classification tool. Then using the variations between spectral ranges the image was reclassified and condensed into unique land use types. Of special interest are the hurricane-influenced areas of 2006, the agricultural fields in western Broward County, the landfills in the north and south of the county, and the major canals running across the county (parallel to Interstate 595, I-595). These different land uses of interest are included in the final land classification coverage layer. Classification of raster images of Broward County in terms of land use and land cover (LU/LC). The total area of each of these basins, sub-classified with LU/LC, was used in the creation of the runoff depth $(q)$ throughout the county. Then the raster image was converted to a shapefile layer and clipped using the Broward County Basin layer. 


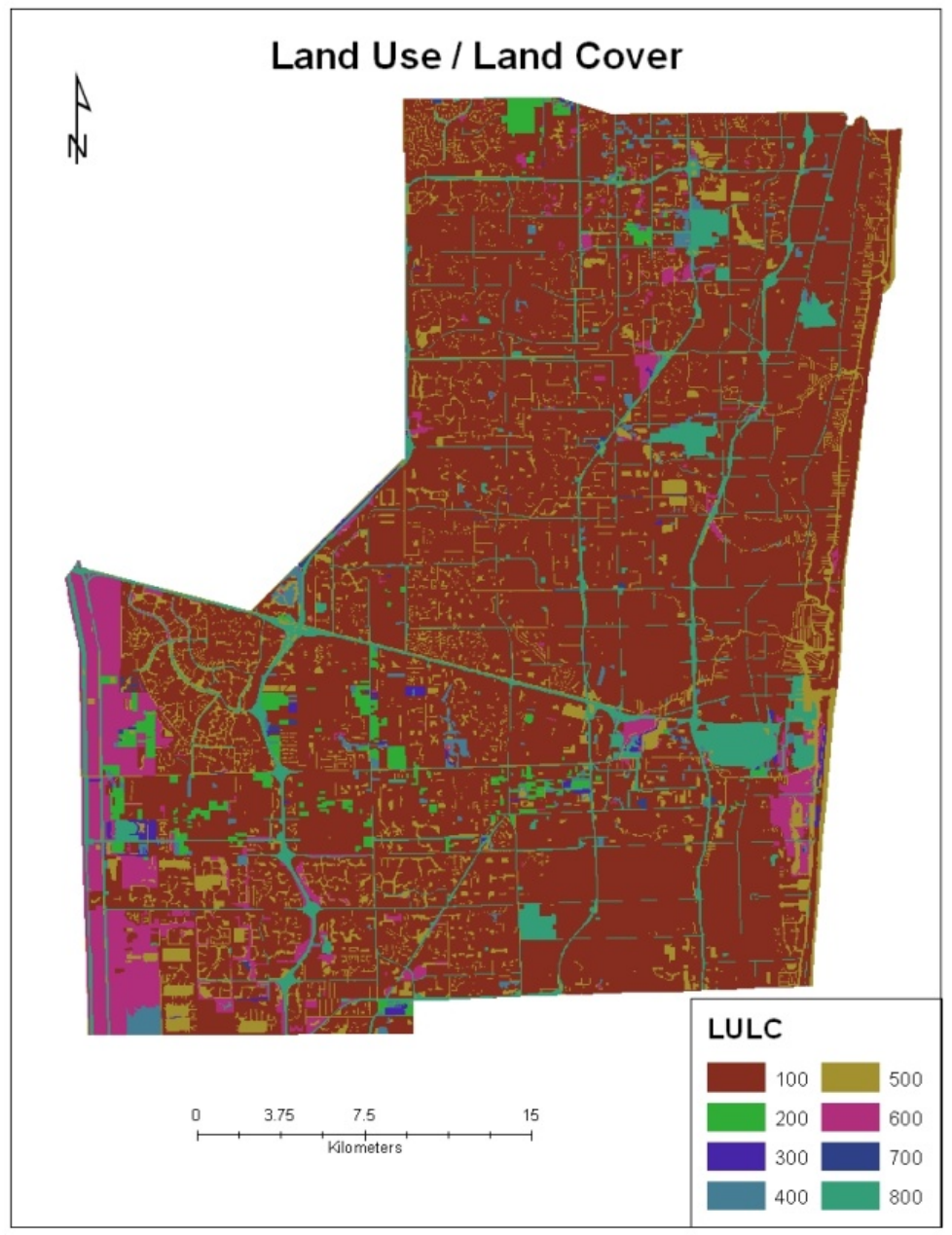

Figure 12: Map of Broward County LU / LC for 2009

The soil layer was then classified into Hydrologic Soil Groups (HSG) based on the minimum infiltration rate of the surface:

Table 10: Hydrological Soil Group

\begin{tabular}{|c|c|}
\hline \multicolumn{2}{|c|}{ Hydrological Soil Group (HSG) } \\
\hline A & Low runoff potential \\
\hline B & Moderately low runoff potential \\
\hline C & Moderately high runoff potential \\
\hline D & High runoff potential \\
\hline
\end{tabular}




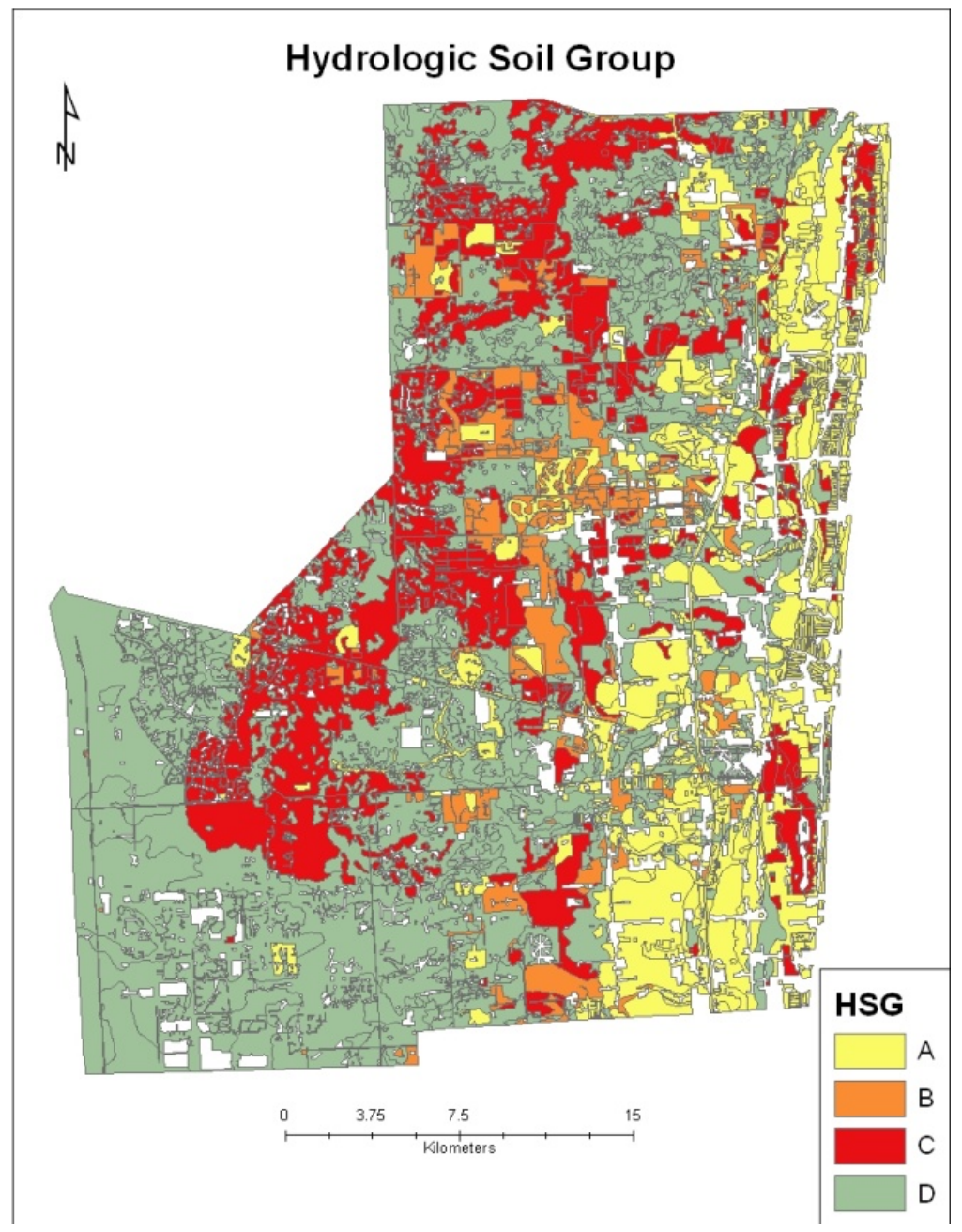

Figure 13: Map of Broward County Hydrologic Soil Groups

The LULC was Intersected with the soil group layer. The $\mathrm{CN}$ values for the runoff estimation ranged from 0 to 98 : lower $\mathrm{CNs}$ indicate low runoff potential while larger numbers indicate increased runoff potential. 
Table 11: HSG vs LU/LC for CN

\begin{tabular}{|c|c|c|c|c|c|}
\hline \multirow{2}{*}{ Land Use } & \multirow{2}{*}{\begin{tabular}{c} 
Land Use \\
Element \\
\cline { 3 - 6 }
\end{tabular}} & \multicolumn{4}{|c|}{ Soil Type } \\
\cline { 3 - 6 } & A & B & C & D \\
\hline Urban & 100 & 89 & 92 & 94 & 95 \\
\hline Agricultural & 200 & 67 & 78 & 85 & 89 \\
\hline Range Land & 300 & 49 & 69 & 79 & 84 \\
\hline Forest & 400 & 43 & 65 & 76 & 82 \\
\hline Water & 500 & 0 & 0 & 0 & 0 \\
\hline Wetlands & 600 & 49 & 65 & 72 & 80 \\
\hline Barren Land & 700 & 77 & 86 & 91 & 94 \\
\hline Roads & 800 & 98 & 98 & 98 & 98 \\
\hline
\end{tabular}




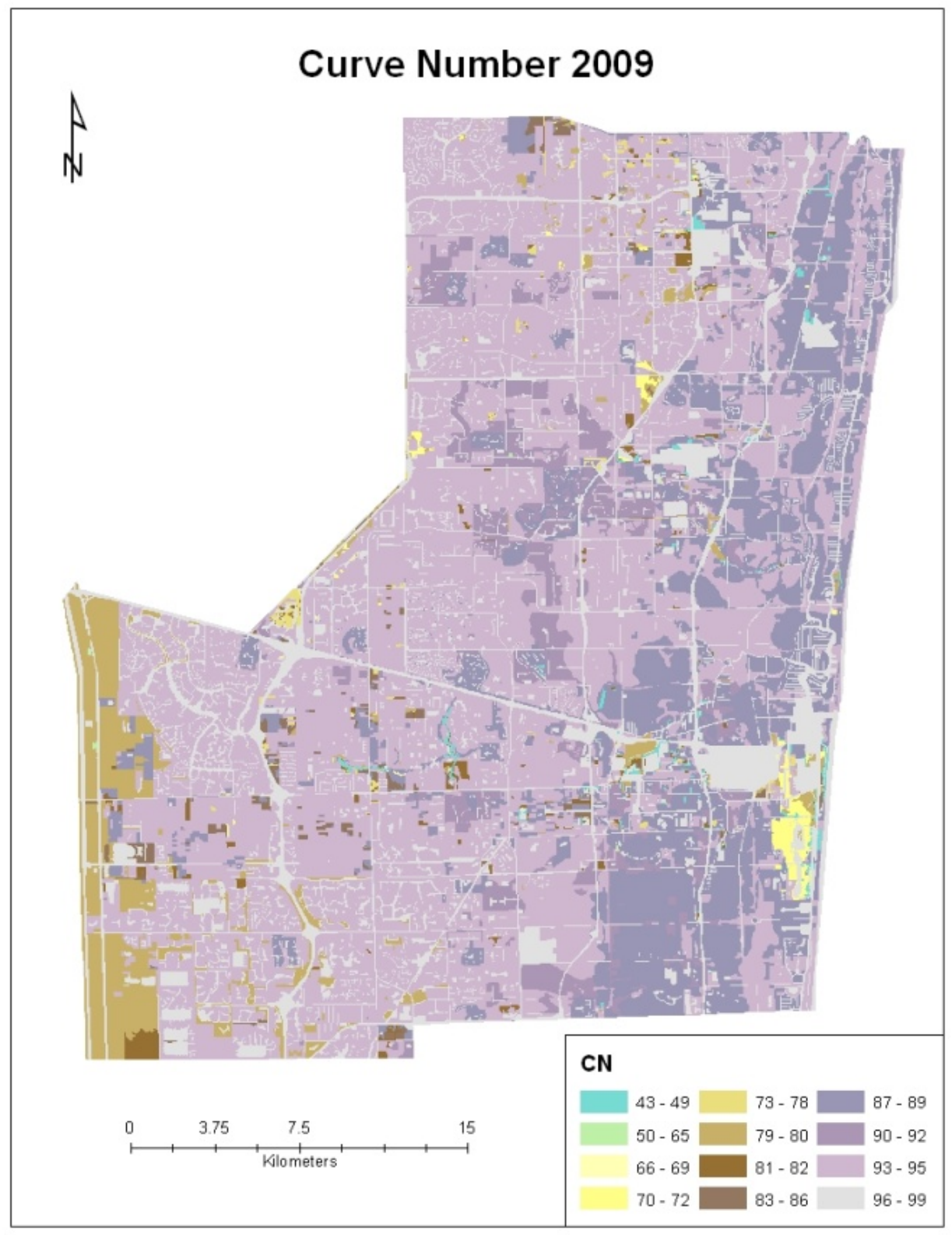

Figure 14: Map of Broward County CN for 2009

Precipitation was also determined for use in the surface runoff equation. The daily rain measurements were taken from 6 rainfall capture stations of the South Florida Water Management District (SFWMD) in eastern Broward County. These were converted into average monthly and annual rainfalls represented in measurements of inches/year. These 
rainfall measurements were imported into Excel and then converted into CSV format for import into the GIS rainfall layer. The GIS layer representing the location of rainfall capture stations throughout the county in point format was downloaded from the SFWMD website. The rainfall point layer was converted into raster format through spline interpolation.

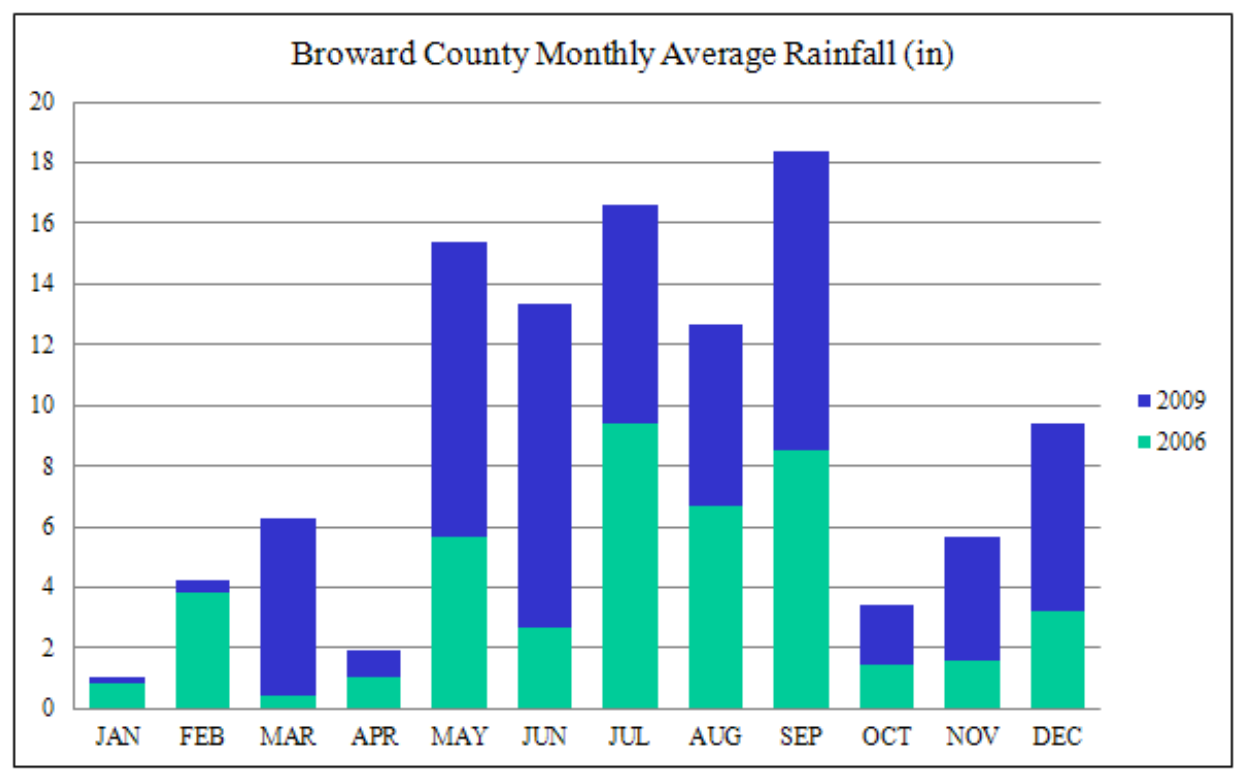

Figure 15: Historical monthly rainfall data for individual field sites, SFWMD, DBHYDRO

The pollution vulnerability range for rating both the soil and LUC was estimated by the following equation:

Soil C \& D + Urban $=$ CN 100/95 = PVI Rating 1

Soil A \& B + Forest $=$ CN 40/49 $=$ PVI Rating 10

Equation 3: PVI CN Rating 
The greater the recharge the greater the chance there is for contaminants to reach the water table. The final runoff depth was determined by the following equation in GIS using Raster Calculator:

$$
\begin{aligned}
& q=(\mathrm{P}+2-200 / \mathrm{CN})^{2} /(\mathrm{P}-8-800 / \mathrm{CN}) \\
& \text { Volume }\left(\mathrm{m}^{3}\right)=(\mathrm{Q} / 1000) * \text { Area }\left(\mathrm{m}^{2}\right) \\
& \quad q=\text { Total Runoff }\left(\mathrm{m}^{3}\right) ; \mathrm{CN}=\text { Runoff Curve Number; } \mathrm{P}=\text { Rainfall }(\mathrm{mm})
\end{aligned}
$$

Equation 4: CN Method 


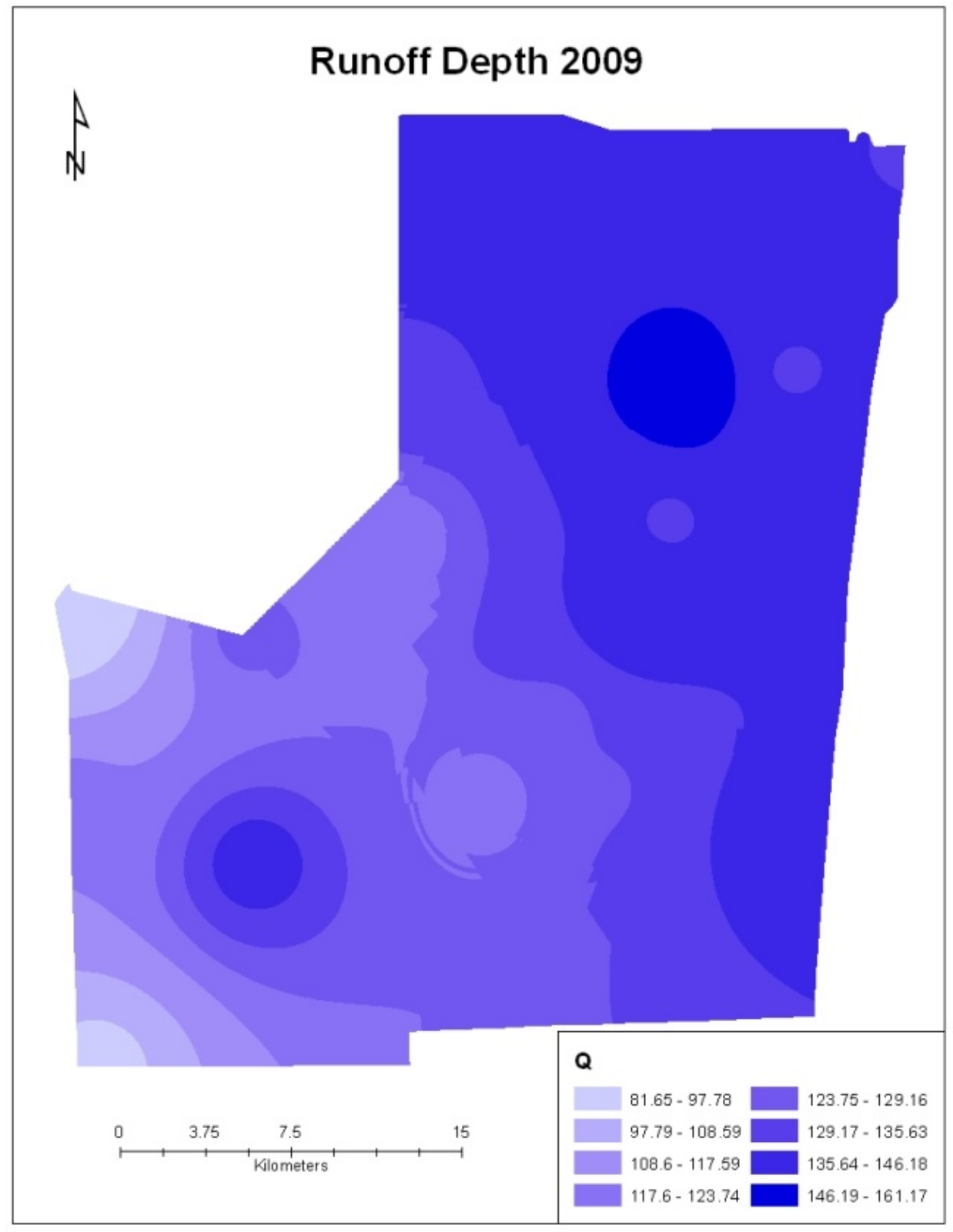

Figure 16: Map of Runoff Depth 


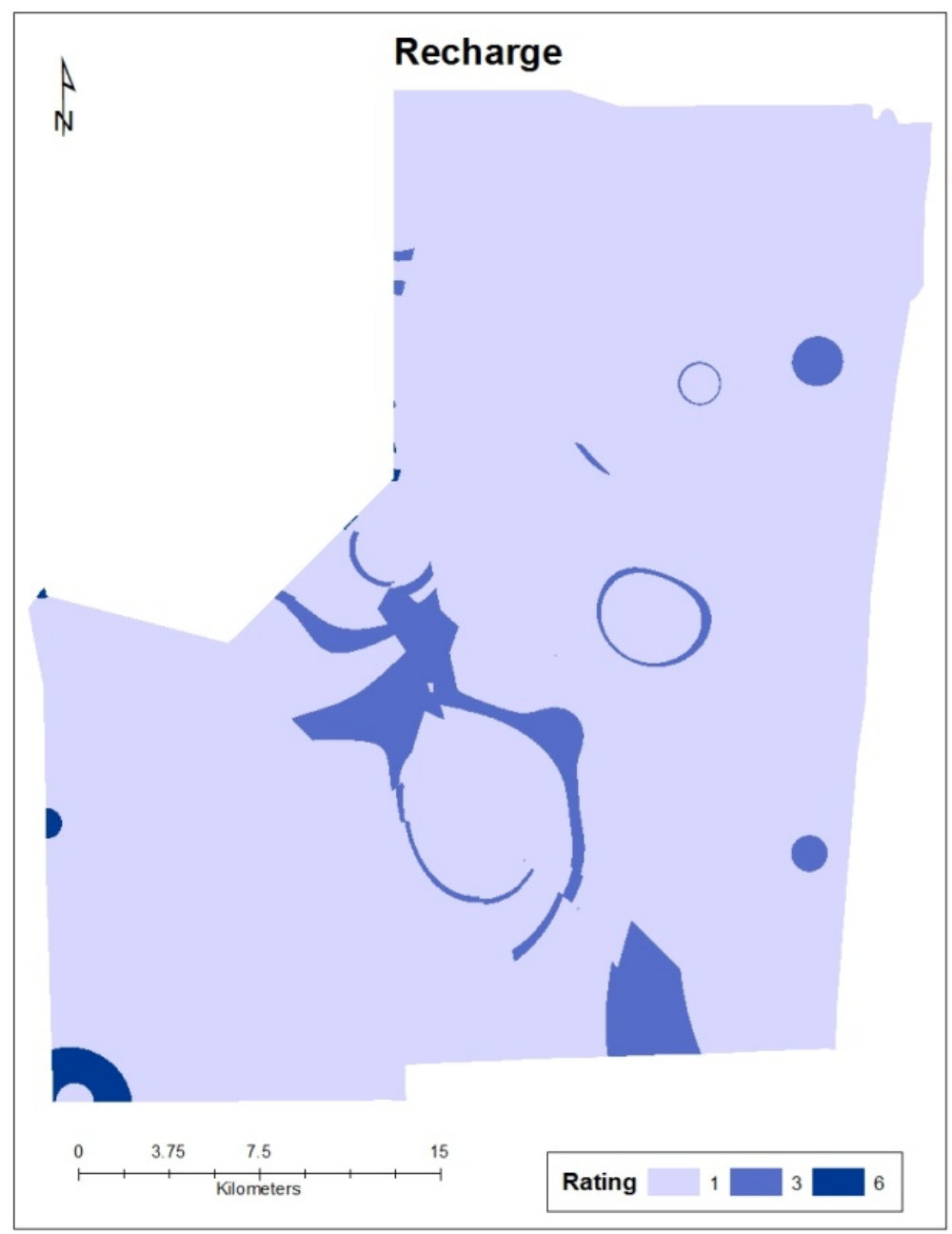

Figure 17: Map of Broward County Recharge Pollution Vulnerability Rating

\subsubsection{Aquifer Media}

The aquifer media map was a downloaded layer from the Florida Geographic Data Library (FGDL) Metadata Explorer. It was created in 2010 and was a part of the state DRASTIC Vulnerability Areas of the Surficial Aquifer System GIS layer and was published by the Florida Department of Environmental Protection (FDEP). However, the original dataset of classified aquifer media was from the USEPA. The final aquifer media rating pollution vulnerability map was prepared by assigning sensitivity rating values as: 
Table 12: Aquifer Media Pollution Vulnerability Rating

\begin{tabular}{|c|c|}
\hline Aquifer Type & $\boldsymbol{R}_{\boldsymbol{a}}$ \\
\hline Limestone & 10 \\
\hline Peat & 8 \\
\hline Sand Shell and Marl & 4 \\
\hline
\end{tabular}

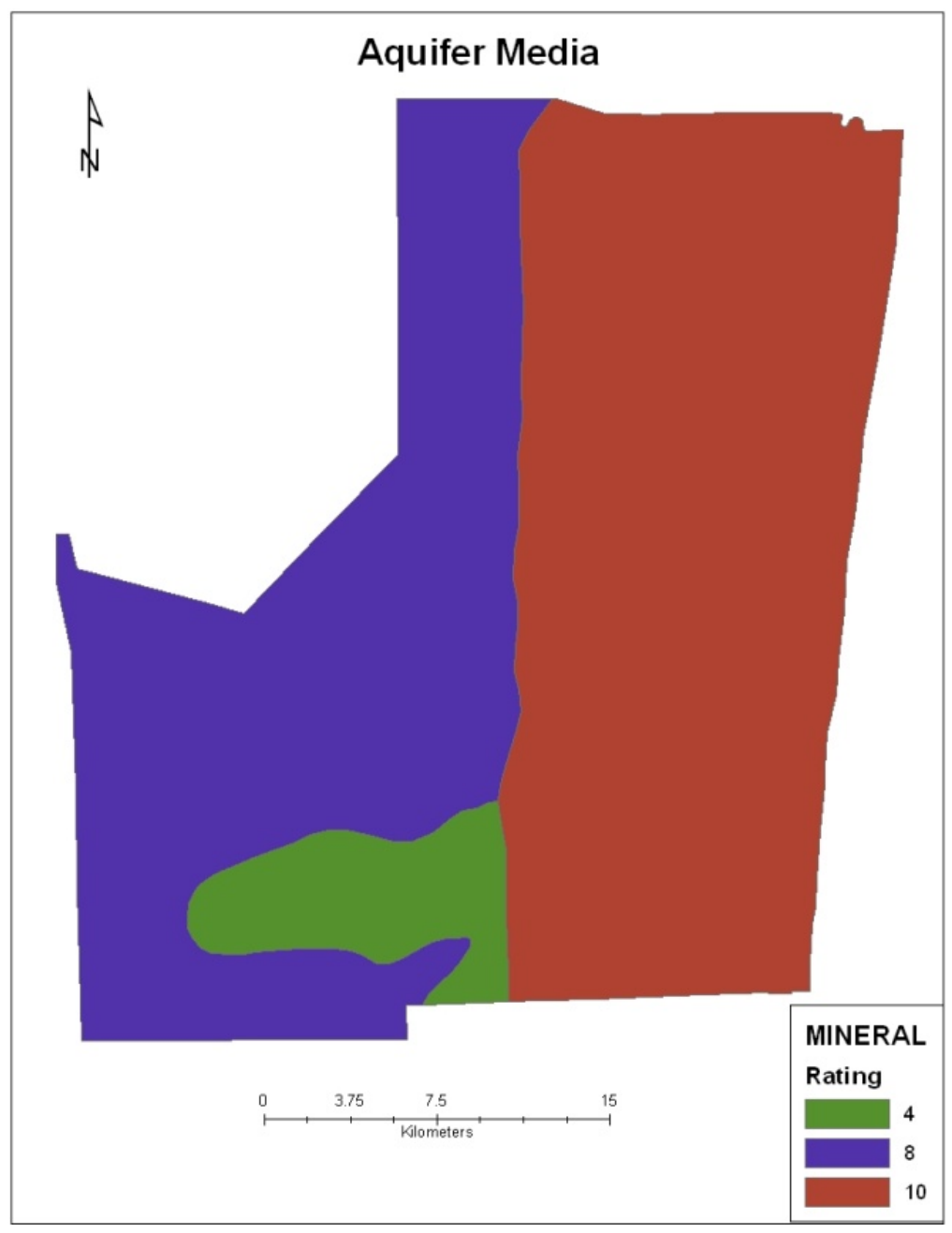

Figure 18: Map of Broward County Aquifer Media Pollution Vulnerability Rating 


\subsubsection{Soil Media}

The soil media map was obtained from the 1990 US Department of Agriculture, National, January 2009 LANDSAT5-TM for LULC. The soil media rating for the pollution vulnerability map was prepared by assigning sensitivity rating values as:

Table 13: Soil Media Rating Table

\begin{tabular}{|c|c|}
\hline $\begin{array}{c}\text { Soil Media } \\
\text { Type }\end{array}$ & $\boldsymbol{R}_{\boldsymbol{s}}$ \\
\hline Udorthents & 10 \\
\hline $\begin{array}{c}\text { Limestone/ } \\
\text { sand }\end{array}$ & 9 \\
\hline Sandy loam & 6 \\
\hline Marly/loam & 5 \\
\hline Silty loam & 4 \\
\hline Clay loam & 3 \\
\hline Muck & 2 \\
\hline
\end{tabular}




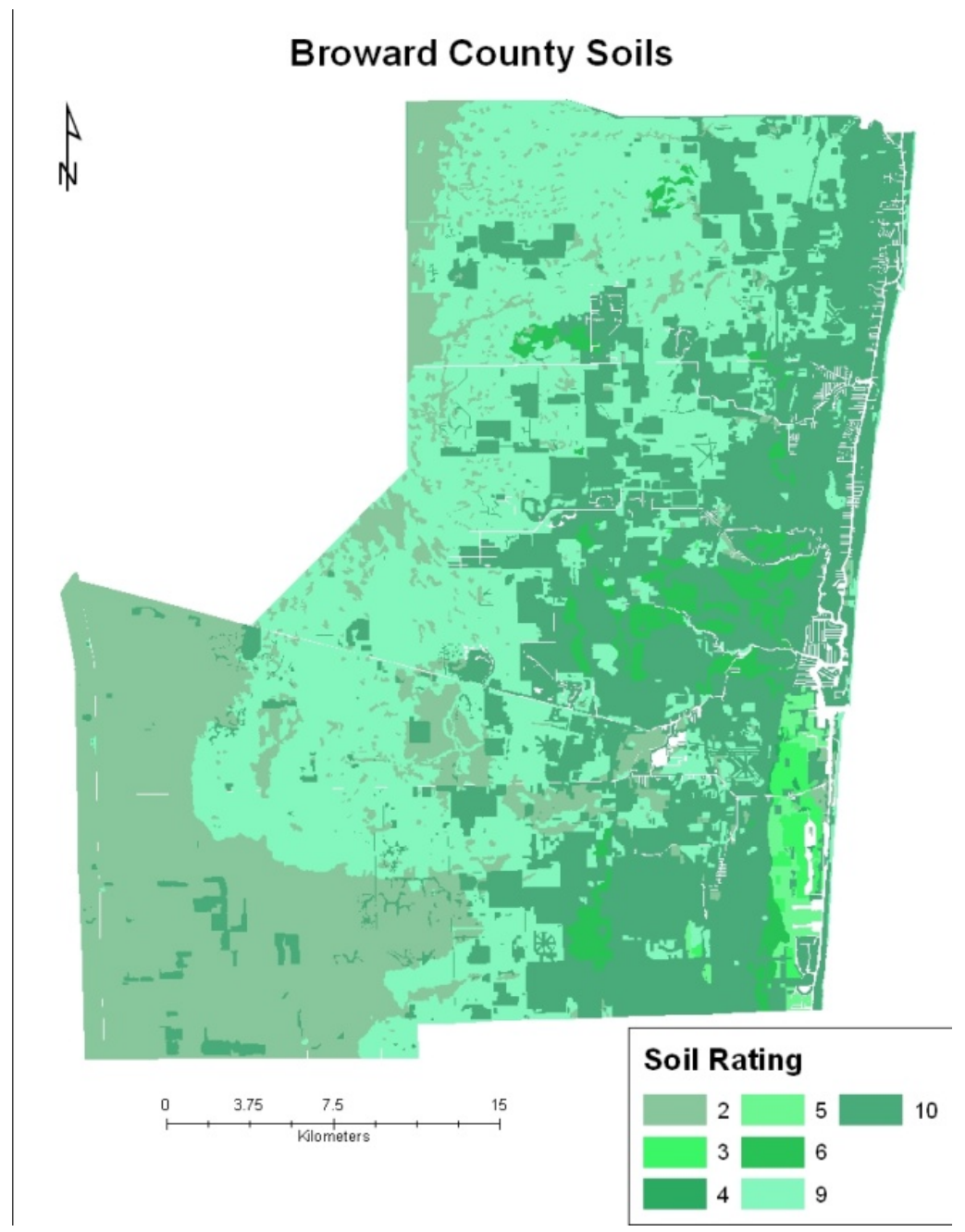

Figure 19: Map of Soil Type Pollution Vulnerability Rating

\subsubsection{Impact to Vadose Zone}

The impact to vadose zone map was a downloaded layer from the FGDL Metadata Explorer. It was created in 2010 and was a part of the state DRASTIC Vulnerability Areas of the Surficial Aquifer System GIS layer and was published by the FDEP. However, the original dataset was from the USEPA. This layer is the representation of the impact of the unsaturated zone above the water table, which controls the passage and attenuation of the 
contaminated material to the aquifer (Pathak 2011). The final impact to vadose zone rating pollution vulnerability map was prepared by assigning sensitivity rating values as:

Table 14: Impact to Vadose Zone Rating Table

\begin{tabular}{|c|c|}
\hline Vadose Zone & $\mathbf{R} \boldsymbol{i}$ \\
\hline Karst Limestone & 8 \\
\hline Bedded Limestone & 9 \\
\hline Sand and Gravel & 10 \\
\hline
\end{tabular}

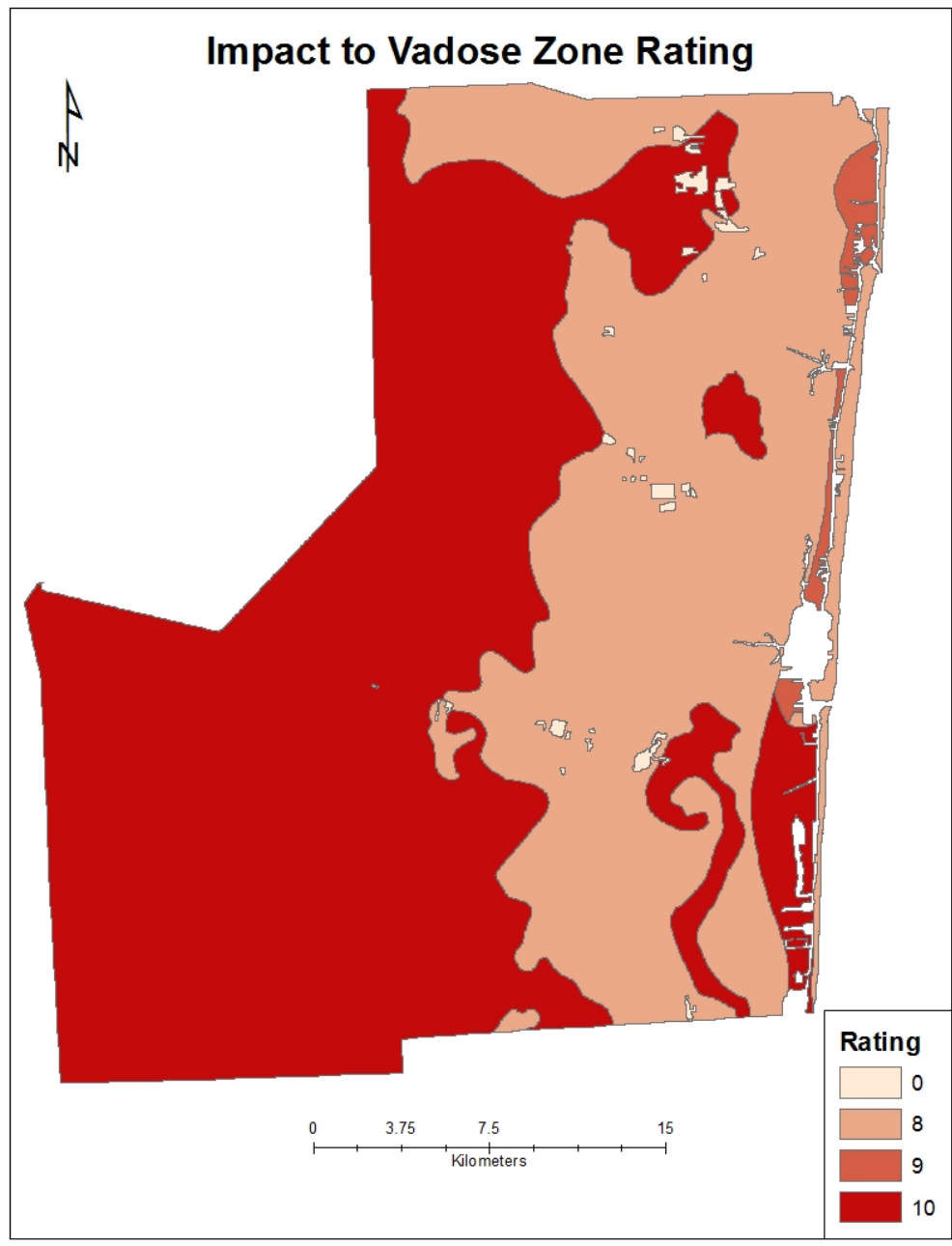


Figure 20: Map of Broward County Impact to Vadose Zone Pollution Vulnerability Rating

\subsubsection{Hydraulic Conductivity}

The hydraulic conductivity map was created from the point layer of sites contaminated with petroleum and non-petroleum constituents. The Broward County EAR licensing program section maintains the conductivity points. The hydraulic conductivity is measured from the field pump tests implemented at each contaminated site in need of monitoring. The final impact to vadose zone rating pollution vulnerability map was prepared by assigning sensitivity rating values as:

Table 15: Hydraulic Conductivity Rating Table

\begin{tabular}{|c|c|}
\hline $\begin{array}{c}\text { Hydraulic } \\
\text { Conductivity (m/d) }\end{array}$ & $\boldsymbol{R}_{\boldsymbol{c}}$ \\
\hline $0.03-3.99$ & 1 \\
\hline $4-11.99$ & 2 \\
\hline $12-28.98$ & 4 \\
\hline $29.01-40.89$ & 6 \\
\hline $41.71-51.24$ & 8 \\
\hline
\end{tabular}

Spline interpolation technique was used to create the raster grid conductivity coverage of eastern Broward County. The hydraulic conductivity raster was converted from a 32-bit to an 8-bit layer so that an attribute table could be attached to the cells and assigned a rating. The hydraulic conductivity ranged from 0.11 to 168.12 feet/day, which was then converted to meters/day. The raster attribute table was built and then reclassified through 
Raster Calculator: Int(“cond3meters"); changed from 32-bit to 8-bit to create the attribute table.

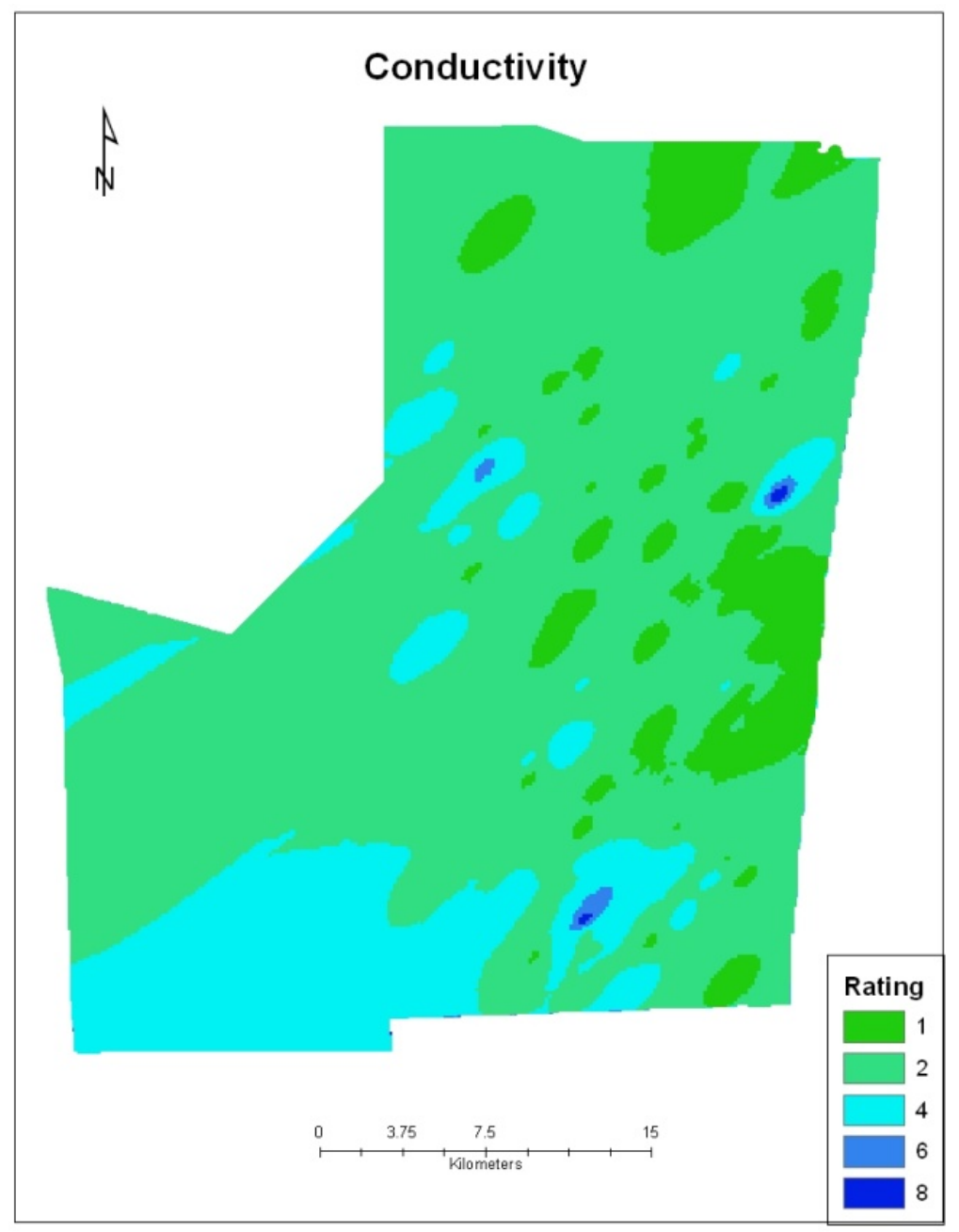

Figure 21: Map of Broward County Hydraulic Conductivity Pollution Vulnerability Rating

\subsection{Sensitivity and Validation of the Contamination Map}

Each of the 6 environmental parameters has a final attribute column representative of the outcome for the joining of each weight and rating. If the environmental parameter was in 
raster format it was converted to polygon and the output attribute column was then added. The outcome attribute was found by multiplying the pollution vulnerability rate by the weight assigned to the parameter. The final Joined layer includes all of the intersected parameter output data, which is added together to get a PVI for Broward County.

The continuous PVI layer, representative of specific spatial marks, such as gasoline stations, landfills, and potable well radii, was overlaid with the yearly nitrate point layers of contamination. This combination generated a correlation graph between contaminant concentration movement over time and those areas that are vulnerable to pollution. The correlation overlay is performed in order to expand on the analysis explored in objective 2 when the well fields of Broward County were tracked for contaminants due to the aquifer surface vulnerability to contamination.

In order to explain the contaminant concentration trends occurrence graphs were generated and overlaid through the use of the interpolated layers created in objectives 1 and 2. For instance, to determine if there the correlation between the nitrate contaminant layers and the PVI was statistically significant a regression curve was generated within the graph. The creation of continuous contaminant raster concentrations using GIS generates the ability to spatially analyze the layers for varying chemical concentrations. The changes in chemical concentration were observed as a response to changes in the six parameters of the vulnerability index; all of which embody environmental changes such as rainfall runoff and land cover over a temporal timeframe. This last objective would 
analyze each potential relationship between nitrates and the PVI to determine, through temporal trends, if any of the variables have a statistically significant influence on any of the contaminant concentrations. 


\section{RESULTS AND DISCUSSION}

This chapter introduces the results of the 3 different contaminant interpolations, the results of the PVI analysis, as well as the relationship between the measures pollutant data and the pollution vulnerability coverage. The impact that spatial clustering of the known points, limited to within the well fields, on the final contaminant interpolation coverage is also discussed. The sensitivity of the PVI to each contributing factor is also explored.

\subsection{Contaminant Interpolation}

The contaminant point data was tracked in order to create interpolated coverage. It was found that $\mathrm{OK}$ was the least biased and most robust compared to spline and inverse distance weighted methods (Whitman, 2010). This is due to the similar hierarchical cluster analysis across all well fields distributed unevenly throughout the county. Therefore, throughout the interpolation process a second order polynomial trend removal was used in the interpolation of these layers, unless otherwise stated. The quality of the interpolation method was quantified by comparing the interpolated concentration values of all grid elements with the corresponding known values in the reference data grid. The total number of contaminant detection points in the dataset, low known values, high known values, high known values once the outliers were removed from the dataset, the high predicted values from the interpolated dataset, RMS Error ( $\sim 1)$, RMS Standardized $(\sim 0)$, average standard error, the known average and the interpolated average are included in Tables 16, 17, and 18. These standards were metrics used to estimate an overall measure of interpolated coverage quality for each of the three contaminants over 
the 6 years. The three tables each have a Date column which represents the averaged quarterly concentrations at each of the contaminant detection points. The contaminant concentrations in these tables are shown in $\mathrm{mg} / \mathrm{L}$.

\subsubsection{Nitrate Spatial Concentrations}

The mean yearly nitrate concentration decreased $38.76 \%$ over the six-year period (from 0.0005 to $0.1553 \mathrm{mg} / \mathrm{L}$ ). From the 89 available stations, nitrate concentrations above the MDL of $0.0005 \mathrm{mg} / \mathrm{L}$ were measured at 72 wells in 2006, 71 wells in 2007, 53 wells in 2008,52 wells in 2009,61 wells in 2010 , and 50 wells in 2011 . The nitrate concentrations show a wide variability in the study area, with values ranging from 0.0005 up to $30.8005 \mathrm{mg} / \mathrm{L}$ (Table 14). 
Nitrate (mg/L): Average Yearly Concentrations

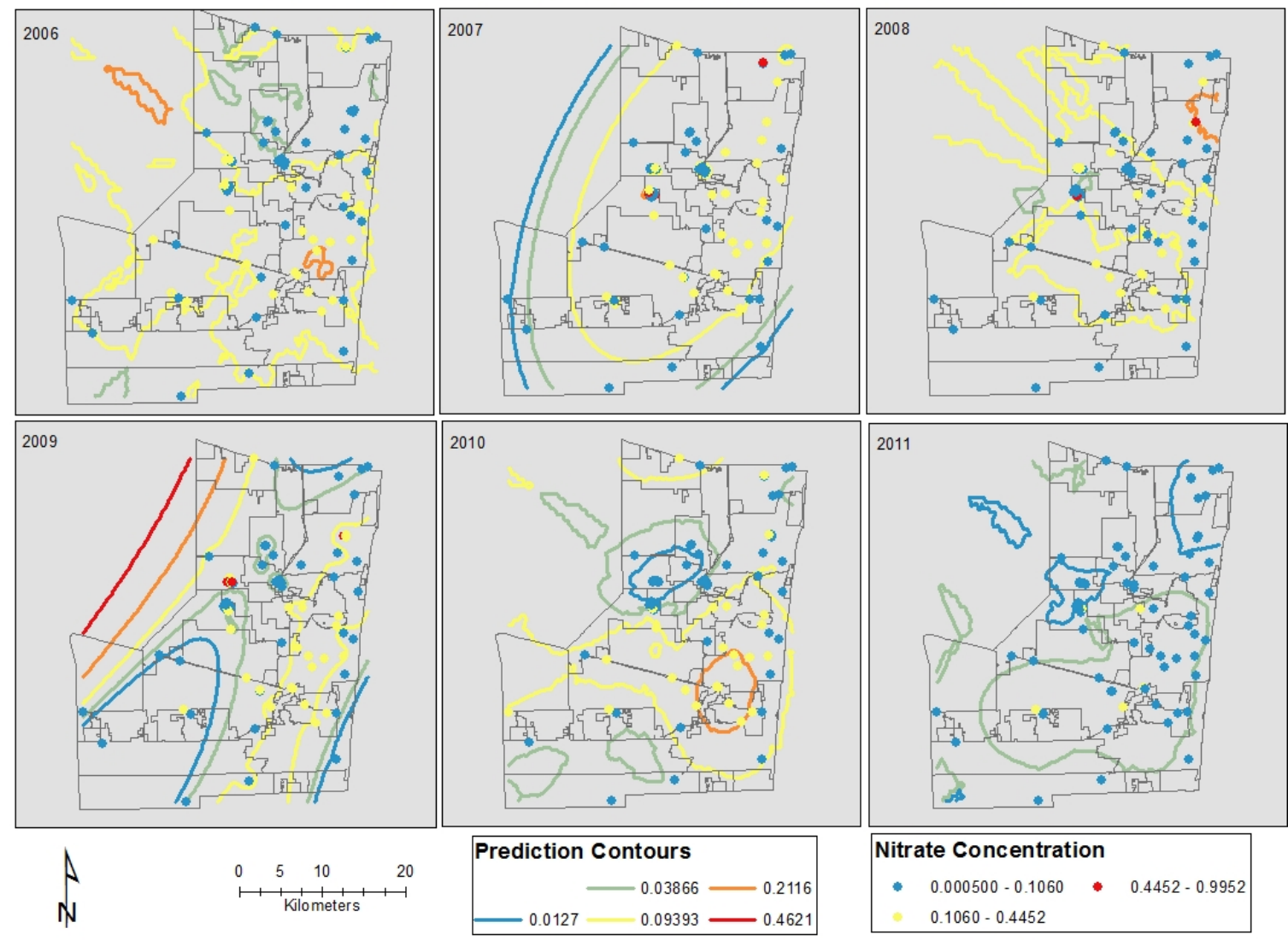

Figure 22: Map of Nitrate Interpolation Results

Table 16: Nitrate Interpolation Results

\begin{tabular}{|c|c|c|c|c|c|c|c|c|c|c|c|}
\hline \multicolumn{10}{|c|}{ Yearly Nitrate (98 points) } \\
\hline Date & $\begin{array}{c}\text { Total } \\
\text { Points }\end{array}$ & $\begin{array}{c}\text { Low } \\
\text { Known }\end{array}$ & $\begin{array}{c}\text { Low } \\
\text { Predicted }\end{array}$ & $\begin{array}{c}\text { High } \\
\text { Known }\end{array}$ & $\begin{array}{c}\text { High, } \\
\text { Outlier } \\
\text { Removed }\end{array}$ & $\begin{array}{c}\text { High } \\
\text { Predicted }\end{array}$ & $\begin{array}{c}\text { RMS } \\
\text { Error }\end{array}$ & $\begin{array}{c}\text { RMS } \\
\text { Standardized }\end{array}$ & $\begin{array}{c}\text { Average } \\
\text { Standard } \\
\text { Error }\end{array}$ & $\begin{array}{c}\text { Known } \\
\text { Average }\end{array}$ & $\begin{array}{c}\text { Predicted } \\
\text { Average }\end{array}$ \\
\hline Y2006 & 72 & 0.0005 & 0.01333 & 3.7705 & 0.433 & 0.2875 & 0.1020 & 0.7800 & 0.1365 & 0.2715 & 0.0303 \\
\hline Y2007 & 71 & 0.0005 & 0.03383 & 8.2405 & 0.6705 & 0.3235 & 0.1512 & 0.6900 & 0.1529 & 0.4220 & 0.0438 \\
\hline Y2008 & 53 & 0.0005 & 0.002582 & 3.1805 & 0.9953 & 0.2158 & 0.1552 & 1.0600 & 0.1467 & 0.2406 & 0.0112 \\
\hline Y2009 & 52 & 0.0005 & -0.1304 & 8.542 & 0.7355 & 0.3141 & 0.1442 & 0.9900 & 0.1202 & 0.2783 & 0.0397 \\
\hline Y2010 & 61 & 0.0005 & 0.0006331 & 1.6155 & 0.3555 & 0.266 & 0.0753 & 1.1100 & 0.0691 & 0.1005 & 0.0181 \\
\hline Y2011 & 50 & 0.0005 & 0.00221 & 4.083 & 0.1895 & 0.07948 & 0.0419 & 1.0500 & 0.0400 & 0.0847 & 0.0061 \\
\hline
\end{tabular}


The results of the multiple yearly regressions for nitrates displayed an under-prediction of data coverage at low and high concentrations. However, OK was more efficient at predicting lower ranges of coverage despite the fact that the detections registered as negative numbers. The under prediction at high concentrations was within $0.1 \mathrm{mg} / \mathrm{L}$ for 10 timeframes, greater than $0.1 \mathrm{mg} / \mathrm{L}$ for 13 timeframes, and less than $0.1 \mathrm{mg} / \mathrm{L}$ for 7 timeframes. The RMS Standardized was greater than 0.5 and less than $1.586 .67 \%$ of the 30 timeframes. The average standard error was within 0.1 or less of the RMS prediction error $90 \%$ of the timeframes. The interpolated values were consistently under predicted.

The trend analysis tool for the contaminants demonstrated a U-shaped trend. Typically a second order polynomial for the global trend model was used to create the most representative coverage (Whitman, 2010). A second order trend removal was used because of the skewed spatial and temporal dataset - certain areas within the county had lower detections than others. The contaminant detections were lowest towards the coast, the east of the county, and highest throughout the center of the county.

Even though the amount of nitrate detected through the 6-year time range was not statistically significant, there was a seasonal variation pattern of detection amounts within the quarterly averages. The quarterly nitrate detections showed higher concentrations in quarter 2, April, May and June, and quarter 3, July, August, and September (Figure 22 and 23). 


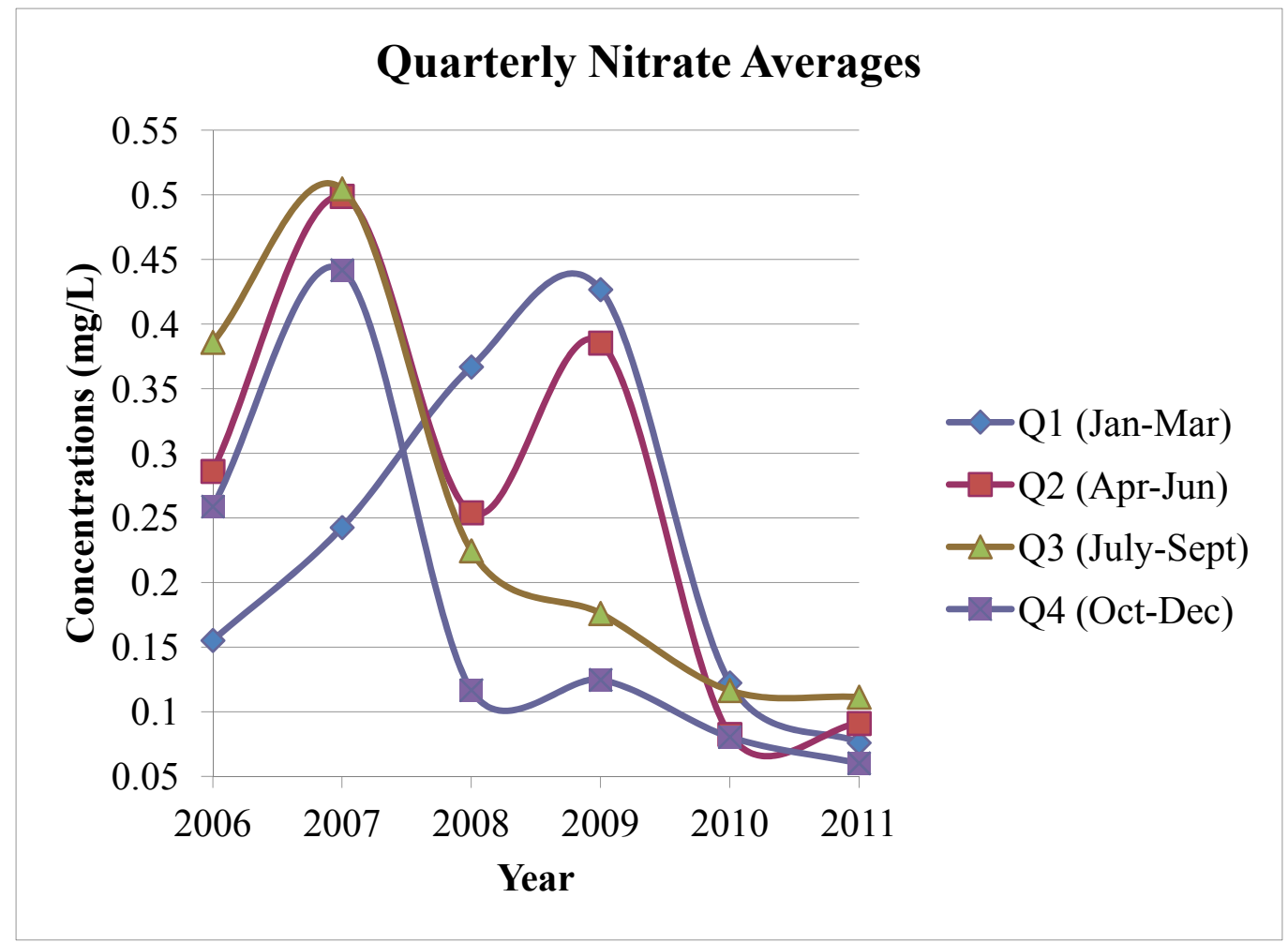

Figure 23: Quarterly Nitrate Concentration Averages (2006 - 2011)

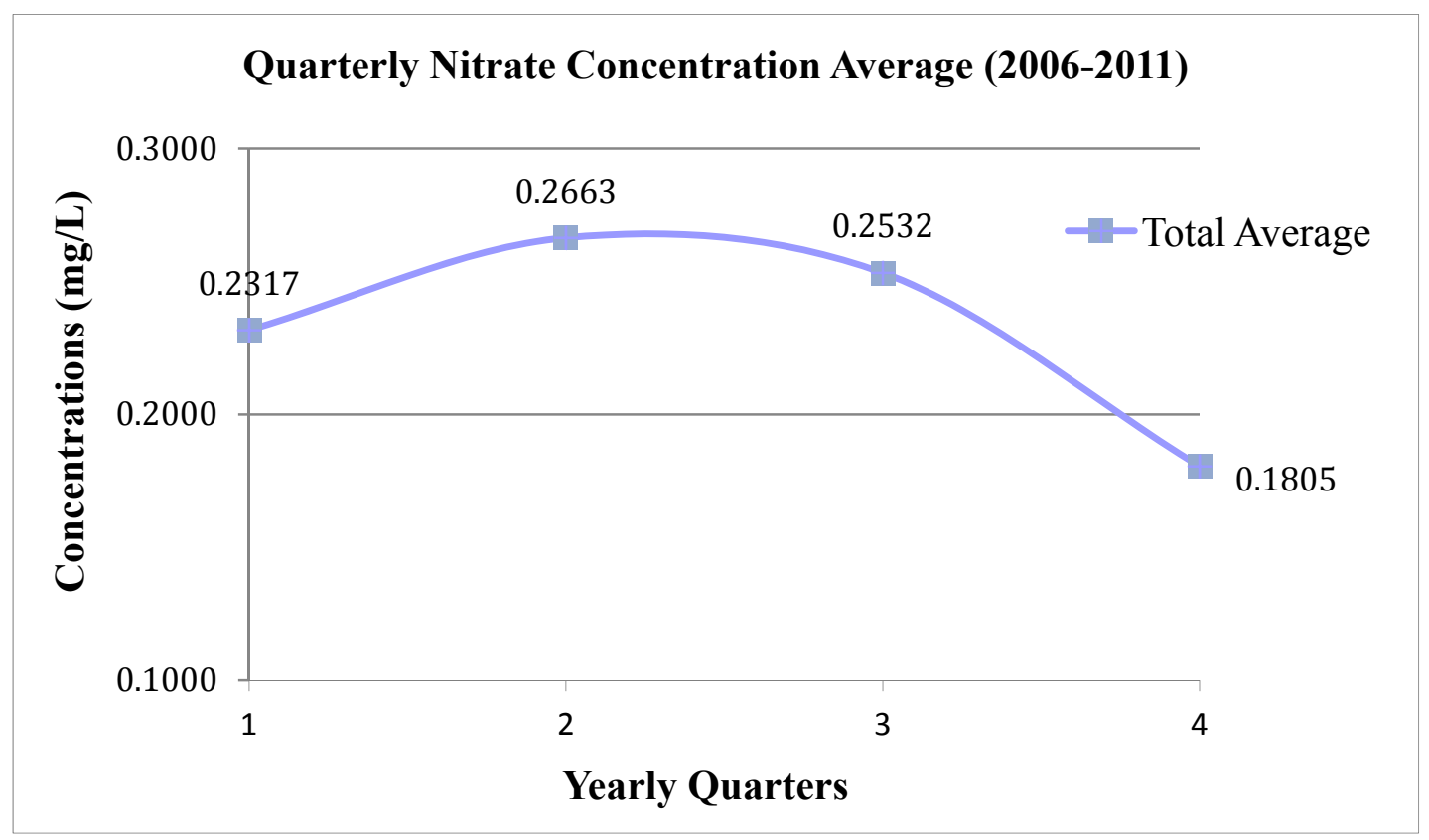

Figure 24: Averaged Quarterly Concentrations for 6-Year Timeframe 
The second and third quarters during the wet season of Florida, consisting of April, May, June, July, August, and September, contained the highest number of contaminant detections $83.33 \%$ of the time. Quarters 1 and 3 had a higher number of detections, which registered higher than the MDL of $0.005 \mathrm{mg} / \mathrm{L}$ (Figure 24 and 25).

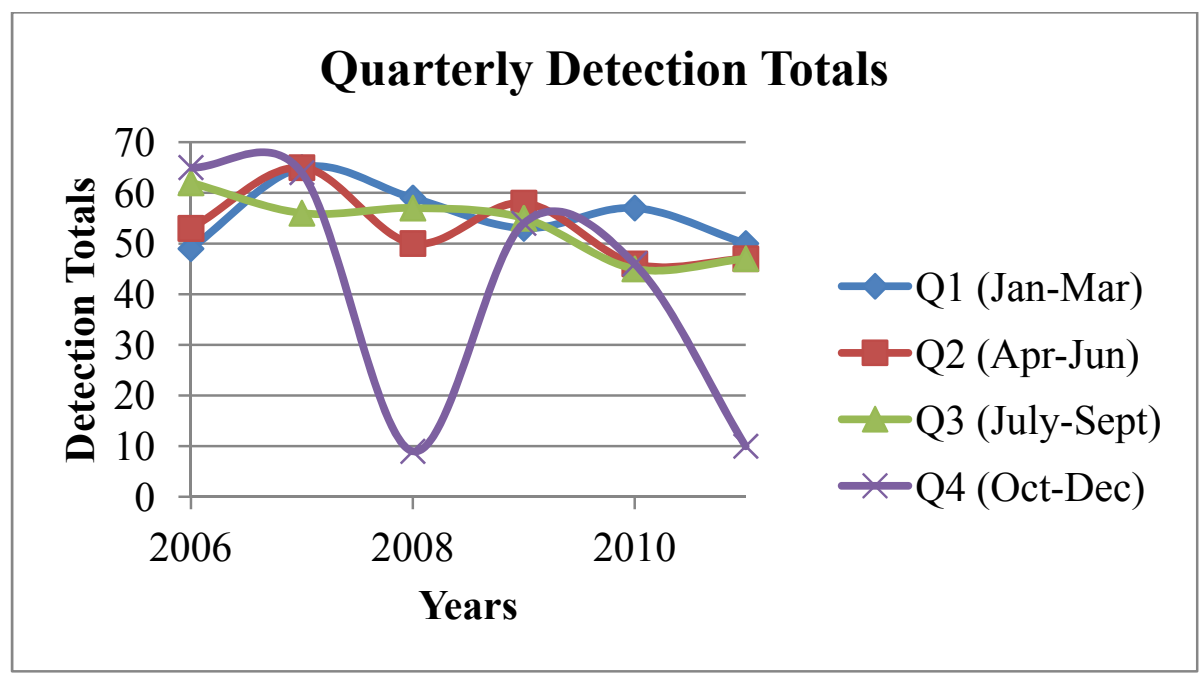

Figure 25: Quarterly Detections Averaged for Nitrate (2006 - 2011)

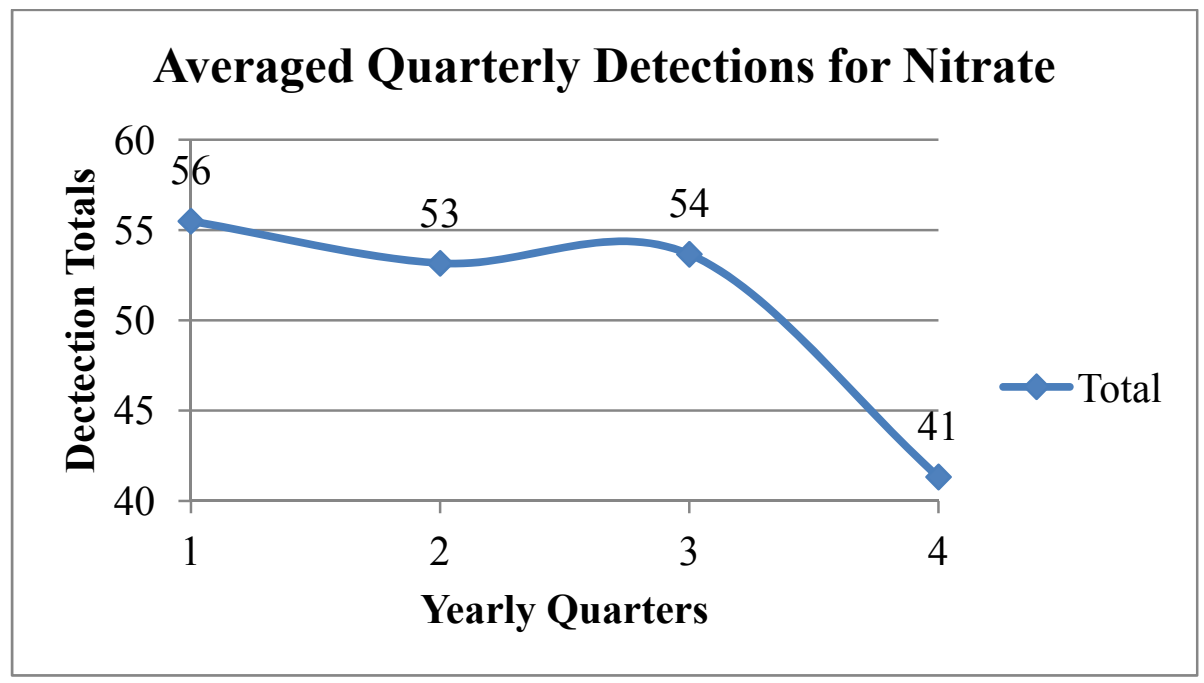

Figure 26: Total Quarterly Detections for Nitrate $(2006$ - 2011) 
The quarterly nitrate coverage maps are included in the appendices in Figures 38 to 43 . The mean quarterly and yearly averages of these years were used in the successive analyses of objectives 1 and 2 .

\subsubsection{Toluene Spatial Concentrations}

The Broward County Well Field Program did not begin testing for toluene until 2007. Despite the lack of monitoring data this contaminant had the second highest number of detection counts in the Broward County monitoring and potable drinking water wells compared to the two other contaminants in this study. Those wells missing toluene concentration data were filled in with the toluene MDL, $0.00009 \mathrm{mg} / \mathrm{L}$, and then the outliers were identified. However, all detections above the MDL would have been considered outliers and all that would have been left in the dataset were the $0.0009 \mathrm{mg} / \mathrm{L}$ MDL for use in the interpolation. The number of detection points was so low each quarter that there were not enough data points to compute an OK interpolation for each yearly quarter. The detections for each quarter were averaged to create a data point containing the average yearly concentration for that monitoring station. Both outliers and MDL were averaged and included in the average yearly concentration dataset. Therefore, this contaminant was only used in objectives 1 and 2 in the development of yearly average vertical change detections across the county.

In the average yearly vertical change detection for 2007 there were 21 detections from the 56 wells that were analyzed for toluene. Six outliers were detected, the removal of which would have made the dataset too small to use with the OK technique. The RMS 
Standardized for this coverage is 0.9674 so the interpolation including all of the polluted wells was generally very reflective of the known contamination points. There were no detections in the center of Broward County surrounding Highway 595. There was one well in each Davie and North Lauderdale (Figure 2) that had a detection greater than $0.002460 \mathrm{mg} / \mathrm{L}$. These wells bordered the area containing no toluene detections causing a U-shaped fit of detection coverage that was reflective of the wells in the North and South with non-minimum concentrations.

In the average yearly vertical change detection for 2008 there were 18 detections from the 56 wells that were analyzed for toluene. Seven outliers were detected, the removal of which would have made the dataset too small to use with the OK technique. The RMS Standardized for this coverage is 1.043 so the interpolation including all of the polluted wells was generally very reflective of the known points of contamination. There were no detections in the middle of Broward County. The Trend Analysis showed that there were contaminants trending in a North-South direction. The analysis also showed a lower amount of contaminant detections trending in an East-West direction surrounded by the higher concentrations in the North-South trending detections. The Davie and North Lauderdale (Figure 2) wells that registered higher levels of toluene in the Y2007 dataset also register high levels in this dataset.

In the average yearly vertical change detection for 2009 there were 10 detections from the 56 wells that were analyzed for toluene. All detections would be considered outliers in this dataset, the removal of which would have made the dataset unusable with the OK 
technique. The RMS Standardized for this coverage is 0.7397 , so the interpolation including all of the polluted wells was generally not very reflective of the known points of contamination. There are four bulls-eye rings in the coverage created by the Kirging interpolation method. They are located in the center (Davie), lower middle region (Pembroke Pines), upper left-hand (Coral Springs), and upper right-hand (Deerfield Beach) portions of the county (Figure 2). Even after outliers were left in the known points the resulting interpolated coverage was not very representative of the known toluene concentrations in Broward County.

In the average yearly vertical change detection for 2010 there were 19 detections from the 56 wells that were analyzed for toluene. Six outliers were detected, the removal of which would have made the dataset too small to be used with the OK technique. The RMS Standardized for this coverage is 0.8966 , so the interpolation including all of the polluted wells was generally not very reflective of the known points of contamination. There were no detections in the northern portion of Broward County, causing a bulls-eye interpolation around a potable well in Plantation (Figure 2). This bulls-eye also connected to the Davie well. The other well detections in those areas were compared to the interpolated concentrations they were correct within $0.0001 \mathrm{mg} / \mathrm{L}$.

In the average yearly vertical change detection for 2011 there were 17 detections from the 56 wells that were analyzed for toluene. Eight outliers were detected, the removal of which would have made the dataset too small to be used with the OK technique. The RMS Standardized for this coverage is 0.8359 , so the interpolation including all of the 
polluted wells was generally not very reflective of the known contamination points.

There were no detections in the northern and southern portions of Broward County.

However, this phenomenon did not cause a bulls-eye interpolation around those potable wells with higher detections in Sunrise, Lauderhill and Fort Lauderdale (Figure 2).

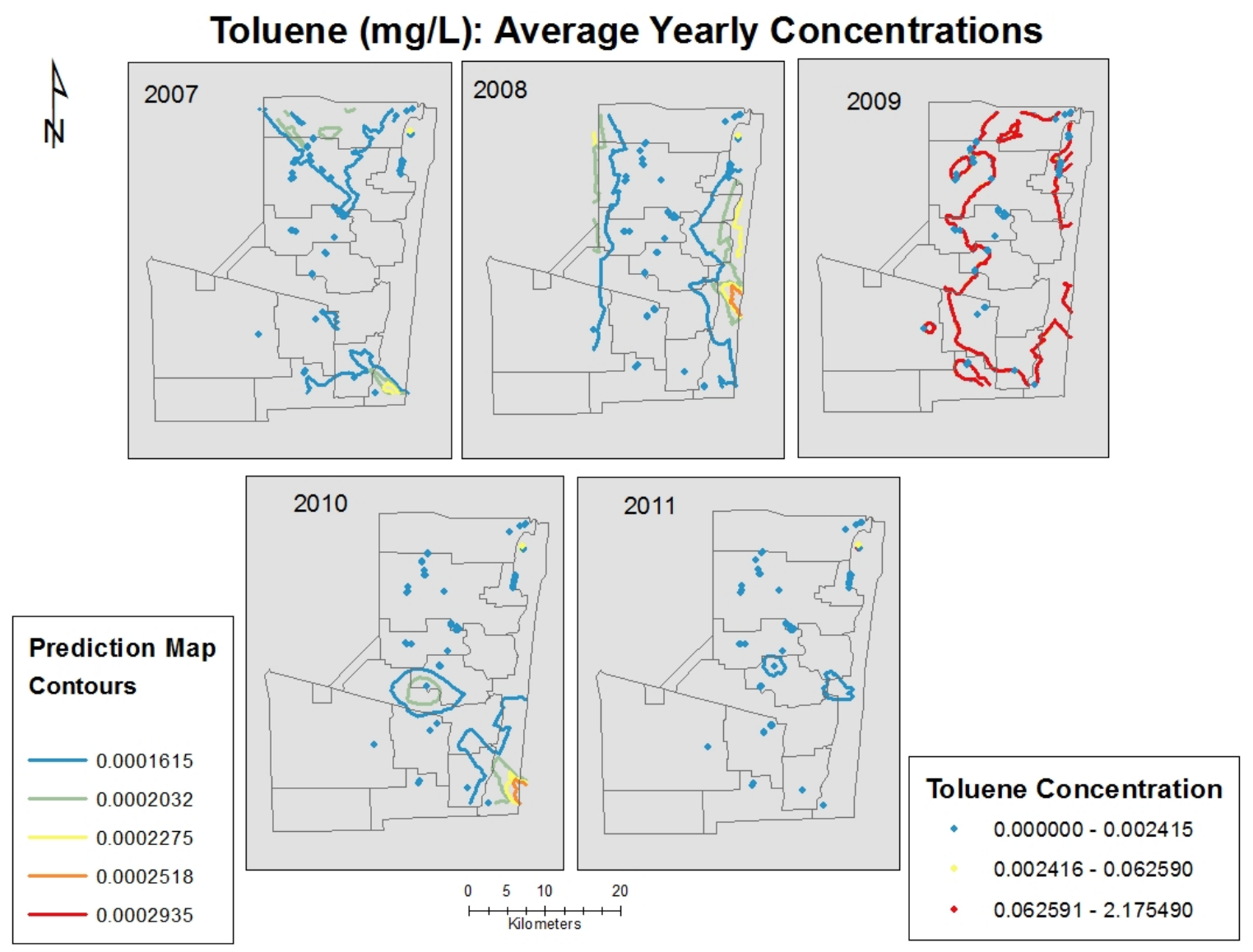

Figure 27: Map of Toluene Interpolation Results 
Table 17: Toluene Interpolation Results

\begin{tabular}{|c|c|c|c|c|c|c|c|c|c|c|}
\hline \multicolumn{11}{|c|}{ Toluene (65 points) } \\
\hline Date & $\begin{array}{c}\text { Total } \\
\text { Points }\end{array}$ & $\begin{array}{c}\text { Minimum } \\
\text { Known }\end{array}$ & $\begin{array}{l}\text { Minimum } \\
\text { Predicted }\end{array}$ & $\begin{array}{c}\text { Maximum } \\
\text { Known }\end{array}$ & $\begin{array}{c}\text { Maximum } \\
\text { Predicted }\end{array}$ & RMS Error & $\begin{array}{c}\text { RMS } \\
\text { Standardized }\end{array}$ & $\begin{array}{c}\text { Average } \\
\text { Standard } \\
\text { Error }\end{array}$ & $\begin{array}{c}\text { Known } \\
\text { Average }\end{array}$ & $\begin{array}{c}\text { Predicted } \\
\text { Average }\end{array}$ \\
\hline Y2007 & 25 & 0.000101 & 0.0002104 & 0.02454 & 7.11200 & 0.00006313 & 0.9222 & 0.00006811 & 0.00133 & -0.01351 \\
\hline Y2008 & 18 & 0.000195 & 0.0001777 & 2.17549 & 7.24600 & 0.00007187 & 1.022 & 0.00007025 & 0.124781 & -0.03025 \\
\hline Y2009 & 10 & 0.000158 & -0.06365 & 0.00209 & 0.01848 & 0.06625 & 0.6784 & 0.03706 & 0.000863 & -0.07699 \\
\hline Y2010 & 19 & 0.000142 & 0.0002403 & 0.014015 & 8.42830 & 2.9055 & 0.9232 & 3.1079 & 0.001194 & 0.0364 \\
\hline Y2011 & 17 & 0.000159 & 0.0002385 & 0.32409 & 7.08410 & 0.00004014 & 0.8359 & 0.00004652 & 0.026615 & -0.003053 \\
\hline
\end{tabular}

These yearly toluene averages possess a SE, NW detection trend. The data did not exhibit a normal distribution in the histogram (it was skewed left) on a Normal QQ Plot.

Therefore, the data was transformed to make it conform to a normal distribution before OK interpolation was implemented. The coverages were generated with a second order polynomial for a global trend model because the semivariogram trended in a South-East and North-East direction across the county. The semivariogram surface indicates that there is a spatial autocorrelation in the data. The directional semivariogram in Geostatistical Analysis can account for the surface trends of the contaminants. The spatial trend was not as strong because there were a low number of clustered data points.

Overarching trends of the toluene detections were that the RMS Standardized was greater than 0.5 and less than $1.580 \%$ of the 5 timeframes. The average standard error was within 0.1 or less of the RMS prediction error $80 \%$ of the timeframes. RMS Standardized for years that the MDL points were taken out was larger than for years that left them in. Even if the MDL points were left in the detected outliers that would have to be removed still caused an RSM Error greater than 1 . 


\subsubsection{Lead Spatial Concentrations}

This dataset was only used to complete objectives 1 and 2. During analysis of the contaminant concentrations of lead the outliers were eliminated from the contaminant detections in the monitoring and potable well data gathered. It became apparent when the outliers were removed before interpolation that there would be too few wells with actual contaminant detections for the $\mathrm{OK}$ to interpolate the points over the large spatial scale of Broward County. In this case these wells with detections were used in conjunction with the seven other vulnerability factors to verify that these are the wells with higher levels of potential vulnerability to pollution in the development of the PVI. The density of detection points was still low enough that the quarters did not have enough data points to compute an $\mathrm{OK}$ interpolation. Therefore, this contaminant was only used in objectives 1 and 2 in the development of yearly average vertical change detections across the county. All seven years registered a potable well in Davie with concentrations greater than the MDL. This well was observed for continuous detections of lead in the PVI analysis map to verify if the high level of lead detection corresponds to the level of well pollution vulnerability over the course of seven years of detection.

In the average yearly vertical change detection for 2006 there were 18 detections from the 84 wells that were analyzed for lead. All detections would be considered outliers in this dataset, the removal of which would have made the dataset unusable with the $\mathrm{OK}$ technique. Therefore the wells having no detections were eliminated and only those wells with quarterly detections were averaged and included in the interpolation coverage for this yearly layer. The RMS Standardized was 1.101 so the interpolation including all of 
the wells registering contaminants was generally very reflective of the detected points of contamination.

In the average yearly vertical change detection for 2007 there were 30 detections from the 84 wells that were analyzed for lead. All detections would be considered outliers in this dataset, the removal of which would have made the dataset unusable with the OK technique. Therefore, the wells having no detections were eliminated and only those wells with quarterly detections were averaged and included in the interpolation coverage for this yearly layer. The RMS Standardized was 1.101 so the interpolation including all of the polluted wells was generally very reflective of the detected points of contamination. There was only one case where one of the potable wells in Davie had a detection level of $0.0070 \mathrm{mg} / \mathrm{L}$ but all other monitoring wells did not register as having anything over the MDL.

In the average yearly vertical change detection for 2008 there were 36 detections from the 84 wells that were analyzed for lead. Sixteen outliers were detected and removed from the dataset. The wells having no detections were eliminated and only those wells with quarterly detections were averaged and included in the interpolation coverage for this yearly layer. The RMS Standardized was 1.041 so the interpolation including all of the polluted wells was generally very reflective of the detected points of contamination. There was only one case located between Lauderhill, North Lauderdale and Pompano Beach where one of the potable wells in each of the three cities caused a definite line of demarcation between the continuous detection coverage. 
In the average yearly vertical change detection for 2009 there were 25 detections from the 84 wells that were analyzed for lead. Of these 25 detections 4 values were eliminated once the outliers were calculated. The wells having no detections were eliminated and only those wells with quarterly detections were averaged and included in the interpolation coverage for this yearly layer. The RMS Standardized was 0.9244 so the interpolation including all of the polluted wells was generally very reflective of the detected points of contamination. There were only two cases between Davie and Margate where there was one potable well in each that had levels of $0.00248 \mathrm{mg} / \mathrm{L}$ and higher. All other monitoring wells and potable wells in the surrounding areas had lower detections; this created a bulls-eye effect in the north and south of the county. However, the interpolated coverage in the east and west of the county is reflective of the well detection values in those areas.

In the average yearly vertical change detection for 2010 there were 25 detections from the 84 wells that were analyzed for lead. Of these 25 detections 9 values were eliminated once the outliers were calculated. The wells having no detections were eliminated and only those wells with quarterly detections were averaged and included in the interpolation coverage for this yearly layer. The RMS Standardized was 0.9485 so the interpolation including all of the polluted wells was generally very reflective of the detected points of contamination. There were only two cases between Davie and Pompano Beach where there was one potable well in each that had levels of $0.05 \mathrm{mg} / \mathrm{L}$ and higher. All other monitoring wells and potable wells in the surrounding areas had lower detections; this created a bulls-eye effect in the middle below Highway 595 in Davie and the northeast in 
Pompano Beach. However, the interpolated coverage in the rest of the county is reflective of the well detection values in those areas.

In the average yearly vertical change detection for 2011 there were 17 detections from the 84 wells that were analyzed for lead. Of these 17 there were no values that were considered outliers. The wells having no detections were eliminated and only those wells with quarterly detections were averaged and included in the interpolation coverage for this yearly layer. The RMS Standardized was 1.0587 so the interpolation including all of the polluted wells was generally very reflective of the detected points of contamination. There was only one case in Davie where there was one potable well in that had detection levels of $0.003120 \mathrm{mg} / \mathrm{L}$. All other monitoring wells and potable wells in the surrounding areas had lower detections; this created a bulls-eye effect in the middle below Highway 595 in Davie. However, the interpolated coverage in the rest of the county is reflective of the well detection values in those areas. 


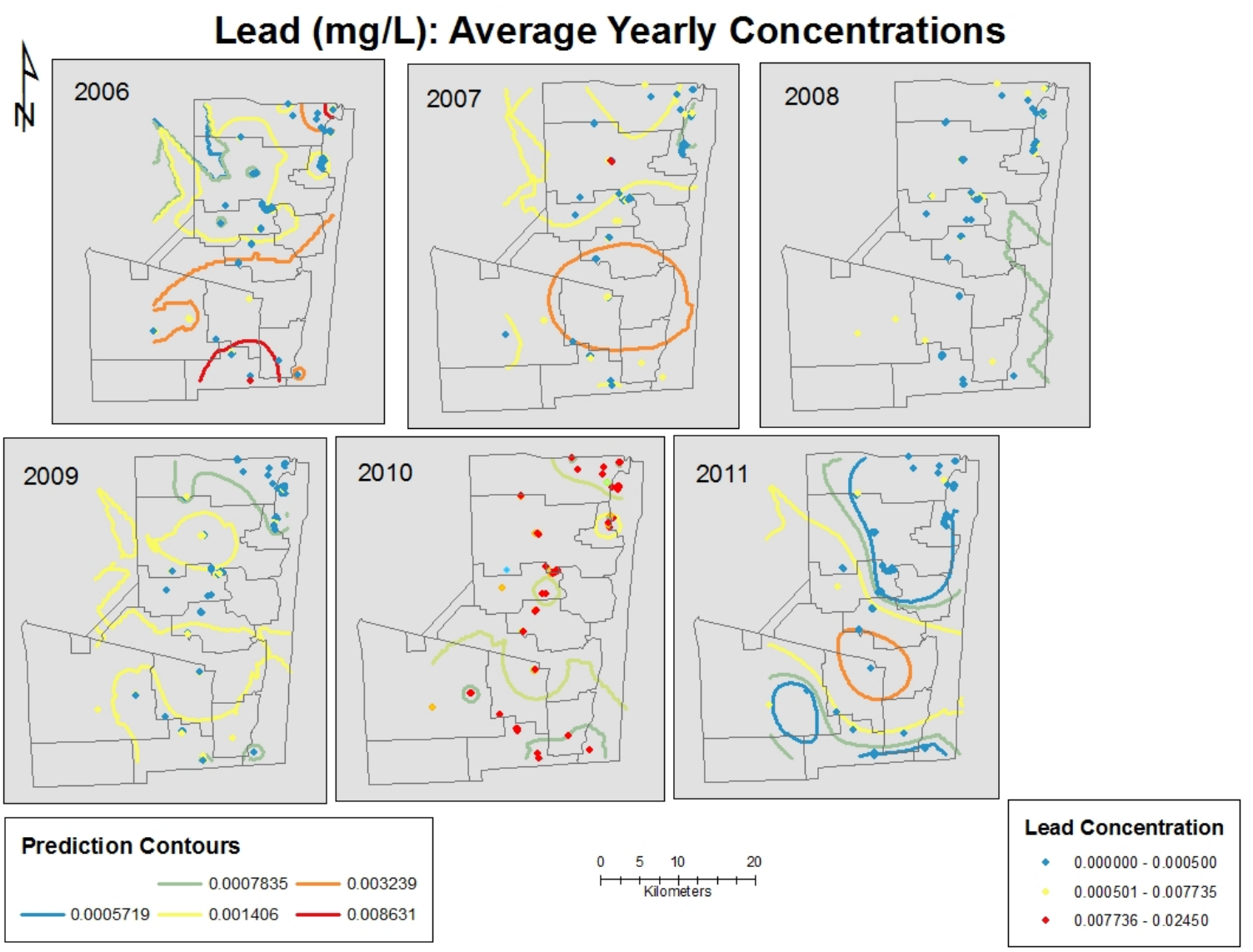

Figure 28: Map of Lead Interpolation Results

Table 18: Lead Interpolation Results

\begin{tabular}{|c|c|c|c|c|c|c|c|c|c|c|}
\hline Date & $\begin{array}{c}\text { Total } \\
\text { Points }\end{array}$ & $\begin{array}{c}\text { Minimum } \\
\text { Known }\end{array}$ & $\begin{array}{c}\text { Minimum } \\
\text { Predicted }\end{array}$ & $\begin{array}{c}\text { Maximum } \\
\text { Known }\end{array}$ & $\begin{array}{c}\text { Maximum } \\
\text { Predicted }\end{array}$ & RMS Error & $\begin{array}{c}\text { RMS } \\
\text { Standardized }\end{array}$ & $\begin{array}{c}\text { Average } \\
\text { Standard } \\
\text { Error }\end{array}$ & $\begin{array}{c}\text { Known } \\
\text { Average }\end{array}$ & $\begin{array}{c}\text { Predicted } \\
\text { Average }\end{array}$ \\
\hline Y2006 & 18 & 0.000501 & 0.0007147 & 0.0245 & 0.011660 & 0.007971 & 1.09653 & 0.006604 & 0.003784 & 0.0004701 \\
\hline Y2007 & 30 & 0.000825 & 0.0006201 & 0.016225 & 0.002229 & 0.002118 & 1.0129 & 0.001995 & 0.003437 & 0.02944 \\
\hline Y2008 & 32 & 0.00055 & 0.0006053 & 0.01185 & 0.001167 & 0.001107 & 1.0552 & 0.001044 & 0.002355 & -0.00002774 \\
\hline Y2009 & 22 & 0.000735 & 0.0005532 & 0.004015 & 0.001614 & 0.001262 & 0.9298 & 0.001268 & 0.002128 & 0.02919 \\
\hline Y2010 & 26 & 0.000505 & 0.0005622 & 0.08725 & 0.001374 & 0.0007802 & 0.9484 & 0.0007858 & 0.007861 & 0.01735 \\
\hline Y2011 & 17 & 0.000623 & 0.0003686 & 0.000623 & 0.002579 & 0.001327 & 1.0587 & 0.001037 & 0.008005 & -0.1236 \\
\hline
\end{tabular}


Overarching trends of the toluene detections were that the RMS Standardized was greater than 0.5 and less than 1.5 in $100 \%$ of the 6 timeframes. The average standard error was within 0.1 or less of the RMS prediction error in $100 \%$ of the timeframes.

\subsection{Area of Interest Temporal Concentrations}

A lateral and vertical model was to be created of the detected contaminants within an AOI representative of the different land use of the county. However, there was not enough data points to complete the $\mathrm{OK}$ interpolation for quarterly nitrate, toluene, and lead chemicals, nor the yearly average toluene and lead maps. There were enough data points to model the three different vertical layers of average yearly nitrate detections. Figures 29, 30, and 31 demonstrate the surface, shallow, and deep nitrate AOI interpolation results.

The yearly average surface $(-5 \mathrm{ft})$ coverages for the 6 timeframes have an average standard error close to RMS prediction error within 0.01 units. Additional trends of the nitrate detection coverage were that the RMS Standardized was greater than 0.5 and less than 1.5 in $100 \%$ of the 6 timeframes. The yearly average standard error was within 0.1 or less of the RMS prediction error in $100 \%$ of the timeframes. However, in 9 of the quarterly timeframes $25.71 \%$ of the surface layers had an RMS Standardized greater than 1.1 and $8.57 \%$ (3 total) had an RMS Standardized less than 0.900. All 8 of the 2010 and 2011 quarterly surface layers had interpolated surfaces with RMS Standardized greater 
than 1.5. Therefore, the quarterly timeframes were not accurate representations of the known quarterly nitrate detections.

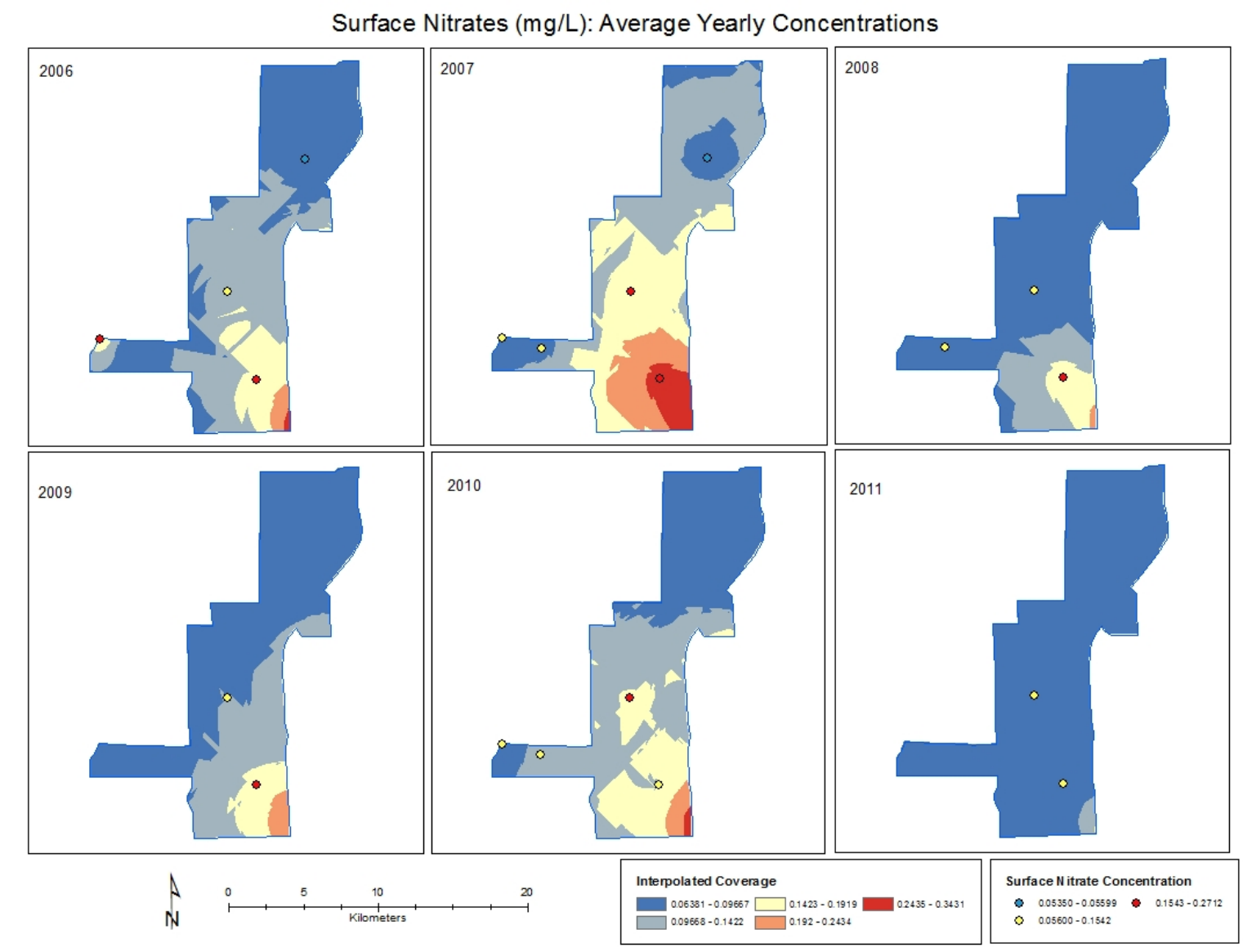

Figure 29: Map of Surface Nitrate AOI Interpolation Results

The yearly average shallow (-15 ft) coverages for the 6 timeframes have an average standard error close to RMS prediction error within 0.4 units. Additional trends of the nitrate detection coverage were that the RMS Standardized was greater than 0.5 and less than 1.5 in $100 \%$ of the 6 timeframes. The yearly average standard error was within 0.1 or less of the RMS prediction error in $83.33 \%$ of the 6 timeframes. However, in 14 of the 
quarterly timeframes $40 \%$ of the shallow layers had an RMS Standardized greater than 1.1 and $2.85 \%$ ( 1 total) had an RMS Standardized less than 0.900 . Three of the quarterly surface layers had interpolated surfaces with RMS Standardized greater than 3 . Therefore, the quarterly timeframes were not accurate representations of the known quarterly nitrate detections.

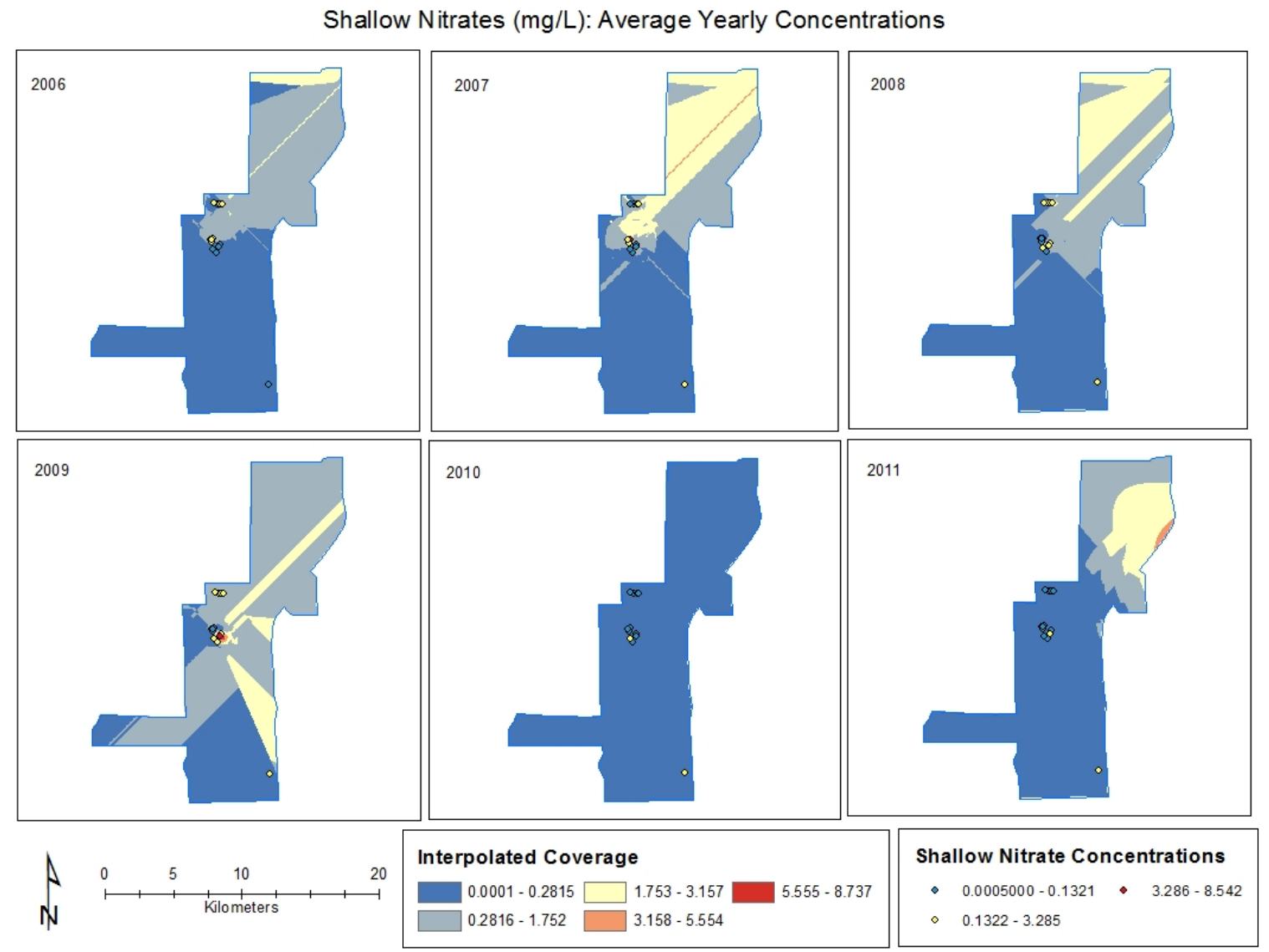

Figure 30: Map of Shallow Nitrate AOI Interpolation Results

All of the yearly average deep (-60 to $-202 \mathrm{ft}$ ) coverages have an average standard error and an RMS prediction error that are greater than 0.01 units of each other. Additional trends of the nitrate detection coverage were that the RMS Standardized was greater than 1.5 in $100 \%$ of the 5 timeframes. The yearly average for $22.85 \%$ ( 8 total timeframes) had 
an RMS Standardized greater than 2. However, 54.28\% (19 total timeframes) of the quarterly deep layers had an RMS Standardized greater than 1.1 and 2.85\% (1 timeframe) had an RMS Standardized less than 0.900. Therefore, it was determined that both the quarterly and yearly timeframes were not accurate representations of the known quarterly nitrate detections.

Deep Nitrates (mg/L): Average Yearly Concentrations

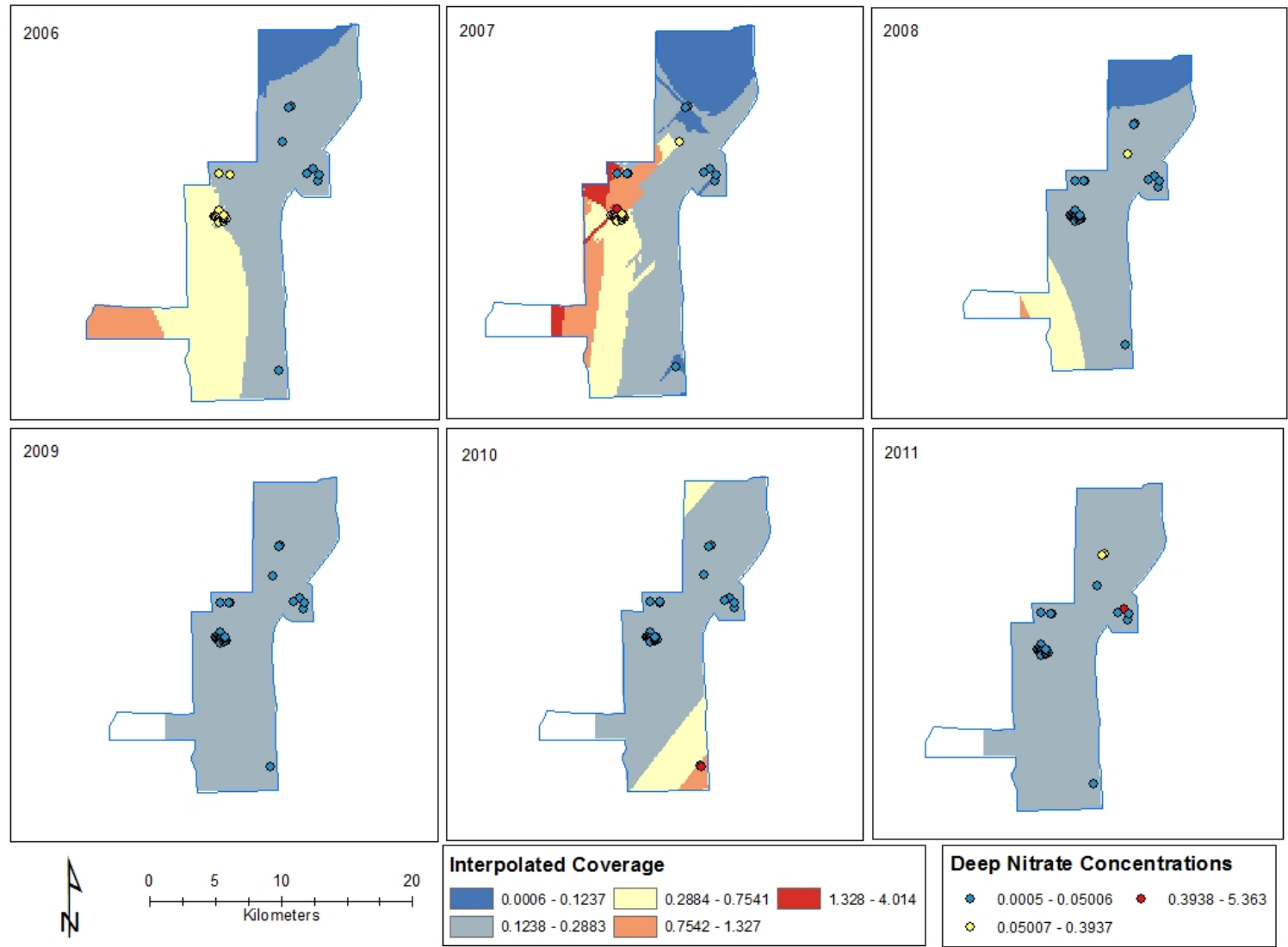

Figure 31: Map of Deep Nitrate AOI Interpolation Results 
Table 19: Nitrate AOI Interpolation Results

\begin{tabular}{|c|c|c|c|c|c|c|c|c|c|c|}
\hline \multicolumn{11}{|c|}{ AOI Nitrate } \\
\hline Date & \begin{tabular}{|c|} 
Total \\
Points, \\
Excluding \\
MDL \\
\end{tabular} & $\begin{array}{c}\text { Minimum } \\
\text { Known }\end{array}$ & $\begin{array}{l}\text { Minimum } \\
\text { Predicted }\end{array}$ & $\begin{array}{l}\text { Maximum } \\
\text { Known }\end{array}$ & $\begin{array}{c}\text { Maximum } \\
\text { Predicted }\end{array}$ & RMS & $\begin{array}{c}\text { RMS } \\
\text { Standardized }\end{array}$ & $\begin{array}{c}\text { Average } \\
\text { Standard } \\
\text { Error }\end{array}$ & $\begin{array}{l}\text { Known } \\
\text { Average }\end{array}$ & $\begin{array}{c}\text { Predicted } \\
\text { Average }\end{array}$ \\
\hline \multicolumn{11}{|c|}{ Surface (5 points), $-5 \mathrm{ft}$} \\
\hline Y2006 & 5 & 0.03375 & -0.02704 & 0.204 & 0.3171 & 0.08248 & 0.9122 & 0.09214 & 0.1172 & 0.04659 \\
\hline Y2007 & 5 & 0.0535 & -0.05648 & 0.27125 & 0.334 & 0.08348 & 0.9509 & 0.08996 & 0.1291 & 0.039478 \\
\hline Y2008 & 5 & 0.04525 & 0.0135 & 0.17425 & 0.1686 & 0.05407 & 1.004824 & 0.05309 & 0.09195 & 0.04316 \\
\hline Y2009 & 5 & 0.0135 & -0.05993 & 0.1575 & 0.2214 & 0.06924 & 1.06382 & 0.06497 & 0.077775 & 0.05334 \\
\hline Y2010 & 5 & 0.047 & -0.06891 & 0.1672 & 0.3076 & 0.08712 & 1.06311 & 0.08079 & 0.1146 & 0.05166 \\
\hline Y2011 & 5 & 0.01162 & 0.002864 & 0.0875 & 0.1106 & 0.04454 & 1.1412 & 0.0395 & 0.04057 & 0.04454 \\
\hline \multicolumn{11}{|c|}{ Shallow, $\mathbf{- 1 5 f t}$} \\
\hline Y2006 & 9 & 0.021 & 0.009348 & 2.8005 & 1.9661 & 1.2465 & 0.9606 & 1.3304 & 1.0313 & 0.06233 \\
\hline Y2007 & 9 & 0.078 & 0.009348 & 8.2405 & 1.9661 & 1.2465 & 0.9606 & 1.3304 & 1.2904 & 0.06233 \\
\hline Y2008 & 10 & 0.078 & 0.0005 & 2.5155 & 2.3197 & 2.4759 & 0.8639 & 2.9614 & 0.8414 & 0.1289 \\
\hline Y2009 & 9 & 0.1855 & -0.02208 & 8.542 & 7.5902 & 2.03385 & 1.01973 & 2.8065 & 1.5947 & 0.05368 \\
\hline Y2010 & 4 & 0.02175 & 0.0004131 & 0.293 & 0.1988 & 0.1233 & 1.1715 & 0.09428 & 0.1461 & -0.002946 \\
\hline Y2011 & 5 & 0.008 & -1.3807 & 0.2255 & 0.4751 & 1.02363 & 1.8856 & 0.5246 & 0.0878 & -0.2951 \\
\hline \multicolumn{11}{|c|}{ Deep (26 points), -60 to $-202 \mathrm{ft}$} \\
\hline Y2006 & 22 & 0.00825 & -0.1441 & 0.733 & 1.4392 & 0.50714 & 1.34749 & 0.32721 & 0.2017 & 0.1581 \\
\hline Y2007 & 17 & 0.00975 & -0.8156 & 5.363 & 4.01428 & 1.026875 & 4.63233 & 0.188308 & 0.587779 & 0.2233 \\
\hline Y2008 & 2 & 0.000575 & -0.2178 & 0.1865 & 0.8614 & 0.4167 & 2.43132 & 0.09159 & 0.187075 & -0.03567 \\
\hline \multicolumn{11}{|l|}{ Y2009 } \\
\hline Y2010 & 10 & 0.00675 & -0.2096 & 1.6155 & 0.4371 & 0.12208 & 1.75635 & 0.0507406 & 0.18315 & 0.07739 \\
\hline Y2011 & 4 & 0.008 & 0.0005 & 0.5875 & 0.1659 & 0.14753 & 1.51437 & 0.0695726 & 0.17775 & 0.01579 \\
\hline
\end{tabular}

The overarching nitrate spatiotemporal trends within the AOI demonstrate that the majority of nitrate detections are located on the surface and in the deeper portions of the aquifer environment. The interpolated surface, shallow, and deep interpolation coverage layers are not very representative of the observed well points within the AOI as demonstrated by the RMS Standardized, RMS, and average standard error final reports. 
The predicted versus measured scatter plot was also less than 45 degrees in all quarterly and yearly timeframes. However, the separation of the individual points demonstrates the actual movement of real time data through the different levels of the aquifer environment. This is demonstrated through the surface to deep coverages from 2006 to 2007: the movement of nitrate through the aquifer is seen in the higher detection points at these two depths of the aquifer environment. The movement of nitrates through the shallow, monitoring well, coverage is demonstrated through the widest range of detections yet is representative of the least number of total detections. These laterally separated individual points within the aquifer allow for greater understanding of the relationship between contaminant concentration and well depth and are further studied within the spatiotemporal correlation graphs.

\subsection{Spatiotemporal Correlation Graphs}

The nitrate detection was at the MDL for most of the monitoring wells across the county for all three depths studied. Figure 27 depicts the distribution range of nitrate concentrations based on well depth and well field location. The outliers were removed from these datasets in the interpolation process. There were 89 points in total that were included in this relationship scatterplot. Of these detection locations 44 were located in surface, at $-5 \mathrm{ft}$, water bodies the detections ranged from 0.0147 to $0.3257 \mathrm{mg} / \mathrm{L}$. The 16 monitoring wells tested, at -15 feet, detected nitrates ranging from 0.0005 to 1.8748 $\mathrm{mg} / \mathrm{L}$. The 29 potable wells detected nitrates ranging from 0.0005 to $0.952 \mathrm{mg} / \mathrm{L}$. As

demonstrated from the previous section the widest range comes from the shallow well 
layer, but contains the least number of well detections. The surface wells contain the most concentrated, and lowest, range of nitrates yet the total number of detections is the greatest of the three depths. The deep wells contain a concentrated density of lower range nitrate detections as well as sporadic nitrate detections at higher ranges. It is shown that the contaminant concentrations increased with increasing well depth but total detections decreased in frequency with increasing well depth. These trends indicate that the nitrates are coming from the surface and filtrating throughout the aquifer towards aquifer depths between -80 feet to -135 feet.

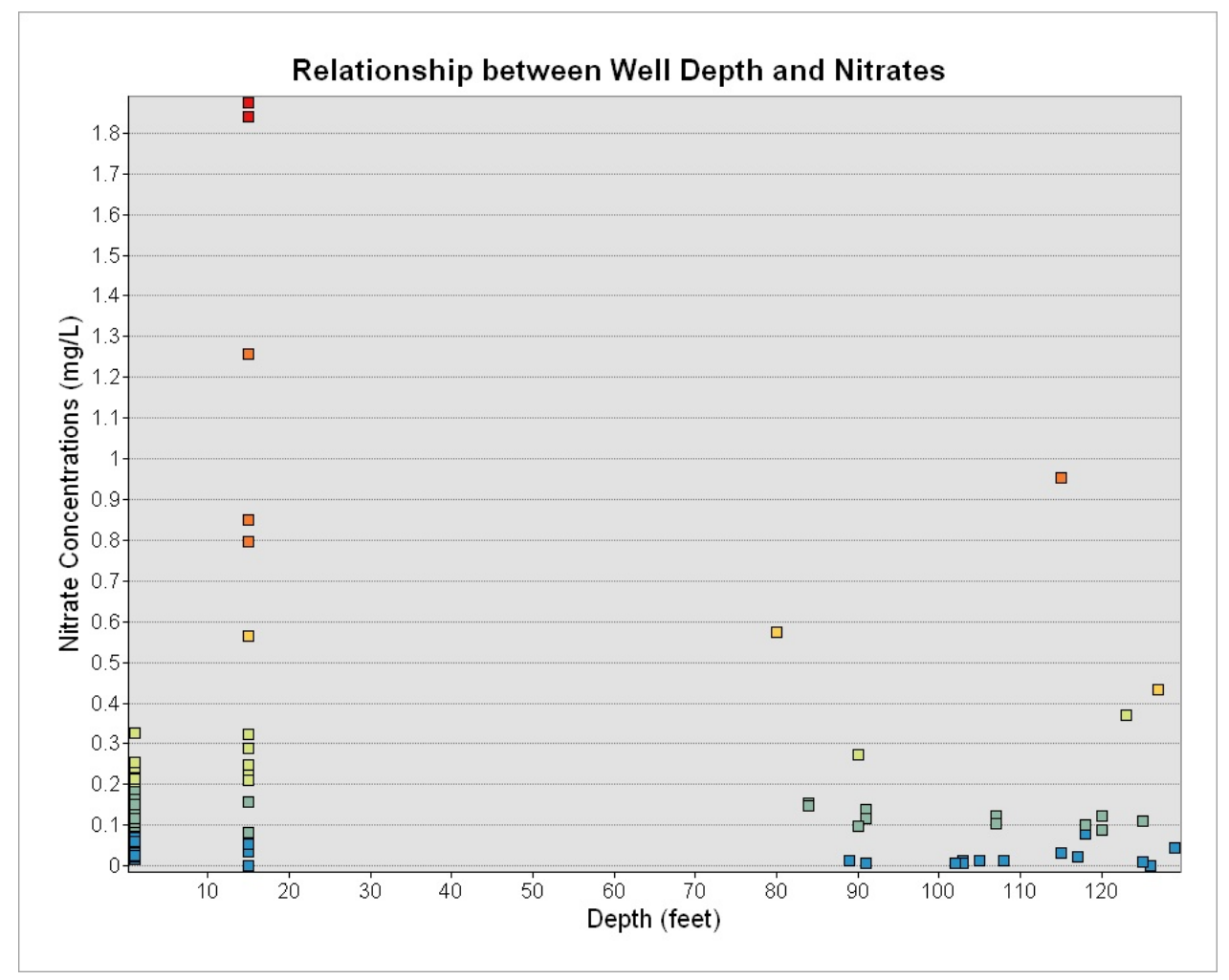

Figure 32: Nitrate well location, depth and concentration relationship 


\subsection{Pollution Vulnerability Index Map}

This section is used to analyze the PVI by calculating which vulnerability factors have an influence on the vulnerability of potable drinking waters wells in Broward County. Direct observation of contaminants in ground water provides the most conclusive results when evaluating ground water vulnerability to pollution. However, in this case, there is not sufficient density of contaminant observations to develop a countywide vulnerability assessment. Therefore, the contaminant with the most observations in drinking water wells, nitrate, throughout Broward County was incorporated into an index method for pollution vulnerability assessment. For the contaminant a relationship graph (Figures 3032) have been developed to determine if there is a significant correlation between the contaminants and the final PVI map. The six categories of vulnerability factor data are depth to water table, recharge (hydrology), aquifer media, soil media (incorporating precipitation), impact to vadose zone, and aquifer conductivity (incorporating well radii and depth).

\subsubsection{Parameter Impact on Pollution Vulnerability Index}

The different factors obtained for the index method are those that are applicable over a large spatial region. For each raster (excluding the contaminate layers which will remain in point format for the relationship graph) each vulnerability factor was rated 1 to 5 .

Vulnerability scores associated with each raster cell for each vulnerability factor was rank correlated to contaminant concentrations in ground water to determine if the final index map correlates with observed data. Of the 6 vulnerability categories it was determined 
that 3 of them influenced the largest spatial area of the county map and contributed the most points to the final output of the PVI map. A summary of the 3 categories with the greatest influence, contributed greater than 40 points, to the final PVI are shown in this subsection.

The first category with the greatest influence on the final PVI map is depth to water table. Approximately $66.82 \%$ of the coverage layer has a PVI contribution of 50 . The highest contribution is centered in the western portion of the county, ranging from the Everglades and ending roughly 5000 meters inland from the ocean. The western portion of the county has a higher water table than the area running along the coastline. The western portion has the shallowest depth to water ranging from -0.3048 to -0.9144 feet while the eastern portion ranges from -1.219 to -13.41 feet. This leads to a greater chance for contaminant infiltration to occur as the depth to water decreases because shallow water levels infer longer contaminant travel times. This aquifer feature determines depth of material or distance through which a contaminant must travel before reaching the aquifer. The greater the distance the contaminant has to travel the greater the opportunity for attenuation to occur or restriction of movement by relatively impermeable layers. The center of the county has the shallowest depth to water and the highest vulnerability potential for pollution.

The second category with the greatest influence on the final PVI map is impact to vadose zone. Approximately $57.63 \%$ of the coverage layer has a PVI contribution of 50 points. 
The highest contribution is centered in the west of the county ending 11,000 meters from the ocean.

The third category with the greatest influence on the final PVI map is recharge. Approximately $99.92 \%$ of the coverage layer has a PVI contribution of 32 points. The highest contribution is centered in the southwest and northeast portions of the county and is based on the greater $\mathrm{CN}$ in existence throughout those parts of the county. The high residential and urban land use coverages had a positive correlation with the increased the nitrate concentrations over time. The higher rank value is also associated with coarser soil which is indicative of a higher infiltration pattern from the surface. The higher precipitation, during May through October, leads to greater runoff volume and increases the chances for infiltration as well. The lower quarterly variance in total rainfall, uniform rainfall, during those months also favors increased infiltration. The larger average rainfall is associated with increased infiltration and therefore a higher rank value for $\mathrm{CN}$.

The fourth category with influence on the final PVI map is aquifer media. Approximately $53.66 \%$ of the coverage layer has a PVI contribution of 30 points. The highest contribution is located along the eastern coastline of the county and spans the area nearly 15,000 meters inland.

The fifth category with influence on the final PVI map is conductivity. The largest output contribution for this layer is found at 24 points. However, the majority $(71.31 \%)$ of the layer is point level 6 and therefore this category does not have one of the largest impacts 
on the final PVI map. There are bulls eye structures spaced randomly throughout the county containing the highest points. However, this setup is not detectable on the final PVI output map.

The sixth category with influence on the final PVI map is soil media. Approximately $33.31 \%$ of the layer coverage contains a contribution of 20 points, $35.37 \%$ at 18 points, and 23.89 at 4 points. The highest contribution ranges across the county from east to west respectively. The HSG of the soil and the $\mathrm{CN}$ of the land use were both used to determine how these surface variables may affect the overall vulnerability of the aquifer. As demonstrated over the 6 year timeframe, there was an increase in impervious surface cover, increasing runoff potential, infiltration, and pollution vulnerability, due to the escalation of urbanization. The largest point coverage also contained coarse soil and udorthents, which are drastically disturbed soils, making those regions highly vulnerable to pollution.

The output of the PVI model reveals that in the southwest of the county is under high vulnerability and the northern portion of the county is classified in the low range of medium vulnerability. Along the coastline lies the majority of very high vulnerability classification and the water bodies in that area are also classified as medium vulnerability. Those categories that most affected the final PVI were those that contributed an output greater than 30 for more than $55 \%$ of the county coverage. The largest 2 contributors to the vulnerability index are the highest in the west of the county while the third largest contributor is located in the east of the county. The PVI categories 
that had the most influence on the final index range were located in the surface and deeper layers of the Biscayne Aquifer environment.

Table 20: Pollution Vulnerability Level by Area

\begin{tabular}{|c|c|c|c|}
\hline PVI Range & Area $\left.\mathbf{~ m}^{\mathbf{2}}\right)$ & Percentage & Vulnerability Level \\
\hline $38-56$ & 577800 & $0.05244 \%$ & \multirow{2}{*}{ Low } \\
\hline $57-74$ & 1604700 & $0.1456 \%$ & \\
\hline $77-92$ & 171618700 & $15.57 \%$ & \multirow{2}{*}{ Medium } \\
\hline $94-110$ & 134513600 & $12.21 \%$ & \\
\hline $111-128$ & 515288600 & $46.76 \%$ & \multirow{2}{*}{ High } \\
\hline $129-146$ & 157721800 & $14.32 \%$ & \multirow{2}{*}{ Very High } \\
\hline $147-164$ & 110289700 & $10.01 \%$ & \multirow{2}{*}{} \\
\hline $166-182$ & 10162300 & $0.9224 \%$ & \\
\hline
\end{tabular}




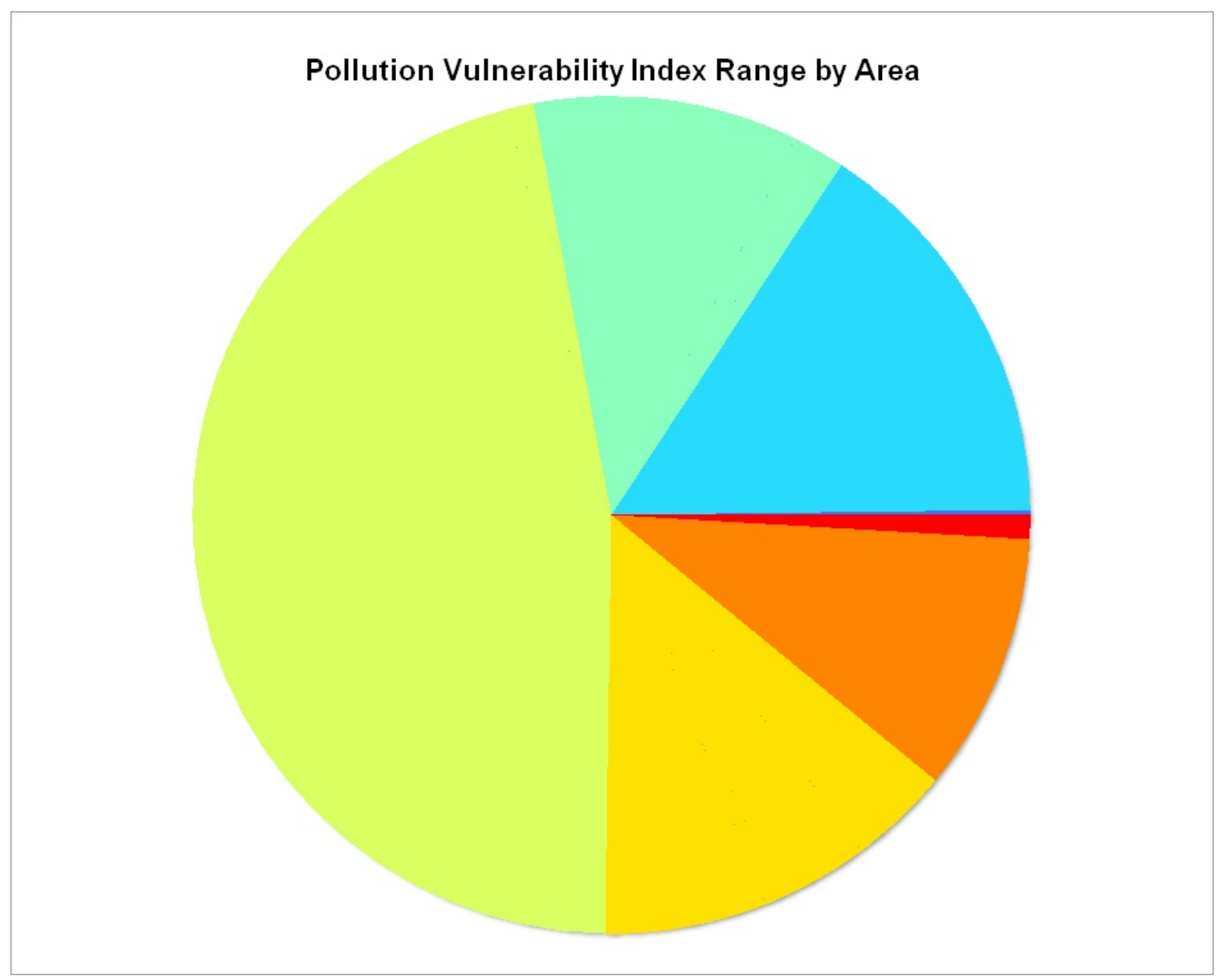

Figure 33: Pie Chart of Pollution Vulnerability by Area, Refer to Figure 34 for Legend PVI Colors 


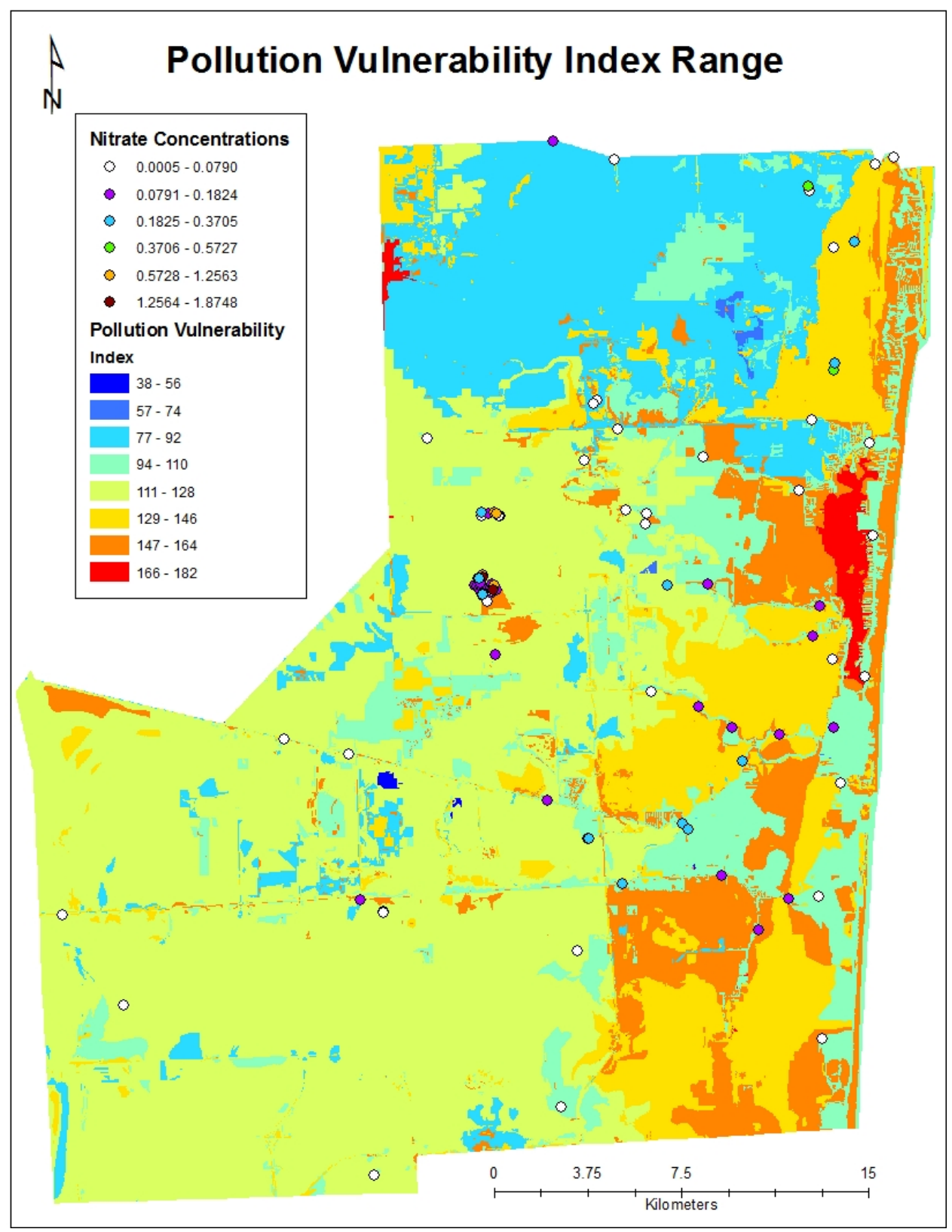

Figure 34: Map of PVI Range

\subsubsection{Validation of Output Pollution Vulnerability Index Model}

In this section the validation of the final output for the PVI model is discussed through cross correlation relationship graphs. Figure 29 demonstrates correlating facility source 
code versus PVI range. In determining the validity of the DRASTIC model potential sources of pollution must be taken into consideration. Contaminant detections in this study have directionality to them, influenced by the groundwater flow directions as well as through the use of certain contaminants at facilities within the well field. In many cases the facility SI indicates where contaminants are potentially originating. Figure 29 shows source code 1 as high pollution potential, source code 2 as medium pollution potential, and source code 3 as low pollution potential.

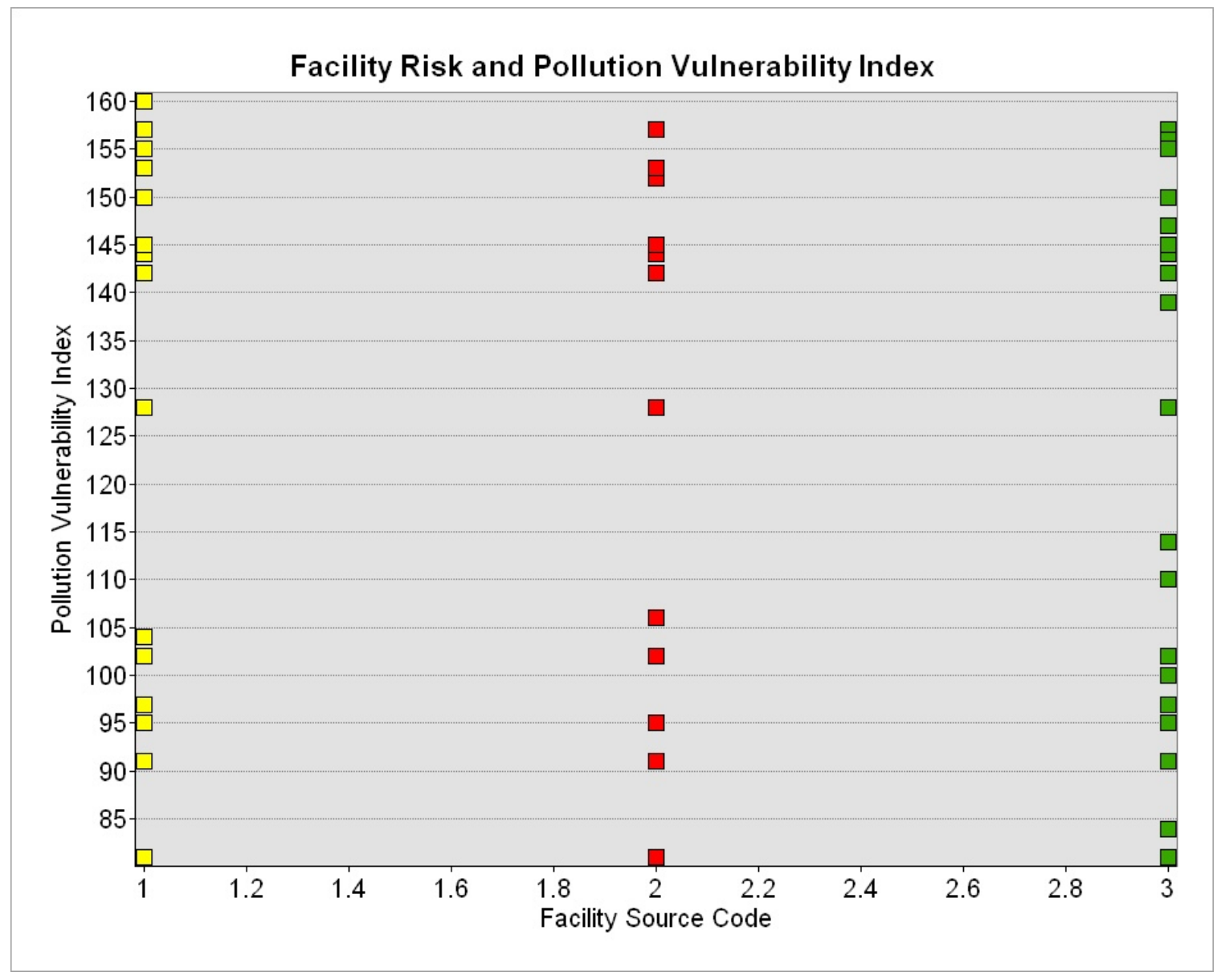

Figure 35: Facility Source and PVI Correlation 
The observed lead and toluene raw data detection points are not sufficient to develop lateral (surface, shallow, and deep) layers. However, the wells that are continuously showing those contaminants were be used in the PVI developed from the six vulnerability categories based on their weighted rank value averages. Those shallow and deep wells that continuously display toluene and lead detections are used to verify if the PVI maps are functioning properly. The contaminant layers, using known field values, are used to validate the accuracy of the PVI. The known field values are also used to determine which vulnerability factors are significant based on the higher observed concentrations in ground water versus the higher vulnerability ratings for the six different vulnerability factors.

The three different yearly contaminant detection concentrations versus the PVI range demonstrated that although there were clusters of matching data there is no correlation representing the entirety of the spatial area covered by the pollution vulnerability map. The interpolation of regional data using geostatistics, the transformation of pollutant contaminant data from vector to raster format, and the process of classifying significant pollutant categories and assigning rates and weights to each range of the factor can result in a final outcome index that may not be representative of the study area. This opportunity for integrating parameters into ranges for the PVI is where the breakdown of detailed information takes place even though the real time data of nitrate, lead, and toluene has a positive correlation with the groundwater PVI (Thirumalaivasan, 2003). The lower concentrations of contaminants were clustered below the index value of 125 , indicating that the aquifer is at low risk in that location. The upper concentration 
detections of the contaminants were all correlated with an index value greater than 125 .

Despite this correlation, a large number of non-detects, or MDL, for each well also contributed to the low numbers of significant correlations between the contaminant detections and the PVI.

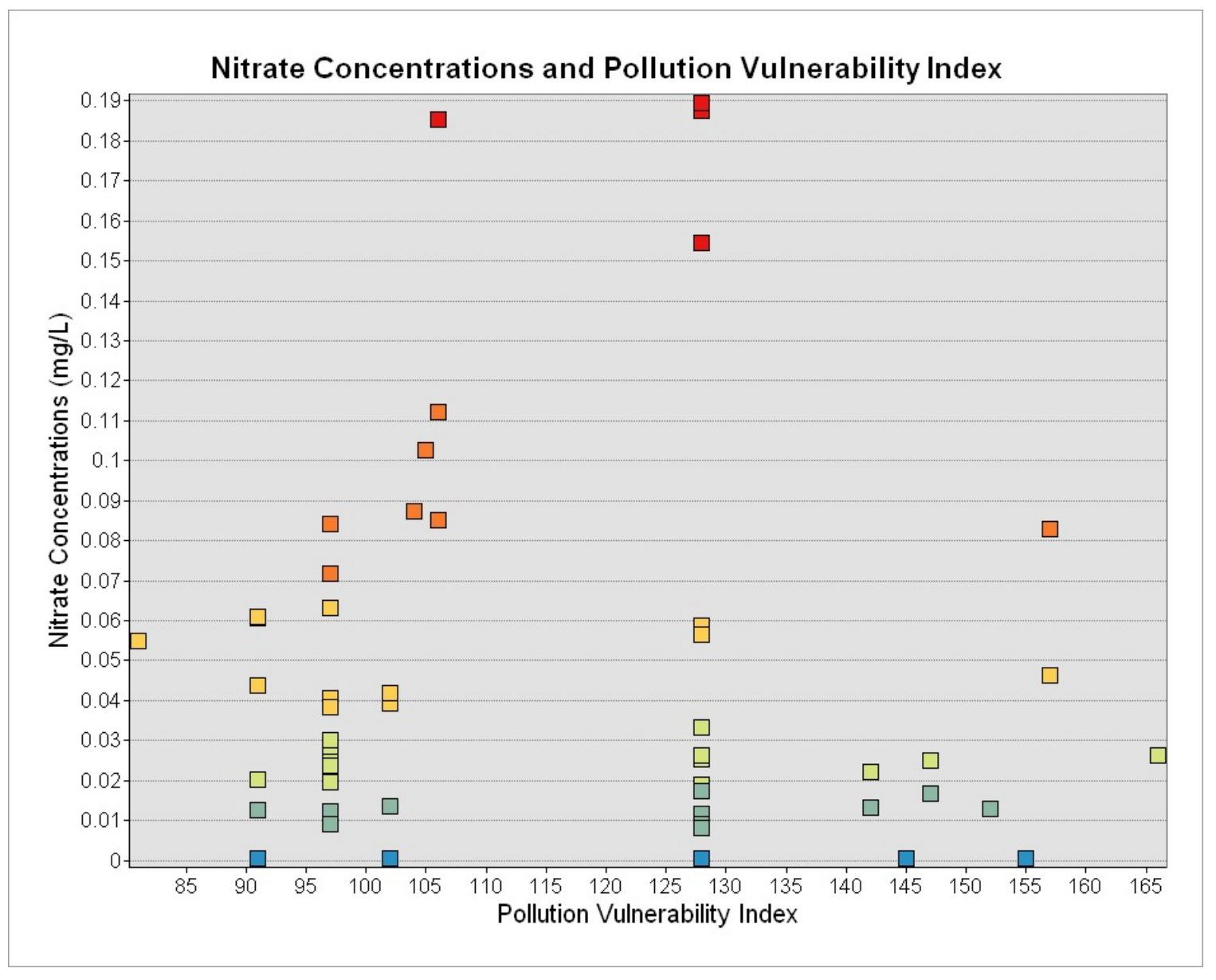

Figure 36: PVI and Nitrate Detection Correlation 


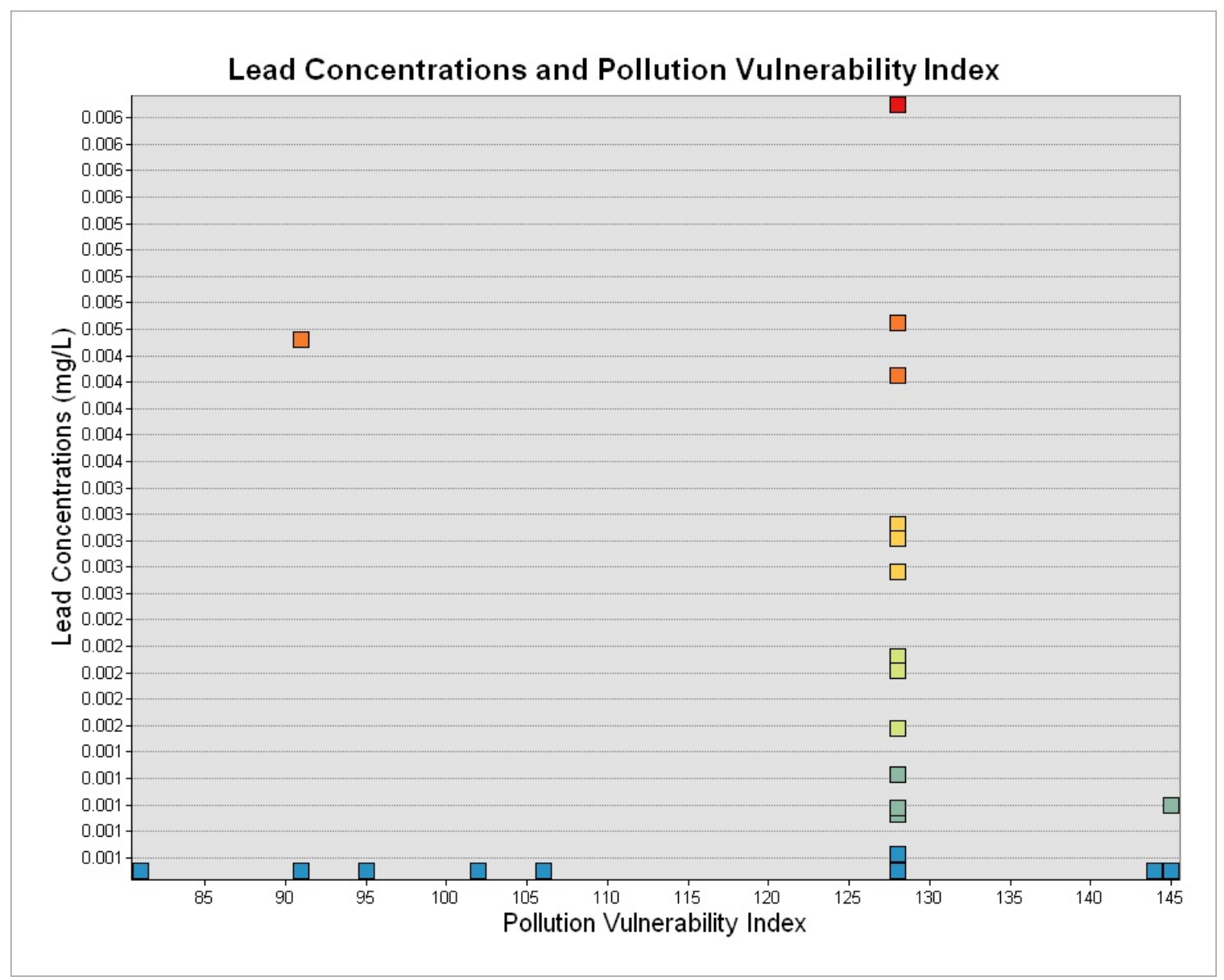

Figure 37: PVI and Lead Detection Correlation 


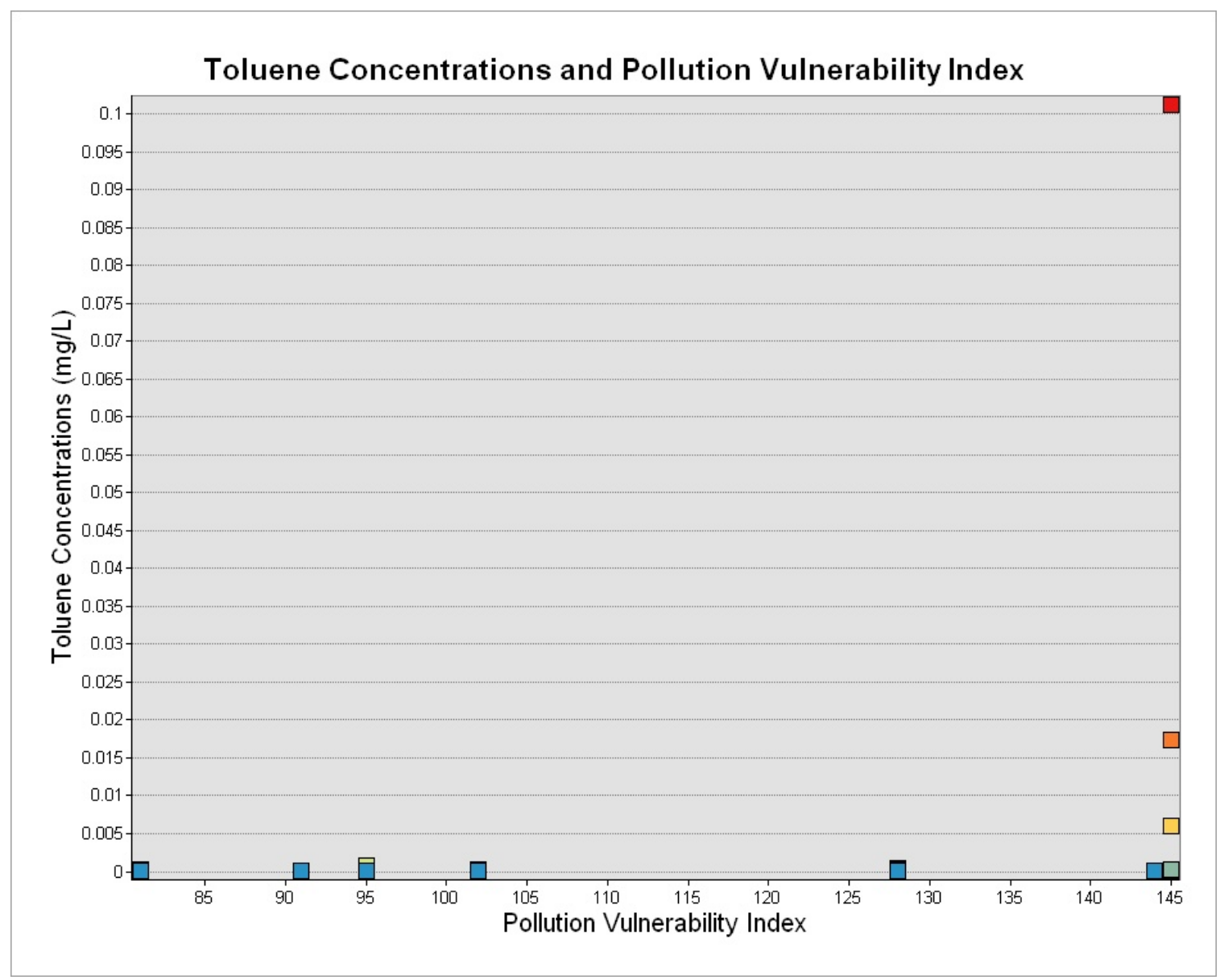

Figure 38: PVI and Toluene Detection Correlation 


\section{CONCLUSION AND RECOMMENDATIONS}

This section summarizes the research findings of this paper as well as verifying how well the results obtained answer the research questions and objectives posed at the beginning of this study. Various problems encountered during the creation of the interpolation coverages and the PVI is discussed.

\subsection{Conclusions}

Through the recording of nitrate, lead, and toluene into table format and ensuing interpolation of the individual points into raster coverage it was determined that yearly quarters 2 and 3 (Table 2) contain the highest concentrations and the greatest numbers of detection points. This phenomenon is perhaps due to the increase in rain and runoff during those 6 months of the year. The AOI shallow layer, taken from -15 feet, contains the widest range of concentrations for nitrates but contains the least number of detections. The AOI surface layer contains the most concentrated cluster of low detections and the deeper layers contain aspects of the low and high detections of the surface and shallow while both contain the highest number of detections. This leads to the conclusion that contaminants travel through the aquifer media of the shallow layers to pass between the surface and deep layers of the aquifer. However, there were not enough detections to perform this type of analysis on other contaminants with different properties, like lead and toluene, it is unclear whether or not this conclusion would be applicable to their movement within this type of aquifer. In addition the detections were all taken within a cone of influence created by a pumping potable wellhead. Therefore, contaminant 
movement through the aquifer depths may behave differently than when in an aquifer environment not influenced by the drawdown of a potable well.

Despite those two shortcomings of the study the impact to the aquifer concerning contaminant movement can be seen most clearly in the surface and deep aquifer layers. The PVI and AOI study of nitrates indicates that the biggest influences to lateral spatiotemporal contaminant movement are factors located at the surface and deep layers of the aquifer environment. The quarterly nitrate and yearly lead, toluene, and nitrate country coverages further demonstrate that the spatiotemporal vertical movement that chemicals have within the aquifer environment are also dependent on the properties of contaminants themselves, like weight. The less dense chemicals like lead and toluene found with higher frequency in the shallow monitoring wells and not in the deeper potable wells.

\subsection{Recommendations}

The accuracy of the interpolation coverage results can only be improved upon with the implementation of increasingly accurate detection points. This can be accomplished by updating groundwater monitoring well protocols though increased sampling frequency of current wells to further track areas of existing groundwater vulnerability and pollution. Furthermore, a monitoring well grid could be developed to determine where the contaminants are originating from and traveling to by drilling and sampling new wells throughout the county. This would be a useful tool in determining what businesses, as 
well as when, well field inspections should take place because the conductivity within the aquifer is so high moving contaminants through well fields at a high rate of movement.

In lieu of the implementation of the expensive and time-consuming way of tracking contaminants in the previous section is the development of a PVI map of the area in question. The index can be created in within a GIS environment because the system is a helpful instrument when computing pollution vulnerability indices of groundwater over entire watersheds (Thapinta, 2002). Furthermore, in this current political and economic environment the PVI is a useful tool in determining which limited resources should be appropriated to those areas within the well field program where they are most needed. The PVI also contains different categories that can be updated and tracked: for instance changing land cover within Broward County. This in turn is a good indicator of potential and future threats to well field contamination and can be used as a preliminary evaluation tool for use in well field planning. 


\section{LIST OF REFERENCES}

Almasri, Mohammad N., and Jagath J. Kaluarachchi. "Modeling Nitrate Contamination of Groundwater in Agricultural Watersheds." Journal of Hydrology 343.3-4 (2007): 21129. Print.

Bailly-Comte, Vincent, et al. "Water Exchange and Pressure Transfer between Conduits and Matrix and their Influence on Hydrodynamics of Two Karst Aquifers with Sinking Streams." Journal of Hydrology 386.1-4 (2010): 55-66. Print.

Cao, Xinde, et al. "Lead Transformation and Distribution in the Soils of Shooting Ranges in Florida, USA." Science of The Total Environment 307.1-3 (2003): 179-89. Print.

"Chemical Summary for Toluene." EPA 749-F-94-021a. Office Pollution Prevention and Toxics, Aug. 1994. Web. 10 Sept. 2012. <http://www.epa.gov/chemfact/s_toluen.txt $>$.

Davis, Harley T., et al. "Identifying Natural and Anthropogenic Sources of Metals in Urban and Rural Soils using GIS-Based Data, PCA, and Spatial Interpolation." Environmental Pollution 157.8-9 (2009): 2378-85. Print.

Dixon, B. "Applicability of Neuro-Fuzzy Techniques in Predicting Ground-Water Vulnerability: A GIS-Based Sensitivity Analysis." Journal of Hydrology 309.1-4 (2005): 17-38. Print.

Florea, Lee J., and H.L. Vacher. "Eogenetic Karst Hydrology: Insights from the 2004 Hurricanes, Peninsular Florida." Ground Water 45.4 (2007): 439-46. Print.

---. "Groundwater Vulnerability Mapping: A GIS and Fuzzy Rule Based Integrated Tool." Applied Geography 25.4 (2005): 327-47. Print.

Gurdak, Jason J., and Sharon L. Qi. "Vulnerability of recently recharged groundwater in principal aquifers of the United States to nitrate contamination." Environmental Science Technology 46.11 (2012): 6004-12. Print.

Han, D. M., H. L. Xu, and X. Liang. "GIS-Based Regionalization of a Karst Water System in Xishan Mountain Area of Taiyuan Basin, North China." Journal of Hydrology 331.3-4 (2006): 459-70. Print.

Harvey, R. W., D. W. Metge, A. M. Shapiro, R. A. Renken, C. L. Osborn, J. N. Ryan, K. J. Cunningham, and L. Landkamer. "Pathogen and chemical transport in the karst limestone of the Biscayne aquifer: 3 . Use of microspheres to estimate the transport potential of Cryptosporidium parvum oocysts." Water Resources 44.8 (2008): 1-12. Print. 
Heath, Ralph C. Basic Ground-Water Hydrology. 3rd ed. North Carolina Department Of Natural Resources: United States Geological Survey Water-Supply Paper 2220, 1983.

Huan, Huan, Jinsheng Wang, and Yanguo Teng. "Assessment and Validation of Groundwater Vulnerability to Nitrate Based on a Modified DRASTIC Model: A Case Study in Jilin City of Northeast China." Science of The Total Environment 440.0 (2012): 14-23. Print.

Jain, Manoj K., Umesh C. Kothyarib, and Kittur G. Ranga Rajub. "A GIS based distributed rainfall-runoff model." Journal of Hydrology 299.1-2 (2004): 107-35. Print.

Kerr, Robert S. "DRASTIC: A Standardized System for Evaluating Ground Water Pollution Potential Using Hydrogeologic Settings." National Service Center for Environmental Publications (NSCEP). United States Environmental Protection Agency, June 1987. Web. 3 Feb. 2012. Path: EPA Home; NSCEP; Document Display.

Lake, Iain R., et al. "Evaluating Factors Influencing Groundwater Vulnerability to Nitrate Pollution: Developing the Potential of GIS." Journal of environmental management 68.3 (2003): 315-28. Print.

Landers, D.H., S.L. Simonich, D.A. Jaffe, L. H. Geiser, D.H. Campbell, A.R. Schwindt, C.B. Schreck, M.L. Kent, W.D. Hafner, H. E. Taylor, K.J. Hageman, S. Usenko, L.K. Ackerman, J.E. Schrlau, N.L. Rose, T.F. Blett, and M.M. Erway. 2008. The Fate, Transport, and Ecological Impacts of Airborne Contaminants in Western National Parks (USA). EPA/600/R-07/138. U.S. Environmental Protection Agency, Office of Research and Development, NHEERL, Western Ecology Division, Corvallis, Oregon.

Lead in Paint, Dust, and Soil. US Environmental Protection Agency, 18 Aug. 2011. Web. 22 Sept. 2011. $<$ http://www.epa.gov/lead/>.

Manda, Alex K., and Michael R. Gross. "Identifying and Characterizing Solution Conduits in Karst Aquifers through Geospatial (GIS) Analysis of Porosity from Borehole Imagery: An Example from the Biscayne Aquifer, South Florida (USA)." Advances in Water Resources 29.3 (2006): 383-96. Print.

Mattern, Samuel, Dominique Fasbender, and Marnik Vanclooster. "Discriminating Sources of Nitrate Pollution in an Unconfined Sandy Aquifer." Journal of Hydrology 376.1-2 (2009): 275-84. Print.

Miller, Chris. "The use of a GIS to compare the land areas captured by very basic and complex wellhead protection area models." Environmental Health 68.4 (2005): 21-6, 28. Print. 
Morio, M., M. Finkel, and E. Martac. "Flow Guided Interpolation - A GIS-Based Method to Represent Contaminant Concentration Distributions in Groundwater." Environmental Modelling \& Software 25.12 (2010): 1769-80. Print.

Navas, A., et al. "Assessing Soil Redistribution in a Complex Karst Catchment using Fallout 137Cs and GIS." Geomorphology.0 Print.

NOAA Technical Report NWS 34, Mean Monthly, Seasonal, and Annual Pan Evaporation for the US, R. K. Farnsworth and E. S. Thompson, Dec. 1982.

Nobre, R. C. M., et al. "Groundwater Vulnerability and Risk Mapping using GIS, Modeling and a Fuzzy Logic Tool." Journal of contaminant hydrology 94.3-4 (2007): 277-92. Print.

Pacheco, Fernando A. L., and Luís F. Sanches Fernandes. "The Multivariate Statistical Structure of DRASTIC Model." Journal of Hydrology 476.0 (2013): 442-59. Print.

Pathak, Dhundi Raj, and Akira Hiratsuka. "An Integrated GIS Based Fuzzy Pattern Recognition Model to Compute Groundwater Vulnerability Index for Decision Making." Journal of Hydro-environment Research 5.1 (2011): 63-77. Print.

"Perchloroethylene Fact Sheet." Chemicals In the Environment: OPPT Chemical Fact Sheets. EPA, Office of Pollution Prevention and Toxics, 5 Oct. 2010. Web. 17 Aug. 2011. <http://www.epa.gov/chemfact/f_perchl.txt>.

Pore Classes. Ed. Heather Henkel. U.S. Department of the Interior, U.S. Geological Survey, 15 Jan. 2013. Web. 1 Apr. 2013.

$<$ http://sofia.usgs.gov/publications/papers/porosity_flow/classes.html>.

Potable Well Locations, GIS data. Broward County, Fort Lauderdale, Florida \& Potable Well Calculated 10 day and 30 day Radii; Pump rate (ft3/yr); Municipalities of Broward County

Rahman, Atiqur. "A GIS Based DRASTIC Model for Assessing Groundwater Vulnerability in Shallow Aquifer in Aligarh, India." Applied Geography 28.1 (2008): 3253. Print.

Randhir, Timothy O., and Olga Tsvetkova. "Spatiotemporal Dynamics of Landscape Pattern and Hydrologic Process in Watershed Systems." Journal of Hydrology 404.1-2 (2011): 1-12. Print.

Rasiah, V., J.D. Armour, A L. Cogle, and S K. Florentine. "Nitrate import-export dynamics in ground water interacting with surface water in a wet tropical environment." Australian Journal of Soil Research 48.4 (2010): 361-70. Print. 
Rivest, M., D. Marcotte, and P. Pasquier. "Sparse Data Integration for the Interpolation of Concentration Measurements using Kriging in Natural Coordinates." Journal of Hydrology 416-417.0 (2012): 72-82. Print.

"Water: Safe Drinking Water Act (SDWA)." Laws \& Regulations: Safe Drinking Water Act. USEPA, 6 Mar. 2012. Web. 14 July 2012.

$<\mathrm{http}$ //water.epa.gov/lawsregs/rulesregs/sdwa/index.cfm>.

Renken, R. A., K. J. Cunningham, A. M. Shapiro, R. W. Harvey, M. R. Zygnerski, D. W. Metge, and M. A. Wacker. "Pathogen and chemical transport in the karst limestone of the Biscayne aquifer: 1. Revised conceptualization of groundwater flow." Water Resources 44.8 (2008): 1-16. Print.

Saidi, Salwa, et al. "A GIS-Based Susceptibility Indexing Method for Irrigation and Drinking Water Management Planning: Application to Chebba-Mellouleche Aquifer, Tunisia." Agricultural Water Management 96.12 (2009): 1683-90. Print.

Screaton, Elizabeth, Jonathan B. Martin, Brian Ginn, and Lauren Smith. "Conduit properties and karstification in the unconfined Floridan aquifer." Ground Water 42.3 (2004): 338-46. Print.

Secunda, S., M.L. Collin, and A.J. Melloul. "Groundwater vulnerability assessment using a composite model combining DRASTIC with extensive agricultural land use in Israel's Sharon region." Journal of Environmental Management 54.1 (1998): 39-57. Print.

Shapiro, A. M., R. A. Renken, R. W. Harvey, M. R. Zygnerski, and D. W. Metge. "Pathogen and chemical transport in the karst limestone of the Biscayne aquifer: 2.

Chemical retention from diffusion and slow advection." Water Resources 44.8 (2008): 112. Print.

Thapinta, Anat, and Paul F. Hudak. "Use of Geographic Information Systems for Assessing Groundwater Pollution Potential by Pesticides in Central Thailand." Environment International 29.1 (2003): 87-93. Print.

Thirumalaivasan, D., M. Karmegam, and K. Venugopal. "AHP-DRASTIC: Software for Specific Aquifer Vulnerability Assessment using DRASTIC Model and GIS." Environmental Modeling \& Software 18.7 (2003): 645-56. Print.

Veni, George. "A Geomorphological Strategy for Conducting Environmental Impact Assessments in Karst Areas." Geomorphology 31.1-4 (1999): 151-80. Print.

Vyciene, Gitana. "Generating Continuous Surfaces of Runoff Depth Applying Different Interpolation Methods." Rural Development (2009): 252-57. Print. 
Wang, Junjie, Jiangtao He, and Honghan Chen. "Assessment of Groundwater Contamination Risk using Hazard Quantification, a Modified DRASTIC Model and Groundwater Value, Beijing Plain, China." Science of The Total Environment 432.0 (2012): 216-26. Print.

Whitman, Dean. (2010) lecture notes, GIS and Spatial Analysis for Earth Scientists, Florida International University, October 18, 2010.

Zhang, Bo, et al. "SD-GIS-Based temporal-spatial Simulation of Water Quality in Sudden Water Pollution Accidents." Computers \& Geosciences 37.7 (2011): 874-82. Print. 


\section{APPENDIX}
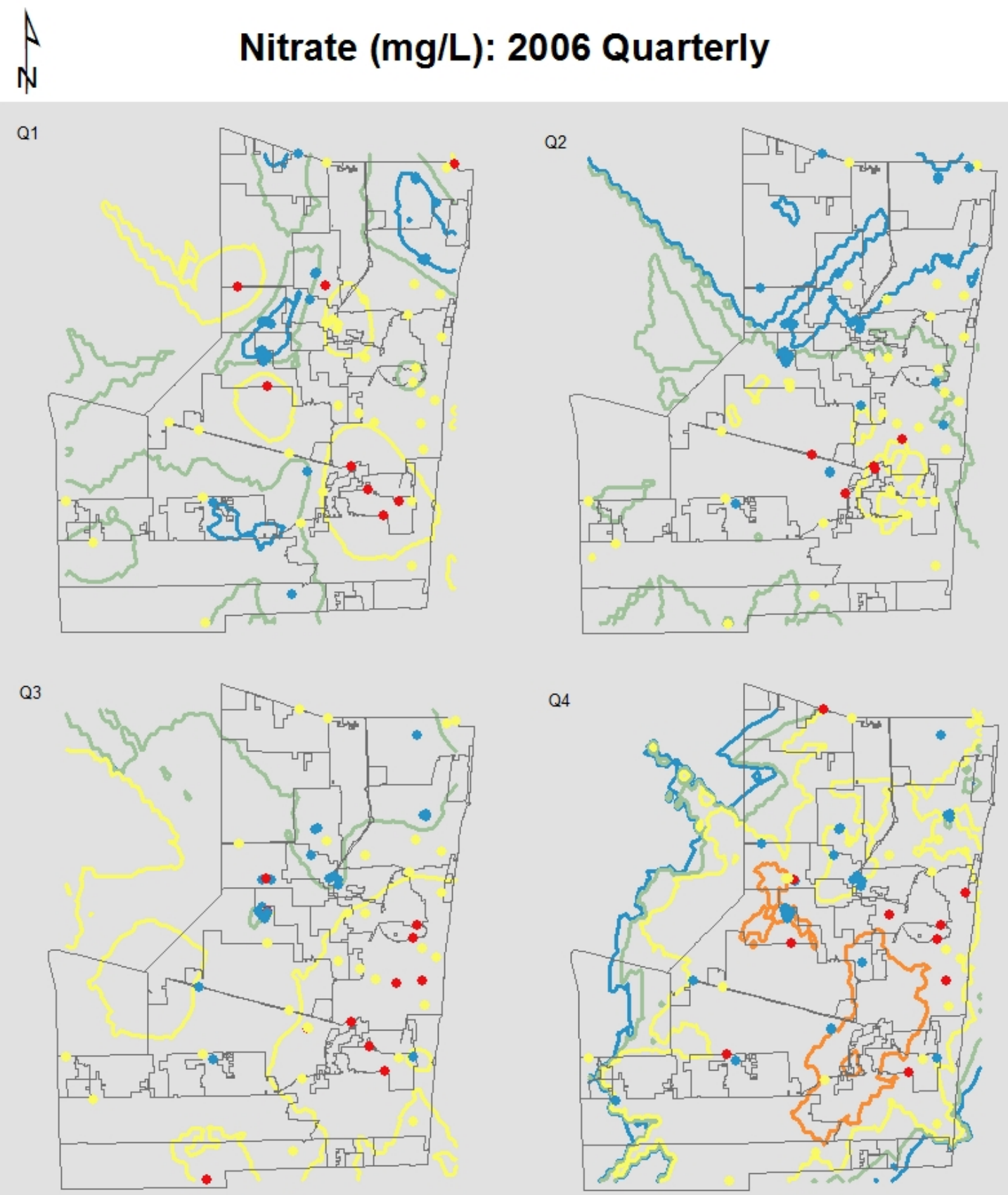

Q4

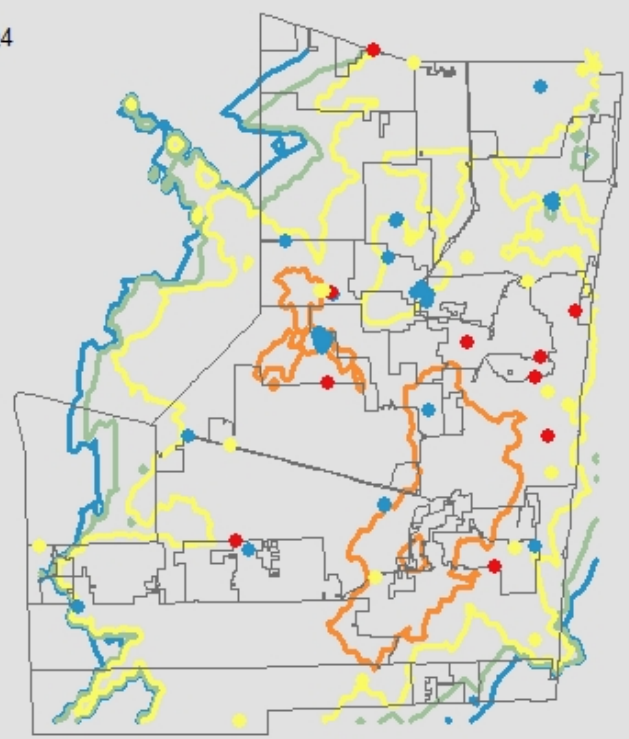

$$
\begin{aligned}
& \text { Predication Contours } \\
& \qquad-0.03585-0.2654 \\
& -0.01046-0.1006-0.6856
\end{aligned}
$$

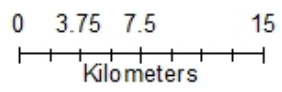

\section{Nitrate Concentrations}

- $0.0005-0.0024 * 0.1545-0.2645$ $0.0025-0.1544$

Figure 39: 2006 Quarterly Nitrate Interpolation Map 
$N$

\section{Nitrates (mg/L): 2007 Quarterly}
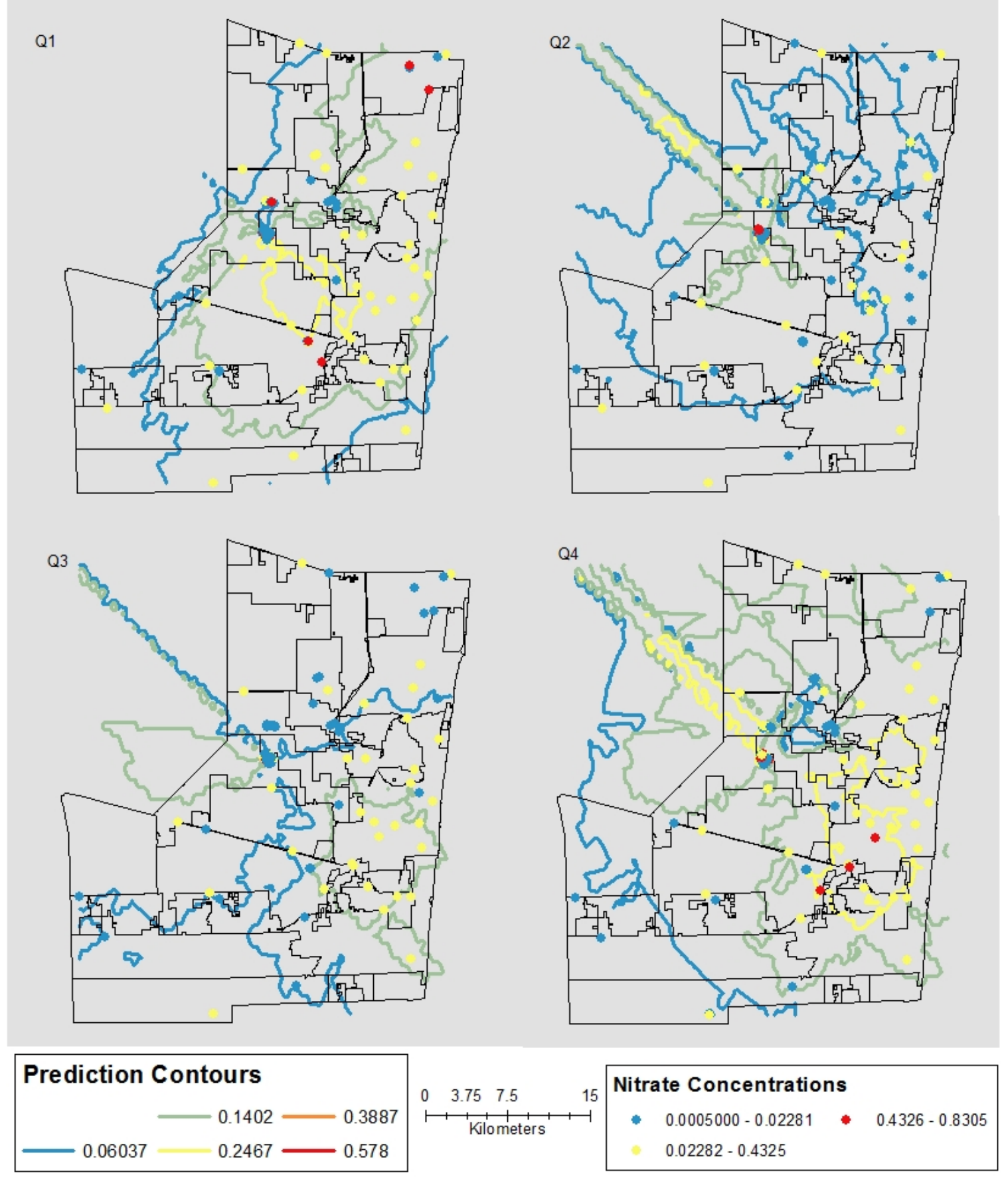

Figure 40: 2007 Quarterly Nitrate Interpolation Map 

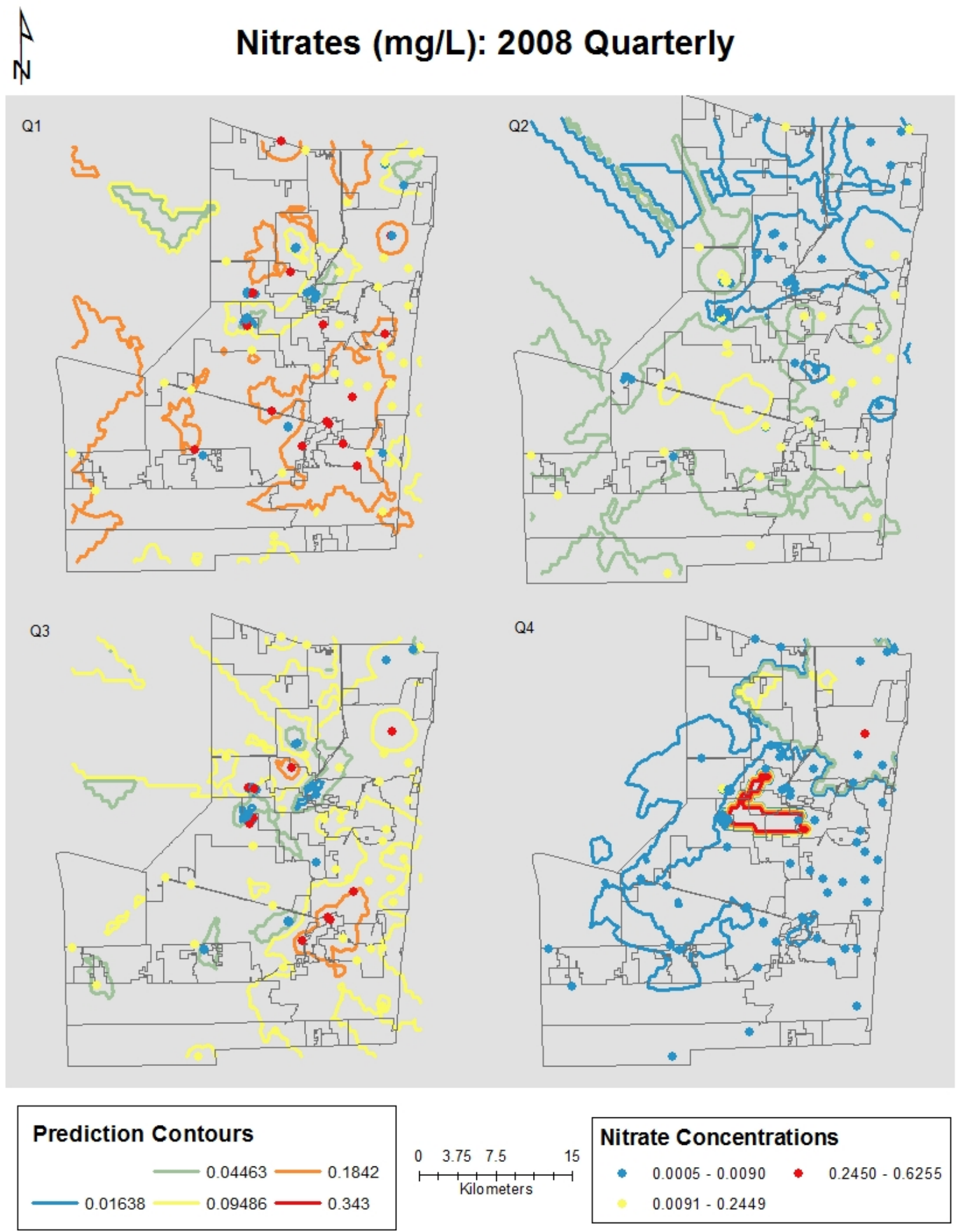

Figure 41: 2008 Quarterly Nitrate Interpolation Map 
$N$

\section{Nitrate (mg/L): 2009 Quarterly}

Q1
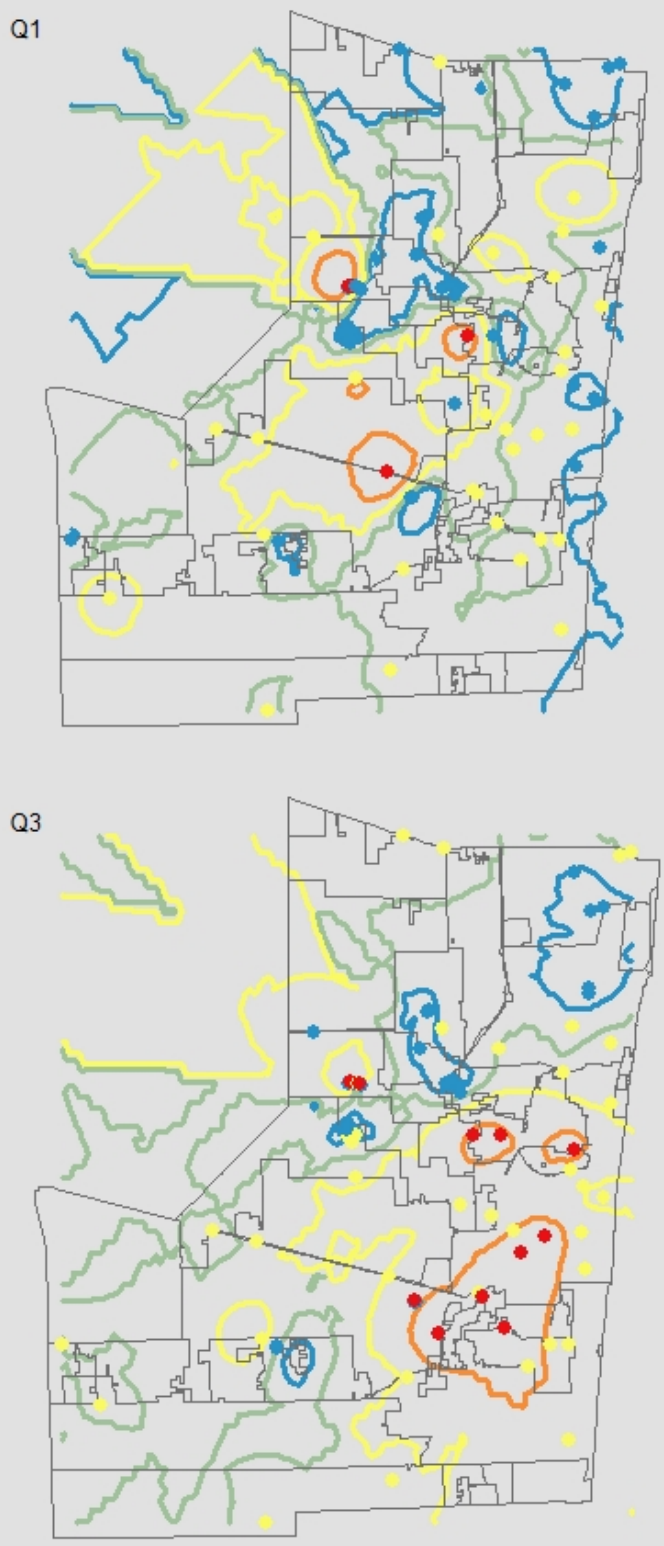

Q2
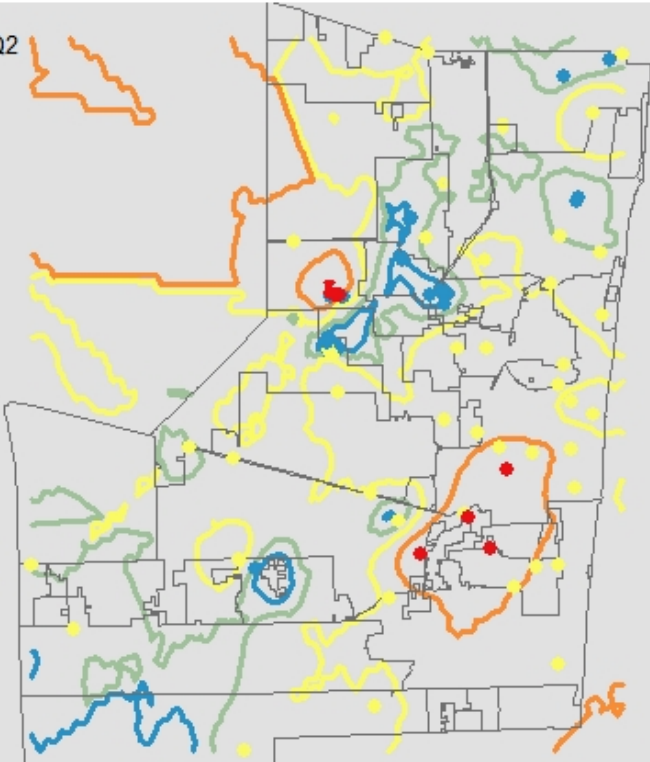

Q4

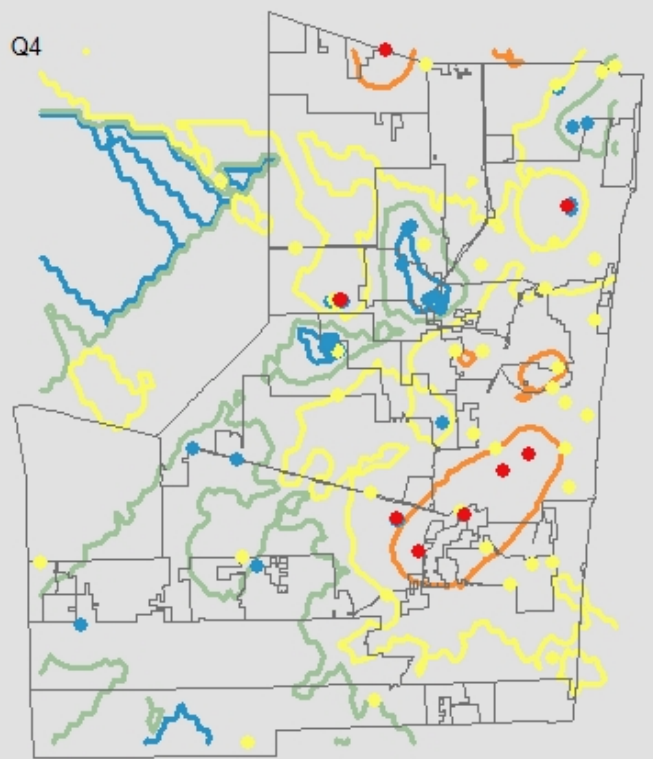

\section{Prediction Contours}

$$
\begin{array}{r}
\longrightarrow 01417-0.03938-0.1715 \\
-0.08585-0.3294
\end{array}
$$

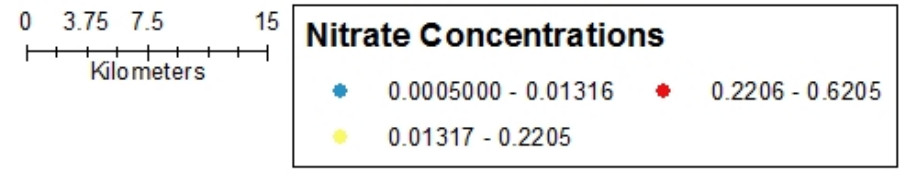

Figure 42: 2009 Quarterly Nitrate Interpolation Map 
N

\section{Nitrate (mg/L): 2010 Quarterly}

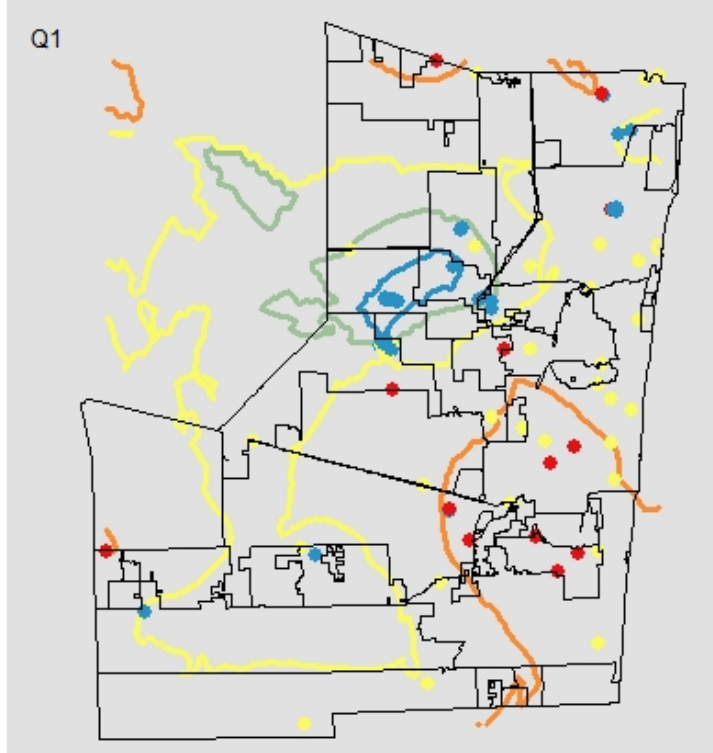

Q2
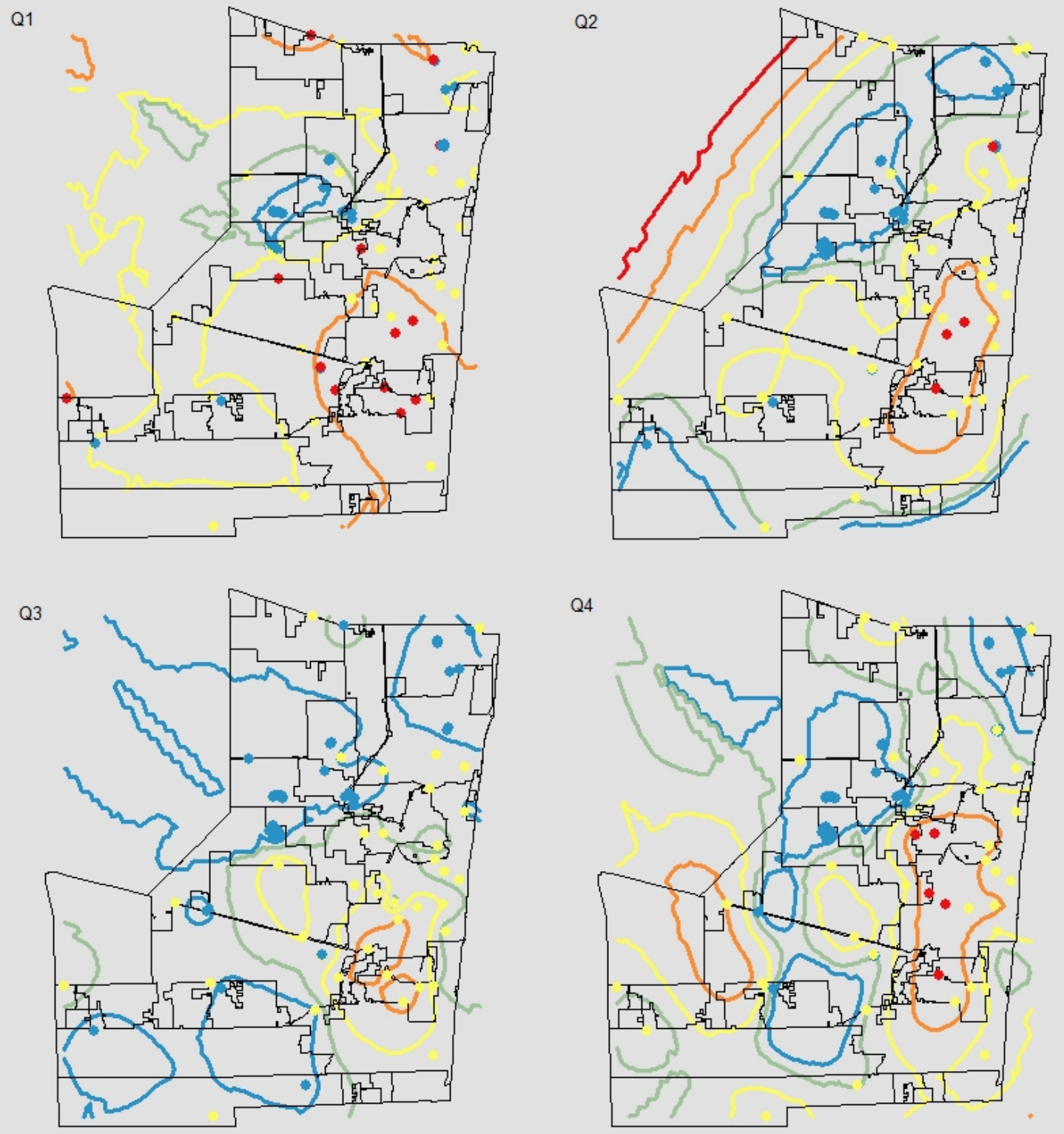

\section{Prediction Contours}

$\begin{array}{rr} & 0.04498-0.1857 \\ -0.01651 & 0.09562-0.3458\end{array}$

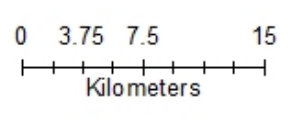

Nitrate Concentrations

- $0.0005000-0.01058$ $0.01059-0.2675$

Figure 43: 2010 Quarterly Nitrate Interpolation Map 
N

\section{Nitrates (mg/L): 2011 Quarterly}
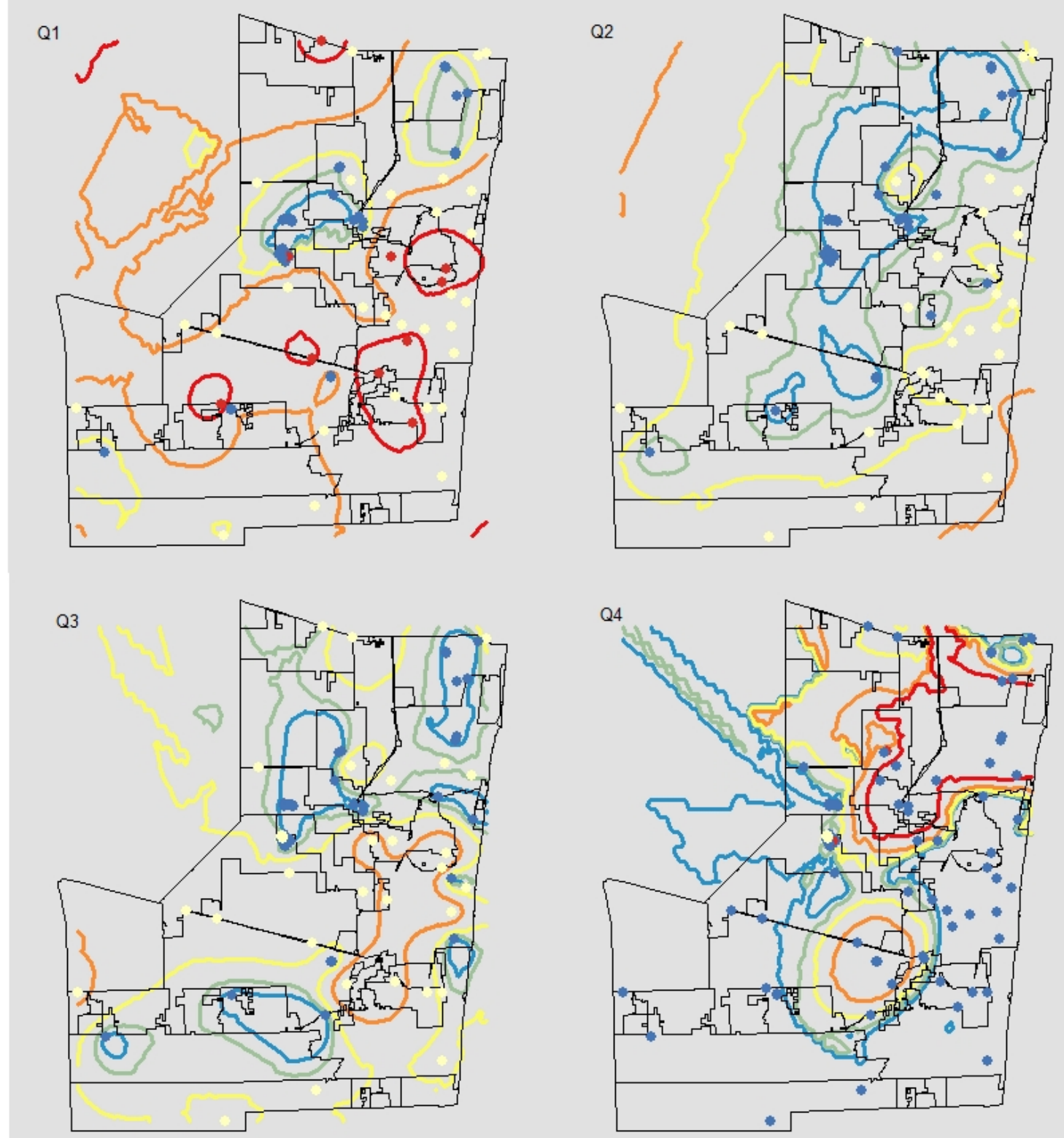

\section{Prediction Contours}

$\begin{array}{rl} & 0.00646-0.04516 \\ -0.00218 & 0.01737-0.116\end{array}$

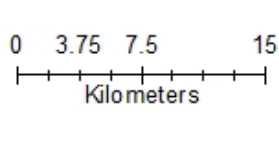
Nitrate Concentrations

* $0.0005000-0.004541 *$ $0.004542-0.1273$

Figure 44: 2011 Quarterly Nitrate Interpolation Map 